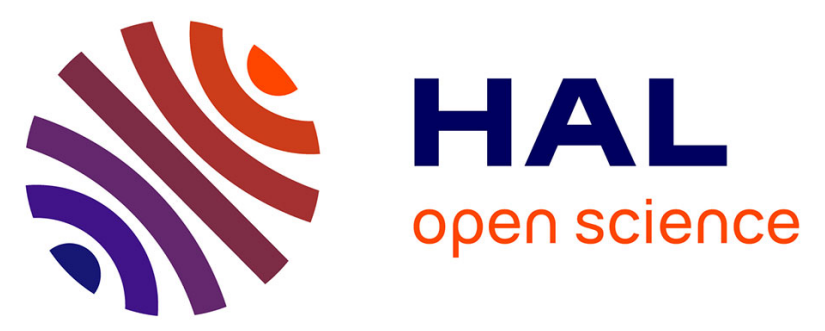

\title{
A thermo-mechanical large deformation constitutive model for polymers based on material network description: Application to a semi-crystalline polyamide
} 66

Aurelien Maurel-Pantel, Erwan Baquet, Jérôme Bikard, Jean-Luc Bouvard, Noëlle Billon

\section{To cite this version:}

Aurelien Maurel-Pantel, Erwan Baquet, Jérôme Bikard, Jean-Luc Bouvard, Noëlle Billon. A thermomechanical large deformation constitutive model for polymers based on material network description: Application to a semi-crystalline polyamide 66. International Journal of Plasticity, 2015, 67, pp.102126. 10.1016/j.ijplas.2014.10.004 . hal-01083213

\section{HAL Id: hal-01083213 https://hal.science/hal-01083213}

Submitted on 7 Mar 2016

HAL is a multi-disciplinary open access archive for the deposit and dissemination of scientific research documents, whether they are published or not. The documents may come from teaching and research institutions in France or abroad, or from public or private research centers.
L'archive ouverte pluridisciplinaire HAL, est destinée au dépôt et à la diffusion de documents scientifiques de niveau recherche, publiés ou non, émanant des établissements d'enseignement et de recherche français ou étrangers, des laboratoires publics ou privés. 
A thermo-mechanical large deformation constitutive model for polymers based on material network description: Application to a semi-crystalline polyamide 66

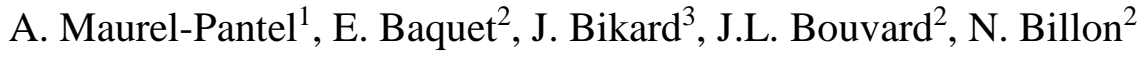 \\ 1- Laboratoire de Mécanique et d'Acoustique, CNRS UPR 7051, 31 chemin J. Aiguier, 13402 Marseille cedex 20, \\ France, $\underline{\text { maurel@1ma.cnrs-mrs.fr }}$ \\ 2- MINES ParisTech, CEMEF-Centre de Mise en Forme des Matériaux, CNRS UMR 7635, BP 207, 06904 Sophia \\ Antipolis Cedex, France, noelle.billon@mines-paristech.fr \\ 3- Solvay R\&I, 85 rue des Frères Perret BP 62, 69192 Saint FONS CEDEX, jerome.bikard@ solvay.com \\ http://www.cemef.mines-paristech.fr
}

*Corresponding author: Dr. Aurélien MAUREL-PANTEL

Address: Laboratoire de Mécanique et d'Acoustique, 31 chemin J. Aiguier, 13402 Marseille cedex 20, France

Tel: + 33 (0) 491164227

Fax: + 33 (0) 491164481

Email: maurel@1ma.cnrs-mrs.fr 


\begin{abstract}
A visco-hyperelastic constitutive model, based on an original approach initially developed by (Billon, 2012) and applied to amorphous rubbery polymers for a one-dimensional formalism, was extended in this study to three-dimensional constitutive equations based on a thermodynamic framework. The model was applied to a semi-crystalline polyamide polymer, PA66. The experiments included tension and shear testing coupled with synchronized digital image correlation and infrared measurements device for capturing the time, temperature, and stress state dependence, as well as the complex thermomechanical coupling exhibited by the material under large deformation. A notion of equivalent strain rate (based on the timetemperature principle superposition) was also introduced to show its capability to build master curves and therefore decrease the number of testing needed to build a material database. The model is based on the Edward Vilgis theory (1986) and accounts for chains network reorganization under external loading through the introduction of an evolution equation for the internal state variable, $\bar{\eta}$, representing the degree of mobility of entanglement points. The model accounting for the equivalent strain rate notion was calibrated using master curves. The thermomechanical model agreed well with the experimental mechanical and temperature measurements under tension and shear conditions. The approach developed in this study may open a different way to model the polymer behavior.
\end{abstract}

Keywords: constitutive model, polymer, slip-link, disentanglement, viscohyperelasticity, thermo-mechanical coupling, polyamide 66 , tensile test, shear test. 


\section{Nomenclature}

\begin{tabular}{|c|c|}
\hline$e_{v}$ & Specific internal energy (per unit volume) \\
\hline$r_{v}$ & Heat source per unit volume \\
\hline q & Heat flux per unit area \\
\hline$\overline{\mathrm{C}}_{\mathrm{v}}$ & Heat capacity per unit volume \\
\hline$\lambda$ & Heat conductivity \\
\hline $\mathrm{h}$ & Thermal convection coefficient (in air) \\
\hline $\mathrm{S}_{\mathrm{v}}$ & Specific entropy (per unit volume) \\
\hline $\mathrm{T}$ & Temperature \\
\hline $\bar{\psi}_{\mathrm{v}}$ & Helmholtz free energy per unit volume \\
\hline$\phi_{\text {th }}$ & Thermal dissipation \\
\hline$\phi_{\text {int }}$ & Inelastic dissipation \\
\hline J & Determinant of the deformation gradient \\
\hline $\mathrm{J}^{\mathrm{e}}$ & Determinant of the elastic deformation gradient \\
\hline $\mathrm{J}^{\mathrm{v}}$ & Determinant of the inelastic deformation gradient \\
\hline $\mathbf{F}$ & Deformation gradient \\
\hline $\mathbf{F}^{\mathbf{e}}$ & Elastic deformation gradient \\
\hline $\mathbf{F}^{\mathbf{v}}$ & Inelastic deformation gradient \\
\hline$\overline{\mathbf{C}}^{\mathbf{e}}$ & Elastic Cauchy-Green tensor \\
\hline 1 & Velocity gradient \\
\hline $\mathbf{1}^{\mathrm{e}}$ & Elastic velocity spatial gradient \\
\hline$\overline{\mathbf{L}}^{\mathbf{v}}$ & Inelastic velocity spatial gradient \\
\hline d & Symmetric part of the velocity gradient \\
\hline$d^{e}$ & Symmetric part of the elastic velocity gradient \\
\hline$\overline{\mathbf{D}}^{\mathbf{v}}$ & Symmetric part of the inelastic velocity gradient \\
\hline $\boldsymbol{\sigma}$ & Cauchy stress tensor \\
\hline$\overline{\mathbf{M}}$ & Mandel stress tensor \\
\hline$\overline{\mathbf{S}}$ & Second Piola-Kirchhoff stress tensor \\
\hline$\sigma_{\text {num }}$ & Numerical stress tensor \\
\hline$\sigma_{\exp }$ & Experimental stress tensor \\
\hline$\left\{\mathrm{I}_{1}^{\mathrm{e}}, \mathrm{I}_{2}^{\mathrm{e}}, \mathrm{I}_{3}^{\mathrm{e}}\right\}$ & Thee invariants of the elastic Cauchy-Green tensor \\
\hline $\mathrm{k}$ & Boltzmann's constant \\
\hline $\mathrm{T}_{\text {ref }}$ & Reference temperature \\
\hline $\mathrm{N}_{\mathrm{C}}$ & Density per unit volume of permanent nodes \\
\hline $\mathrm{N}_{\mathrm{S}}$ & Density per unit volume of slip-link nodes \\
\hline$\alpha$ & Limit of chain extensibility \\
\hline $\bar{\eta}$ & Degree of mobility of the slip links (entanglement points) \\
\hline$\beta$ & Taylor Quinney’s coefficient \\
\hline $\mathrm{w}_{\mathrm{C}}$ & Energy stored in permanent nodes \\
\hline $\mathrm{w}_{\mathrm{S}}$ & Energy stored in entangled network \\
\hline
\end{tabular}


$\left\{\mathrm{z}_{\mathrm{p} 0}, \mathrm{z}_{\mathrm{p} 1}\right\}$

$\dot{\varepsilon}$

$\mathrm{C}_{1}$

$\mathrm{C}_{2}$

$\mathrm{a}_{\mathrm{T} / \mathrm{T}_{\mathrm{ref}}}$

$\mathrm{a}_{\mathrm{T}} \dot{\varepsilon}_{\mathrm{eq}}$

$\bar{\eta}_{0}$

$\chi$

Parameters of the degree of mobility of the slip links

Experimental strain-rate

First WLF parameter

Second WLF parameter

WLF shift factor

Equivalent strain-rate at the reference temperature

Initial value of $\bar{\eta}$

Tensile and shear correction coefficient 


\section{Introduction}

Thermoplastics and more especially semi-crystalline polymers (SCP) have been increasingly applied in the industry due to their potential to fulfill the mechanical, electrical and/or environmental requirements needed for structural applications ranging from automotive, aeronautic to medical sectors. Unfortunately the design of such structural parts submitted overtime to complex loading is not reliable enough to optimally use these polymers. This is mainly due to their complex mechanical behavior that is sensitive to external parameters (such as temperature, strain rate, and triaxiality). As a matter of fact, the thermomechanical viscoelastic/viscoplastic behavior of polymers is not always well understood and modeled.

A large number of material models developed to predict the material response of thermoplastic polymers can be found in the literature (see Bouvard et al. (2009) for a review). Previous work proposed constitutive models combining linear and non-linear springs with dashpots enhanced by specific evolution equations to predict the non-linear viscoelastic response of polymers (Chaboche (1997), Moreau et al. (2005), Khan et al. (2006), Ayoub et al. (2010, 2011), Zaïri et al. (2011), among others). Other constitutive models were proposed to capture the elastic-viscoplastic deformation behavior of solid polymers. (e.g., Bardenhagen et al. (1997), Buckley et al (1995), Khan and Zhang (2001), Zaïri et al. (2005a, 2005b, 2007, 2008), Colak (2005), Pyrz and Zaïri (2007), Dusunceli and Colak (2008), Ghorbel (2008), Drozdov (2009), Regrain et al. (2009)). Different approaches based on material models initially developed for metals were also used to model the mechanical behavior of polymers. For instance, we refer to the viscoplastic model based on overstress (VBO) (Krempl and Khan (2003), Dusunceli and Colak (2008), Khan and Yeakle (2011), or more recently to the constitutive model based on the generalized Frederick-Armstrong-Philips-Chaboche theory (Voyiadjis et al. (2012). Efforts were also developed to model the viscoelasticity or hyper- 
viscoelasticity of polymers when deformed in their rubbery state (e.g. G'Sell and Jonas (1979), Lai et al. (2005), Roguet et al. (2007)).

More recently, the mechanical behavior of semi-crystalline polymer has been extensively investigated in the literature. A large number of models proposed for SCP are based on mixture theory used to combine the behavior of crystalline and amorphous phases. The amorphous phase can be modeled based on the early work of Haward and Thackray (1968). Improvement of this initial model was carried out by several authors (Boyce et al. (1988, 2000), Arruda et al. (1995), Buckley and Jones (1995), Wu and van der Giessen (1995), Govaert et al. (2000), Tomita (2000), Anand and Gurtin (2003), Anand and Ames (2006), Dupaix and Krishnan (2006), Richeton et al. (2007), Belbachir et al. (2010), Zaïri et al. (2010, 2011), among others). More recently, formulations of thermomechanical model were also proposed to capture the material self-heating under large deformation (Ames et al. (2009), Anand et al. (2009), Srivastava et al. (2010a,b), Bouvard et al (2012)).

Many efforts were carried out to describe the complex mechanical behavior of SCP under large deformation behavior. Such models focused on capturing the heterogeneous nature of the SCP microstructure at different scales (at the lamellae, at the spherulite, or at the continuum level) as well as the material dependence to the external loading conditions (such as strain rate, temperature, and/or strain path). Therefore, constitutive equations were proposed to account for the material internal microstructure (such as crystal volume fraction) (see Kennedy et al. (1994), Lee et al. (2003), Rozanski and Galeski (2013), Ponçot et al. (2013), among others). We can also refer to the previously cited VBO model that was extended to SCP by incorporating information regarding the degree of crystallinity (Dusunceli and Colak (2008)). Other approaches were based on the use of rheological models (springdashpots) to capture the complex mechanical behavior of SCP (Lee et al. (1993a, 1993b), Boyce et al. (2000), van Dommelen et al. (2003), Ahzi et al. (2003), Makradi et al. (2005), 
Khan et al. (2006), Ayoub et al. (2010), Ayoub et al. (2011)). Recently, micro-mechanical model using either analytical or either FE-based homogenization scheme were also proposed (Lee et al. (1993a), Nikolov and Doghri (2000), Nikolov et al. (2002), Bédoui et al. (2006), Gueguen et al. (2008), Li and Shojaei (2012), Uchida and Tada (2013), Shojaei and Li (2013)).

Despite the fact that the literature is abundant for the mechanical behavior of SCP under isothermal condition, only few studies focus on the thermomechanical modeling of such material. In this paper, a coupled thermomechanical viscoelastic viscoplastic was proposed and validated for semi-crystalline polymers around their glass transition temperature $(\mathrm{Tg})$. The model is based on the non-gaussian statistic approach of entangled polymer network developed by Edwards and Vilgis (1986) and follows the modification proposed by Billon (2012).

The Edwards and Vilgis model is based on the Ball et al. theory (1981) that introduces the concept of slip-link to account for the entanglement slippage along the network chains. Prior to Billon (2012), several authors have used the Edwards and Vilgis model and have showed its capability to model the polymer network evolution under deformation (see for instance, Urayama et al. (2001), Sweeney et al. (1995, 1996, 1997, 2002), Meissner et al. (2002), Marco et al. (2002) or Gorlier et al. (2001)). Especially, Meissner et al. extended the Edwards and Vilgis model to filler-reinforced networks by incorporating the concept of strain-amplification function.

Recent effort by Billon (2012) focused on proposing constitutive equations to model the time-dependent mechanical behavior of polymers close to their $\mathrm{Tg}$. In addition to the Edward and Vilgis model, the author assumed specific evolution equations for internal state variables related to slip-link and related disentanglement as a source of inelastic mechanisms. Therefore, a phenomenological modeling of disentanglement was used to reproduce the 
viscoelastic behavior of polymers. Additionally, the time and temperature dependence of the material was introduced by the use of a time-temperature superposition principle. The onedimensional isothermal model (i.e. without thermo-mechanical coupling) was applied to amorphous polymers such as PMMA.

In this paper, an extension of the isothermal model developed by Billon (2012) to thermomechanical conditions is presented and applied for a semi-crystalline polymer, polyamide 66 (PA66). The model considers the polymer microstructure at the mesoscopic level. The Edward and Vilgis model was used to give an equivalent chain network to the polymer. In our case, we consider that the crosslink network may represent the crystalline phase and the entangled network the deformation of amorphous region (disentanglement). This study focuses on validating the model on the thermomechanical behavior of the PA6.6 as well as modeling the material self-heating under large deformation. Model refinement in term of a better description of the semi-crystalline structure will be investigated in further effort.

The paper proceeds first by an experimental characterization of a PA 66 polymer over a wide range of strain rates, temperatures, loading conditions (load-unload) and two different stress states (tension and shear). Experimental characterization was performed based on a synchronized digital image correlation and infrared measurements (Section 2). Next the threedimensional thermomechanical formalism of the model is presented following the Generalized Standard Materials (GSM) framework described by Lemaitre and Chaboche (1985), Germain et al. (1983). All constitutive equations were presented within large deformation formalism and followed the thermodynamic framework (Section 3). In Section 4, the model parameters were determined within an inverse identification method and the thermomechanical response of the model was compared to the experimental data. Finally, conclusions were drawn in Section 5. 


\section{Material and experiments}

\subsection{PA66 material and protocol}

An experimental database was built for a semi-crystalline polyamide 66 supplied by Solvay. Tensile and shear samples were machined in the middle zone of a $3 \mathrm{~mm}$-thick injection molded plate. Fig. 1 displays the sample geometries (for tensile and shear loading) as well as their location in the injected plaque. The humidity being known to have an influence on the mechanical properties of the polyamide (Valentin et al. [1987], Verdu [2000]), the material was conditioned at the equilibrium with an air containing $50 \%$ of relative humidity (RH50) during the entire experimental campaign.

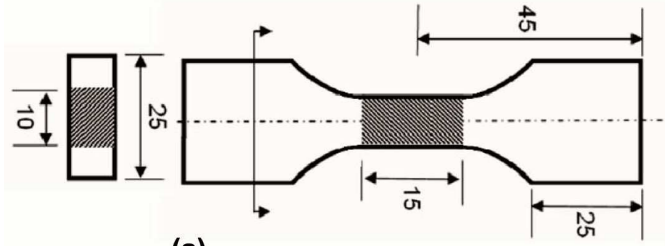

(a)

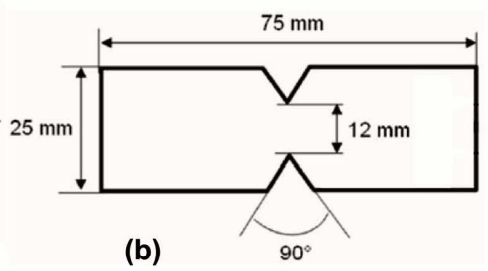

(b)

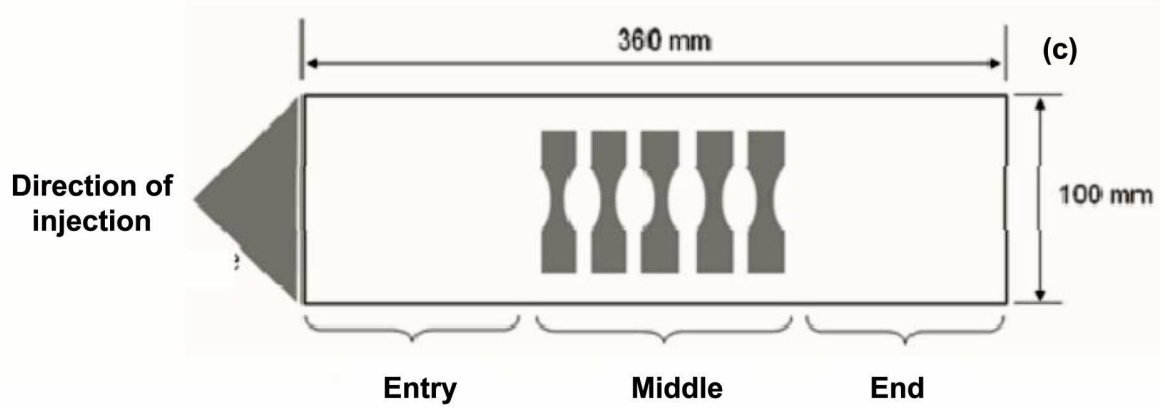

Fig.1. (a) Geometry of tensile sample; (b) Geometry of shear sample; (c) Location of the samples in the injected plaque.

Fig. 2 presents the experimental acquisition device used in this study. Tests were performed at temperatures ranging from $\mathrm{T}_{\mathrm{g}}-60{ }^{\circ} \mathrm{C}$ to $\mathrm{T}_{\mathrm{g}}+30{ }^{\circ} \mathrm{C}$ and for constant true strain rates ranging from $10^{-4} \mathrm{~s}^{-1}$ to $2.4 \mathrm{~s}^{-1}$ (using video-controlled tests (G'sell et al. [2002]) as refer in Fig 2a). Digital image correlation (DIC) on random patterns (Fig. 2b) was used to analyze the strain field on the front face of the sample, while the temperature was measured at the sample 
surface using an infrared (IR) camera (FLIR SC5000) (see Maurel-Pantel et al. (2011) for more details).
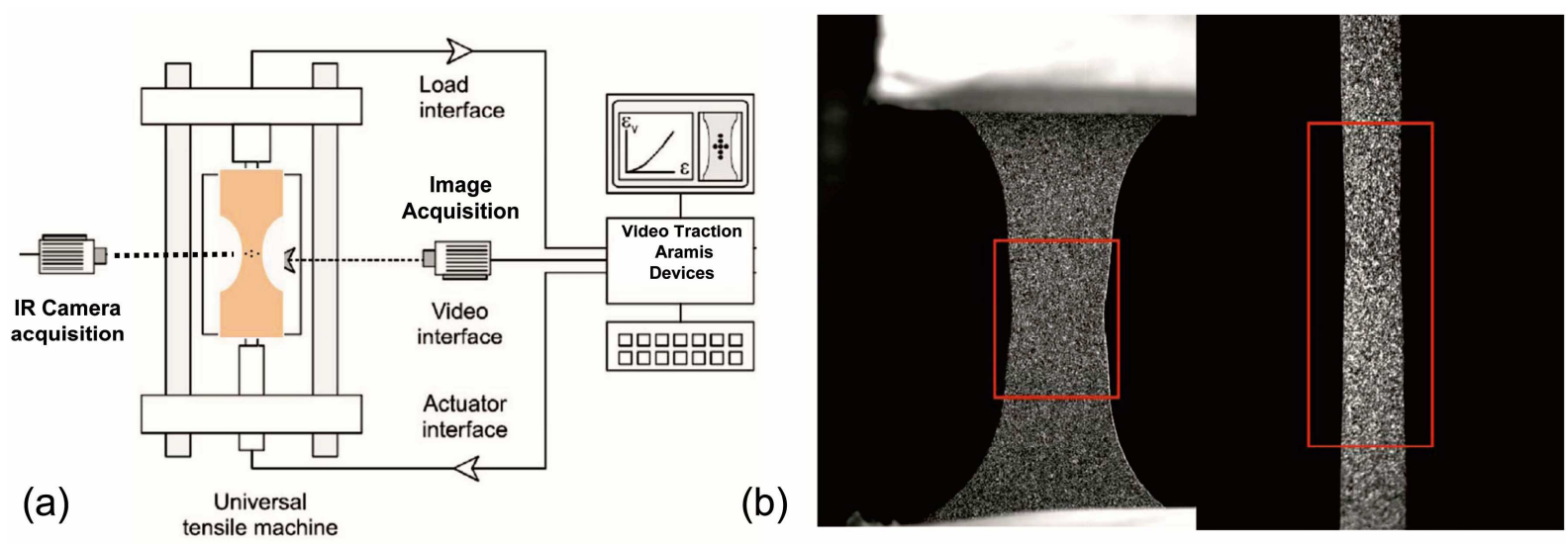

Fig.2. (a) Experimental data acquisition system; (b) View of a tensile sample with a random patterns.

\subsection{Tensile tests}

Tensile tests were performed at constant true strain-rate between $10^{-4} \mathrm{~s}^{-1}$ and $2.4 \mathrm{~s}^{-1}$ (using video control system described in Fig. 2) and at temperatures ranging from $-5^{\circ} \mathrm{C}$ to $60^{\circ} \mathrm{C}$. Typical results of DIC and IR measurements are displayed in Fig. 3 for a tensile test performed at room temperature.
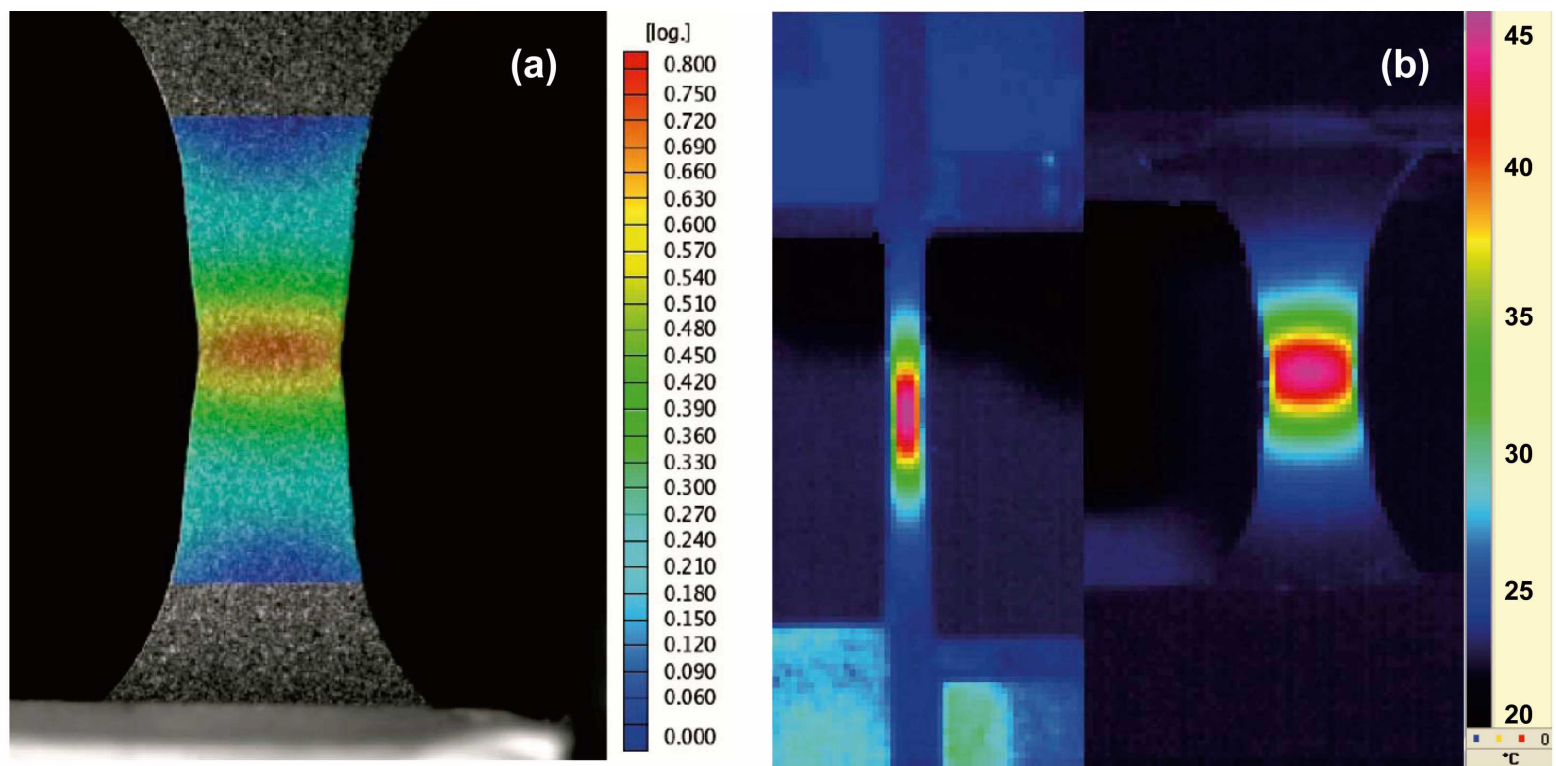

Fig.3. (a) Hencky strain in the longitudinal direction obtained from DIC measurement; (b) IR measurement on the sample side and face for a tensile test $\left(\dot{\varepsilon}=2.410^{-1} \mathrm{~s}^{-1}, \mathrm{~T}=26^{\circ} \mathrm{C}\right)$. 
The DIC method was used to analyze the strain field in the three directions. These threedimensional strain analyses showed that the material can be considered as transverse isotropic, which means that the lateral strain field from the front face is equal to the lateral strain field computed from the sample thickness. We also noticed that the volumic strain (or hydrostatic strain) remains close to zero. Therefore, the material can be considered as isochoric. Thus, we assumed that the material was incompressible. As displayed in Fig. 3a, the strain field was observed to be localized in the middle of the process zone. We also noticed that the temperature field observed on the sample surface could be superimposed to the strain field, the warmer zone being located at the higher strained zone. A small difference was observed in tension for the temperatures measured on the back and side faces of the sample. Such observation was assumed to be due to the low thermal diffusivity of the polymer. However, this difference was so low compared to the overall temperature increase during deformation that this phenomenon was neglected.

In the following, all the stress-strain curves referred to true stress and true strain quantities. The true strain was obtained from DIC measurement by performing an average over a box capturing a homogeneous longitudinal true strain (as observed in Fig. 3a). The true stress was then calculated by applying the condition of transverse isotropy which allows to completely define the evolution of specimen section over time.

Fig. 4 displays the stress-strain and the temperature-strain curves for three different strain rates at room temperature. As shown in Fig. 4a, the material exhibits a time dependent behavior. We also noticed a material softening starting from strain rate of $0.01 \mathrm{~s}^{-1}$ for a strain level of 0.75 . Such material softening is induced by material self-heating (as observed in Fig. 4b) and emphasizes the strong thermomechanical behavior at such low strain rate. Fig. $4 \mathrm{~b}$ also displays: i) a thermoelastic effect that induces a decrease of temperature at small deformation for the different strain rates and; ii) a material self-heating starting at $0.01 \mathrm{~s}^{-1}$ for medium 
strain levels. The thermoelastic effect was also observed for amorphous polymers by Moreau et al. (2005).
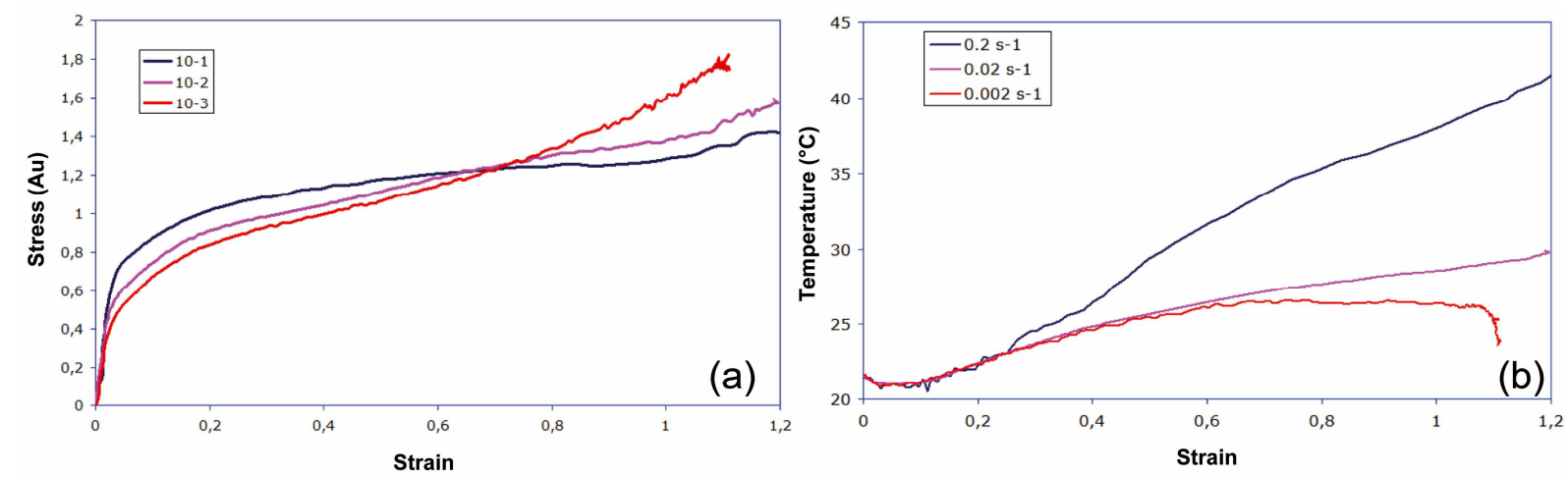

Fig.4. (a) Stress-strain curves and (b) temperature-strain curves for tensile loading conditions at three different strain rates $\left(0.001 \mathrm{~s}^{-1}, 0.01 \mathrm{~s}^{-1}\right.$, and $\left.0.1 \mathrm{~s}^{-1}\right)$ at room temperature.

\subsection{Shear tests}

Shear testing were performed using Iosipescu configuration (described in standard "ASTM D 5379") as illustrated in Fig. 5. The shear sample geometry (displayed in Fig. 1) was chosen for inducing strain localization in the sample. Indeed, Pierron and Vautrin (1997) showed that a triangular notch shape with a specific angle of $90^{\circ}$ was providing a simple shear condition. However, the experimental device described in Fig. 5 did not allow getting strain field measurement in the sample thickness. Shear tests were performed at room temperature for constant strain rates ranging from $3 \cdot 10^{-3} \mathrm{~s}^{-1}$ to $4 \cdot 10^{-1} \mathrm{~s}^{-1}$.
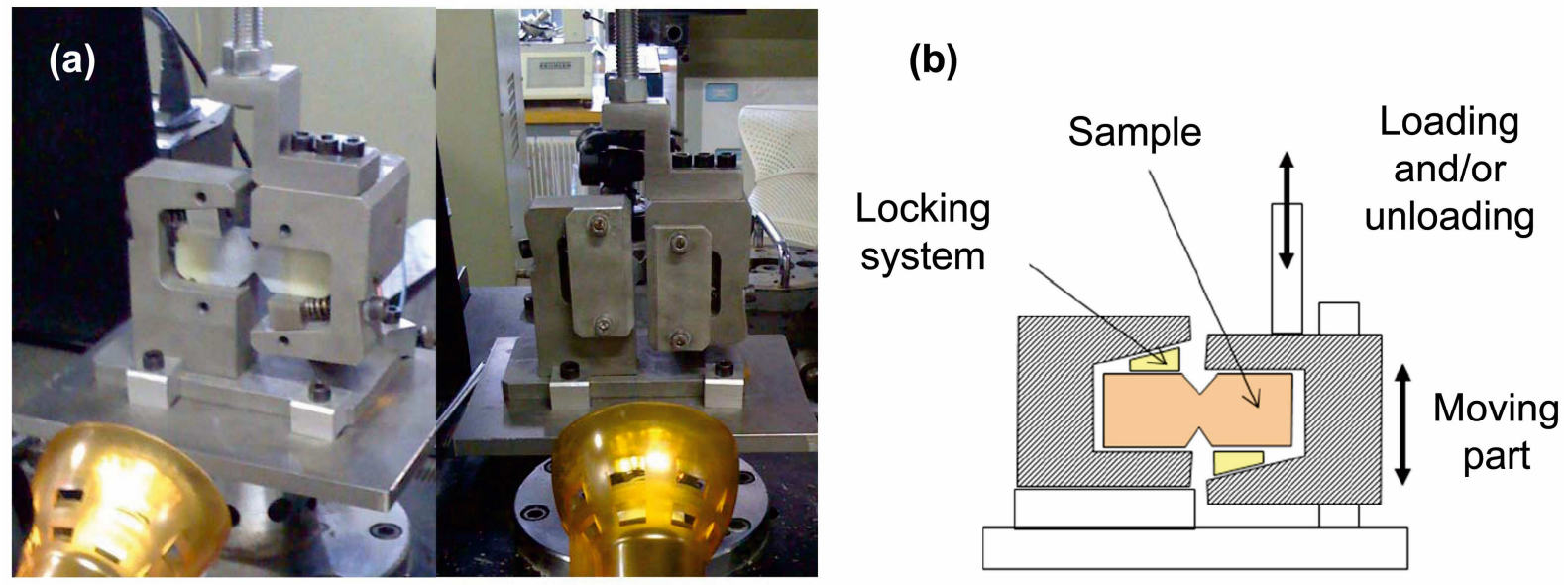

Fig.5. (a) Experimental shear test device based on Iosipescu configuration, (b) schematic view of the mounted shear sample. 
Fig. 6 displays results regarding DIC and IR measurements for a shear test performed at $3.10^{-2}$ $\mathrm{s}^{-1}$ at room temperature. We noticed that the warmer zone was localized in the shear band (representing the higher sheared zone). As noticed before, the self-heating zone was confined and did not propagate due to the low thermal diffusivity of the polymer.
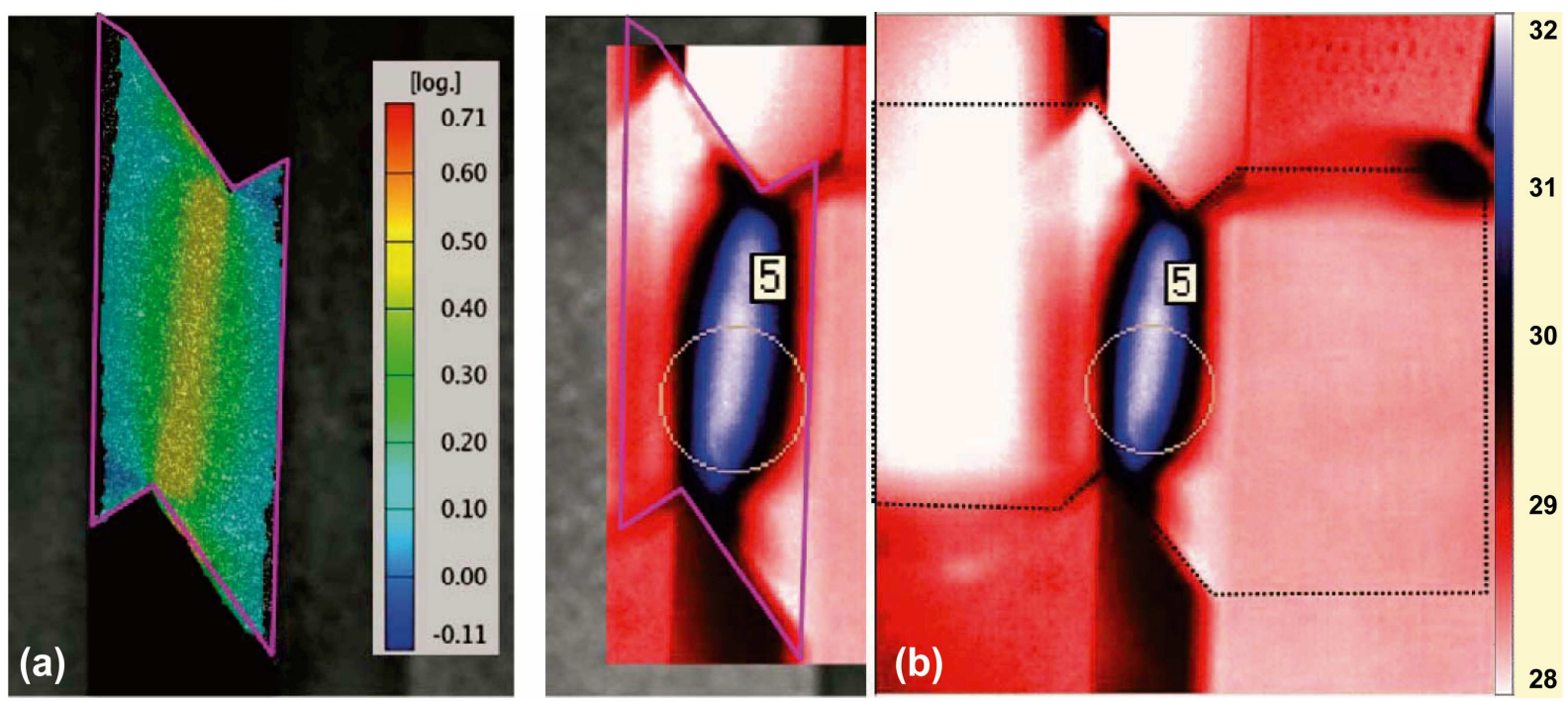

Fig.6. (a) Hencky strain in the direction of shear loading obtained from DIC measurement, and (b) IR measurement on the sample front face under shear loading $\left(\dot{\varepsilon}=3.710^{-2} \mathrm{~s}^{-1}, \mathrm{~T}=29^{\circ} \mathrm{C}\right)$

Fig. 7 displays the stress-strain and the temperature-strain curves for four different strain rates at room temperature. As shown in Fig. 7a, the material exhibits a time dependent behavior. The unloading path was observed to be non-linear with some residual strain. Similar to the tensile tests, thermo-elastic effects inducing material cooling were also observed for small strain levels (Fig. 7b). We also noticed that the material cooling effect was increased with the applied strain rate. 

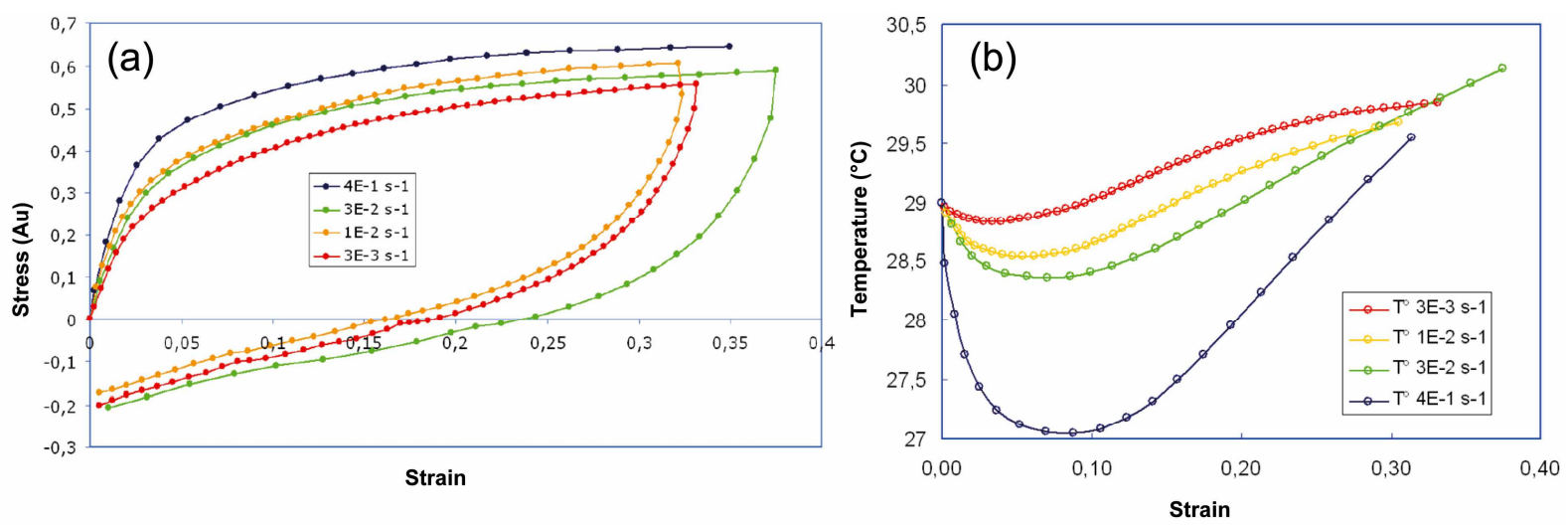

Fig.7. (a) Stress-strain curves and (b) temperature-strain curves measured for four different shear strain rates at room temperature.

\subsection{Dynamic mechanical analyses}

Dynamic mechanical analyses (DMA) were performed in tension to characterize the material $\alpha$-transition temperature and the material visco-elastic domain. Fig. 8 displays the evolution of storage modulus, loss modulus, and $\tan \delta$ as a function of the temperature. We observed an $\alpha-$ transition temperature closed to $78^{\circ} \mathrm{C}$ at $1 \mathrm{~Hz}$. The material also exhibits a strong visco-elastic behavior around its transition temperature.

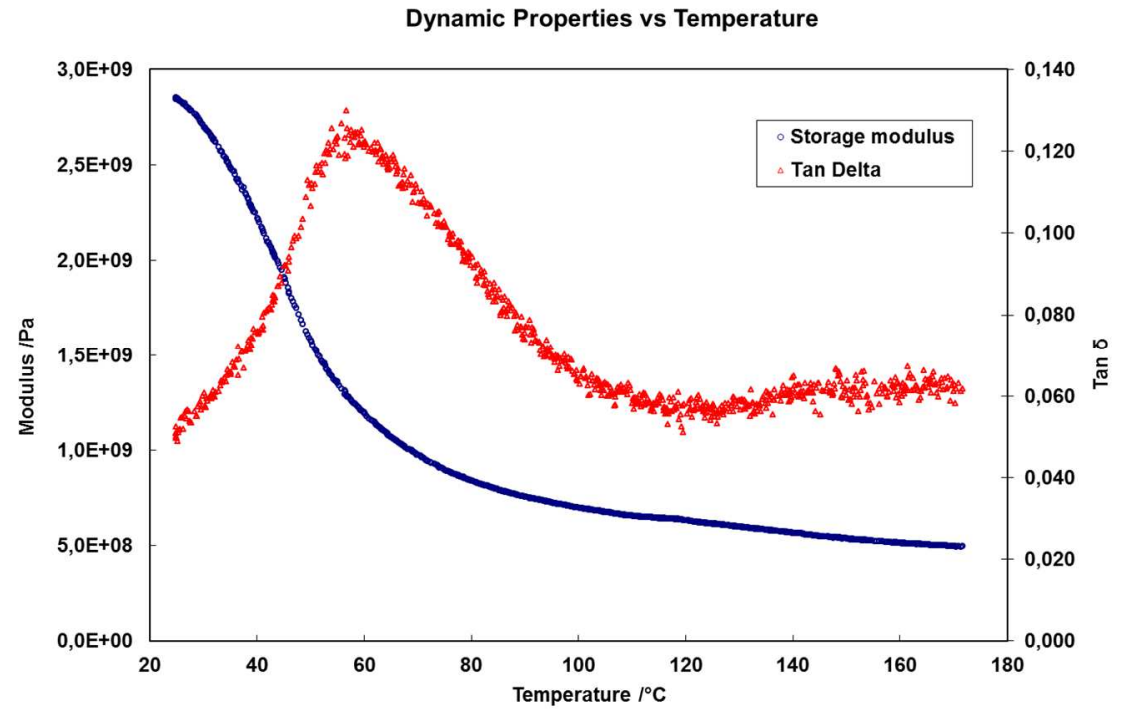

Fig.8. DMA curves at a frequency of $1 \mathrm{~Hz}$ for a PA66 material.

The DMA tests performed at different temperatures for frequencies ranging from $0.1 \mathrm{~Hz}$ to $100 \mathrm{~Hz}$ allowed building a master curve based on the time-temperature superposition 
principle. The time-temperature principle was defined using the classical WLF's approach given by

$$
\log \mathrm{a}_{\mathrm{T}}=-\frac{\mathrm{C}_{1}\left(\mathrm{~T}-\mathrm{T}_{\mathrm{ref}}\right)}{\mathrm{C}_{2}+\left(\mathrm{T}-\mathrm{T}_{\mathrm{ref}}\right)}
$$

where $\mathrm{C}_{1}$ and $\mathrm{C}_{2}$ are material parameters and $\mathrm{T}_{\text {ref }}$ is the reference temperature.

This relationship, introduced by Andrews and Tobolsky (1952), was used to build a master curve that accounts for both time and temperature effect on the mechanical behavior. For polymers an increase of the deformation rate will shift the DMA curves to higher temperatures (i.e. the transition from glassy to rubbery state will occur at higher temperatures).The time-temperature superposition principle was widely used for amorphous polymers,. However few studies investigated this principle for semi-crystalline polymer such as PA66. Fig. 9 displays the methodology used to build the master curve. WLF parameters of $\mathrm{C}_{1}=45.685$ and $\mathrm{C}_{2}=245.06^{\circ} \mathrm{C}$ at $\mathrm{T}_{\text {ref }}=25^{\circ} \mathrm{C}$ were identified for the PA 66.
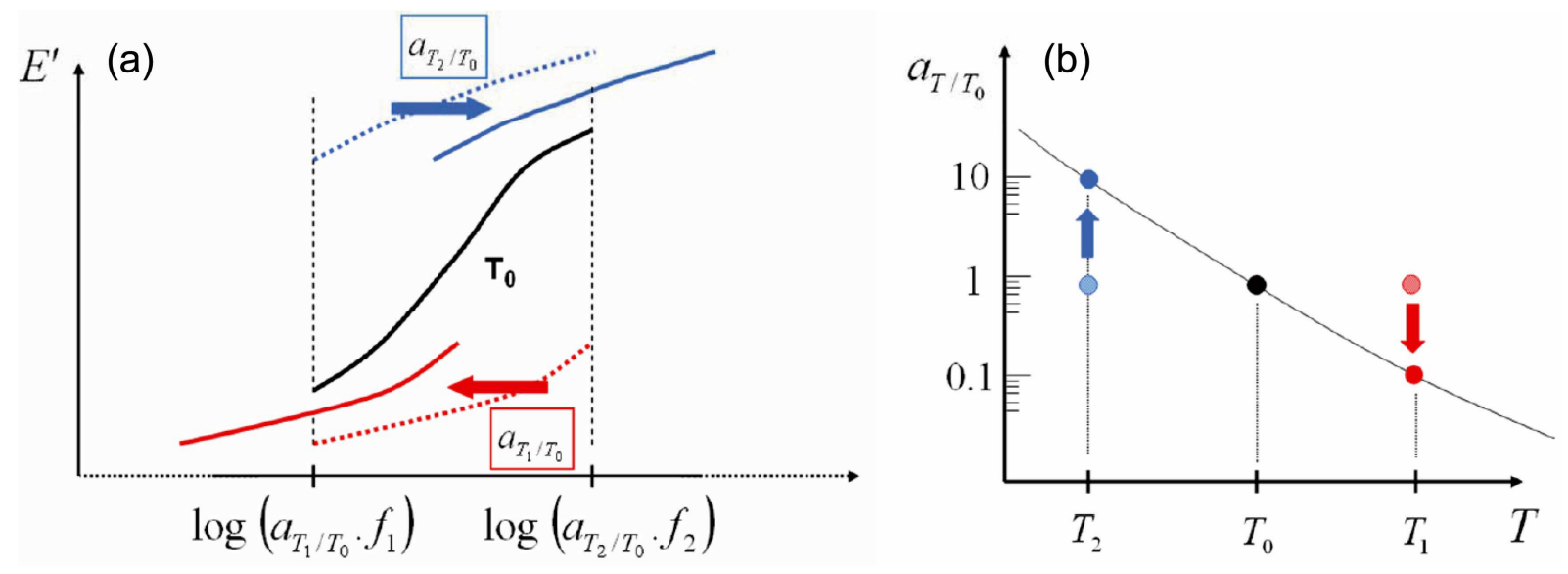

Fig.9. (a) Methodology of getting a master curve at the reference temperature $\mathrm{T}_{0}$ by applying a horizontal shifting $\left(\mathrm{a}_{\mathrm{T}}\right)$ to the frequency curves obtained at different temperatures. (b) Evolution of the coefficient $\mathrm{a}_{\mathrm{T}=\mathrm{T}}$ with the applied temperature.

\subsection{Introduction of the equivalent strain rate notion}


In this section, the notion of equivalent strain rate was introduced. This notion was: i) built from the time-temperature superposition principle obtained from DMA tests and, ii) used to reduce the number of experimental tests performed under tensile and shear conditions. The equivalent strain rate, $\left(\mathrm{a}_{\mathrm{T}} \dot{\varepsilon}_{\mathrm{eq}}\right)$, was based on the time-temperature superposition principle defined at the reference temperature of $25^{\circ} \mathrm{C}$ and was written using Eq.(1) as :

$$
\left(\mathrm{a}_{\mathrm{T}} \dot{\varepsilon}_{\mathrm{eq}}\right)=\mathrm{a}_{\mathrm{T}} \times \dot{\varepsilon}=10^{-\frac{\mathrm{C}_{1}\left(\mathrm{~T}-\mathrm{T}_{\mathrm{Tef}}\right)}{\mathrm{C}_{2}+\left(\mathrm{T}-\mathrm{T}_{\mathrm{ref}}\right)}} \times \dot{\varepsilon}
$$

where $\dot{\varepsilon}$ is the experimental applied strain rate. Fig. 10a shows the different strain rate and temperature conditions investigated in this study for tensile tests. The experimental conditions were defined by 46 couples of $(\dot{\varepsilon}, \mathrm{T})$ ranging from $10^{-4} \mathrm{~s}^{-1}$ to $2.4 \mathrm{~s}^{-1}$ for the strain rates and from $-5^{\circ} \mathrm{C}$ to $60^{\circ} \mathrm{C}$ for the temperatures. As described in Fig. $10 \mathrm{~b}$, these conditions $(\dot{\varepsilon}, \mathrm{T})$ can be plotted as a new curve $\left(\mathrm{a}_{\mathrm{T}} \dot{\varepsilon}_{\text {eq }}, \mathrm{T}\right)$ describing a range of equivalent strain rates ranging from $10^{-9} \mathrm{~s}^{-1}$ to $10^{5} \mathrm{~s}^{-1}$. Notice that: i) one value of equivalent strain-rate is represented by several couples of $(\dot{\varepsilon}, \mathrm{T})$; and ii) these points follow a master curve.
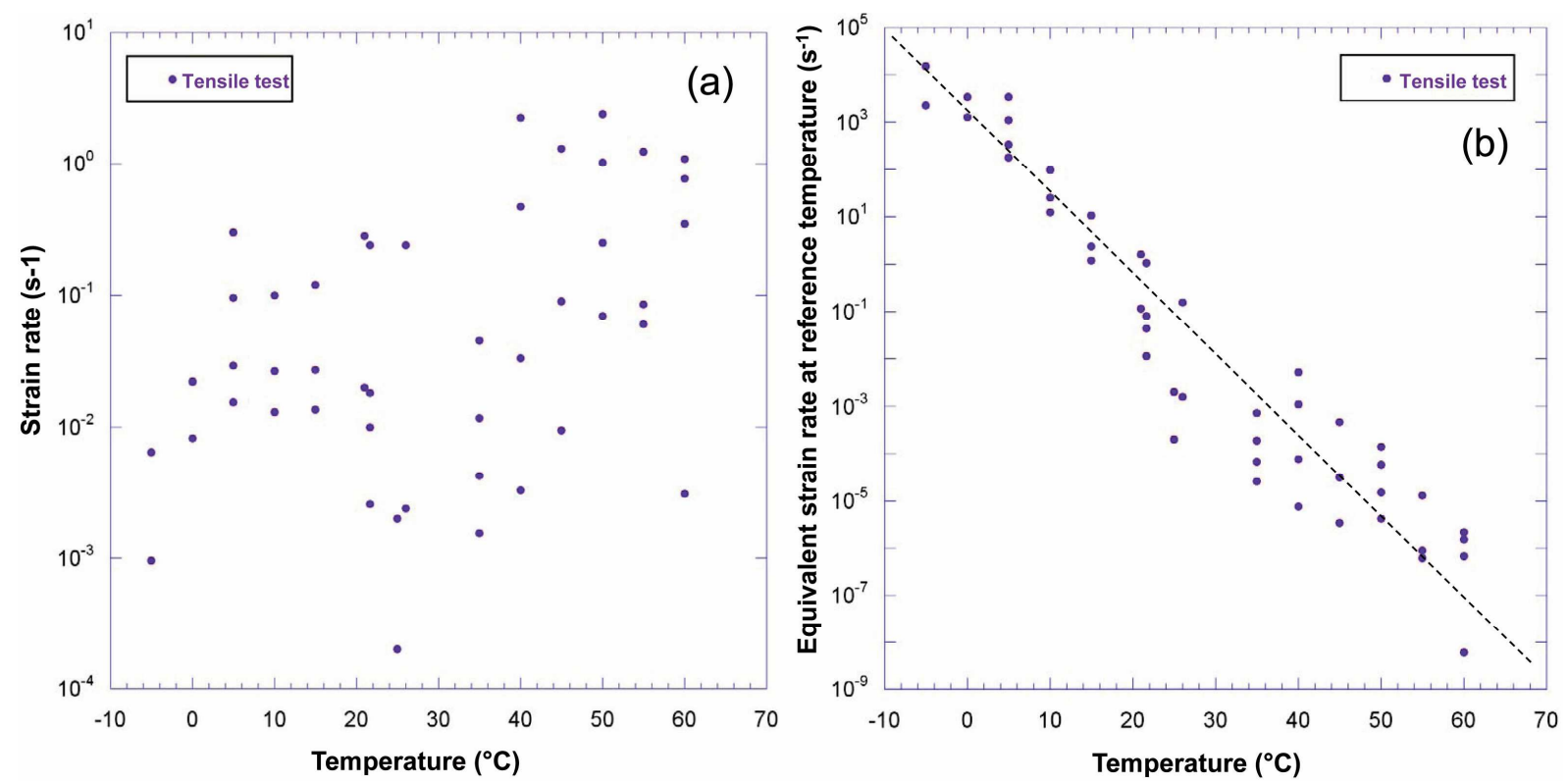

Fig.10.(a) Experimental testing conditions $(\dot{\varepsilon}, \mathrm{T})$ investigated in this study in tension, (b) New formalism based on $\left(\mathrm{a}_{\mathrm{T}} \dot{\varepsilon}_{\text {eq }}, \mathrm{T}\right)$ description leading to the building of a master curve. 
Figs. 11 and 12 display the tensile stress-strain curves obtained for different couples of $(\dot{\varepsilon}, \mathrm{T})$ corresponding to equivalent strain-rates of $\mathrm{a}_{\mathrm{T}} \dot{\varepsilon}_{\mathrm{eq}}=10^{-5} \mathrm{~s}^{-1}$ and $\mathrm{a}_{\mathrm{T}} \dot{\varepsilon}_{\mathrm{eq}}=10 \mathrm{~s}^{-1}$, respectively. Figs. $11 \mathrm{~b}$ and $12 \mathrm{~b}$ display similar mechanical behaviors at the same equivalent strain rate. Notice that the differences observed at large deformation might be induced by material selfheating.
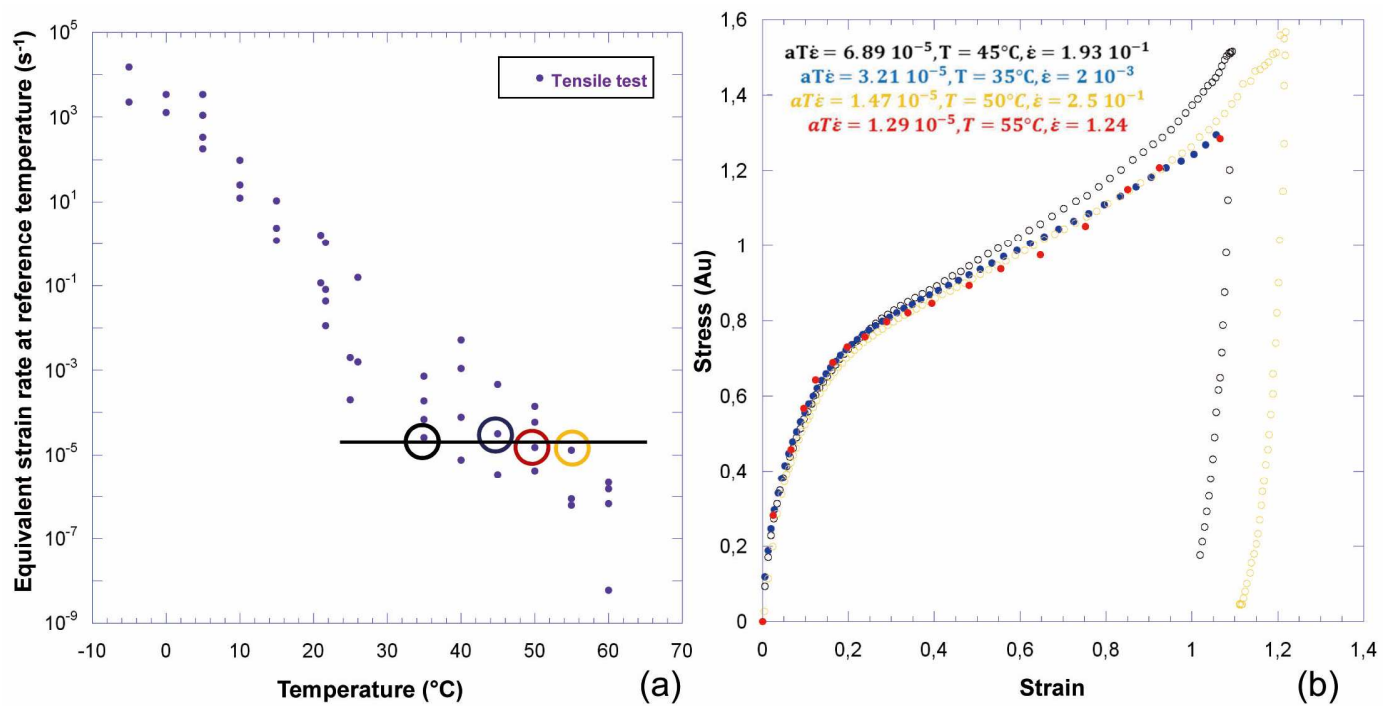

Fig.11. Time-temperature equivalence validation: (a) Experimental testing conditions $\left(\mathrm{a}_{\mathrm{T}} \dot{\varepsilon}_{\mathrm{eq}}, \mathrm{T}\right)$, (b) Tensile stress-strain curves at $\mathrm{a}_{\mathrm{T}} \dot{\varepsilon}_{\mathrm{eq}} \approx 1.510^{-5} \mathrm{~s}^{-1}$
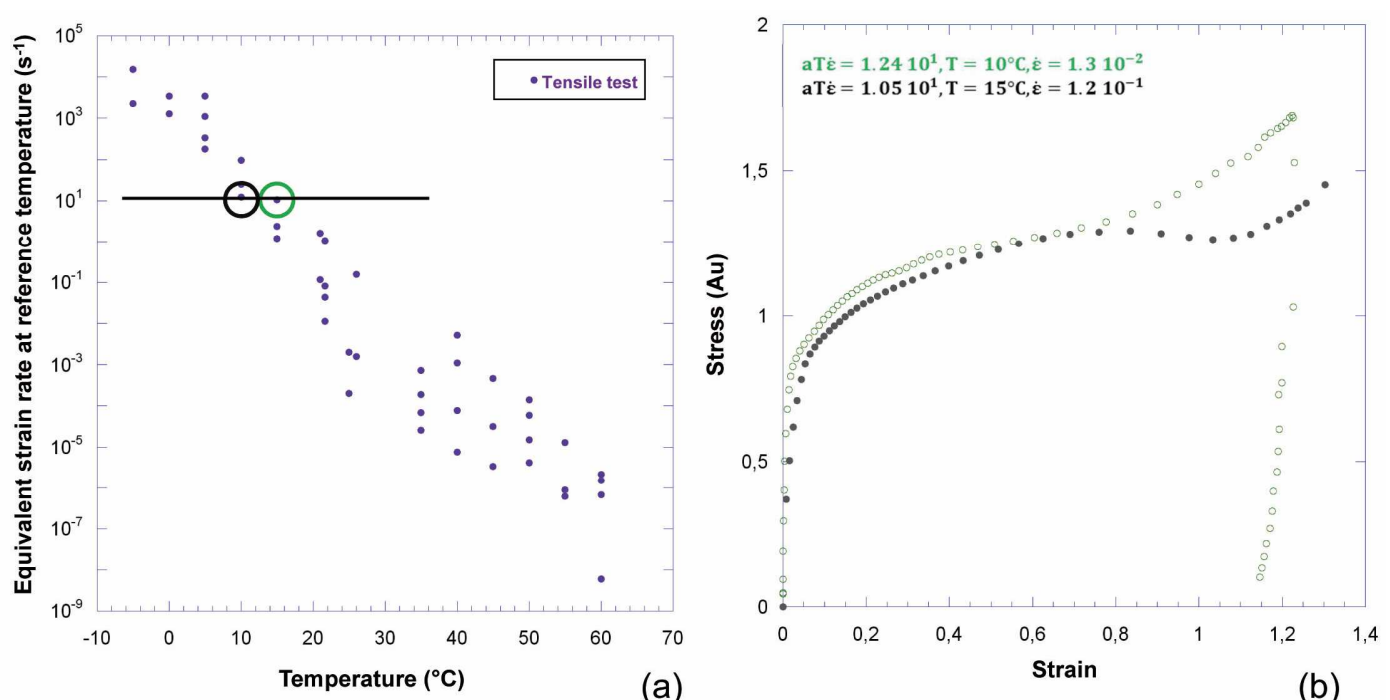

Fig.12. Time-temperature equivalence validation: (a) Experimental testing conditions $\left(\mathrm{a}_{\mathrm{T}} \dot{\varepsilon}_{\mathrm{eq}}, \mathrm{T}\right),(\mathrm{b}) \mathrm{Tensile}$ stress-strain curves at $\mathrm{a}_{\mathrm{T}} \dot{\varepsilon}_{\mathrm{eq}} \approx 10 \mathrm{~s}^{-1}$. 


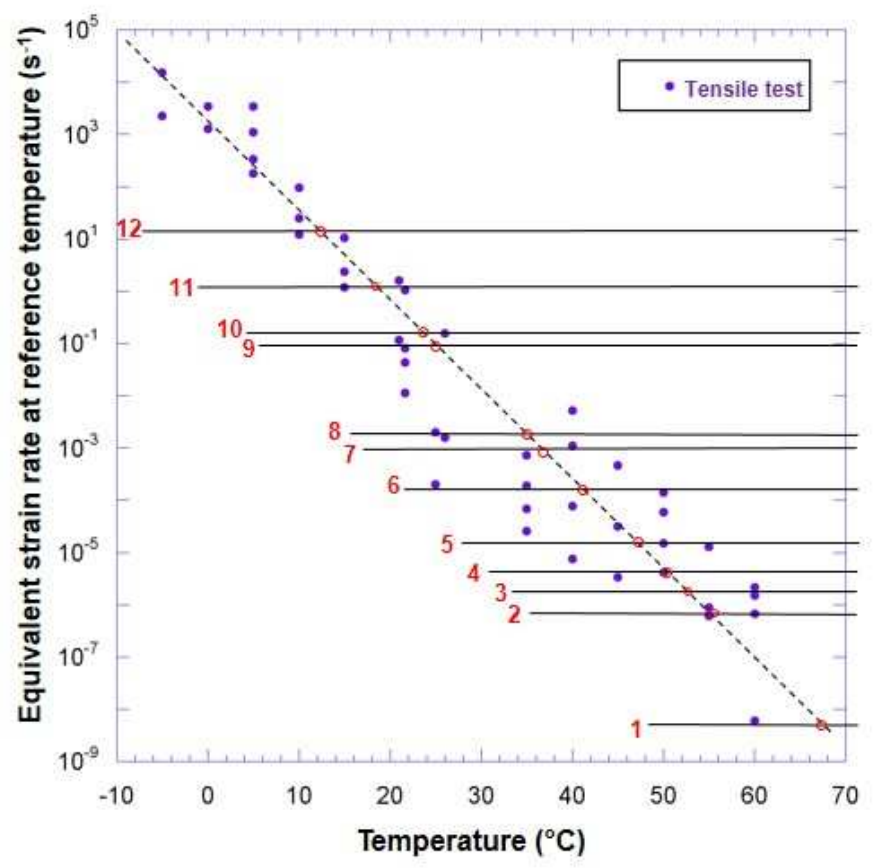

(a)

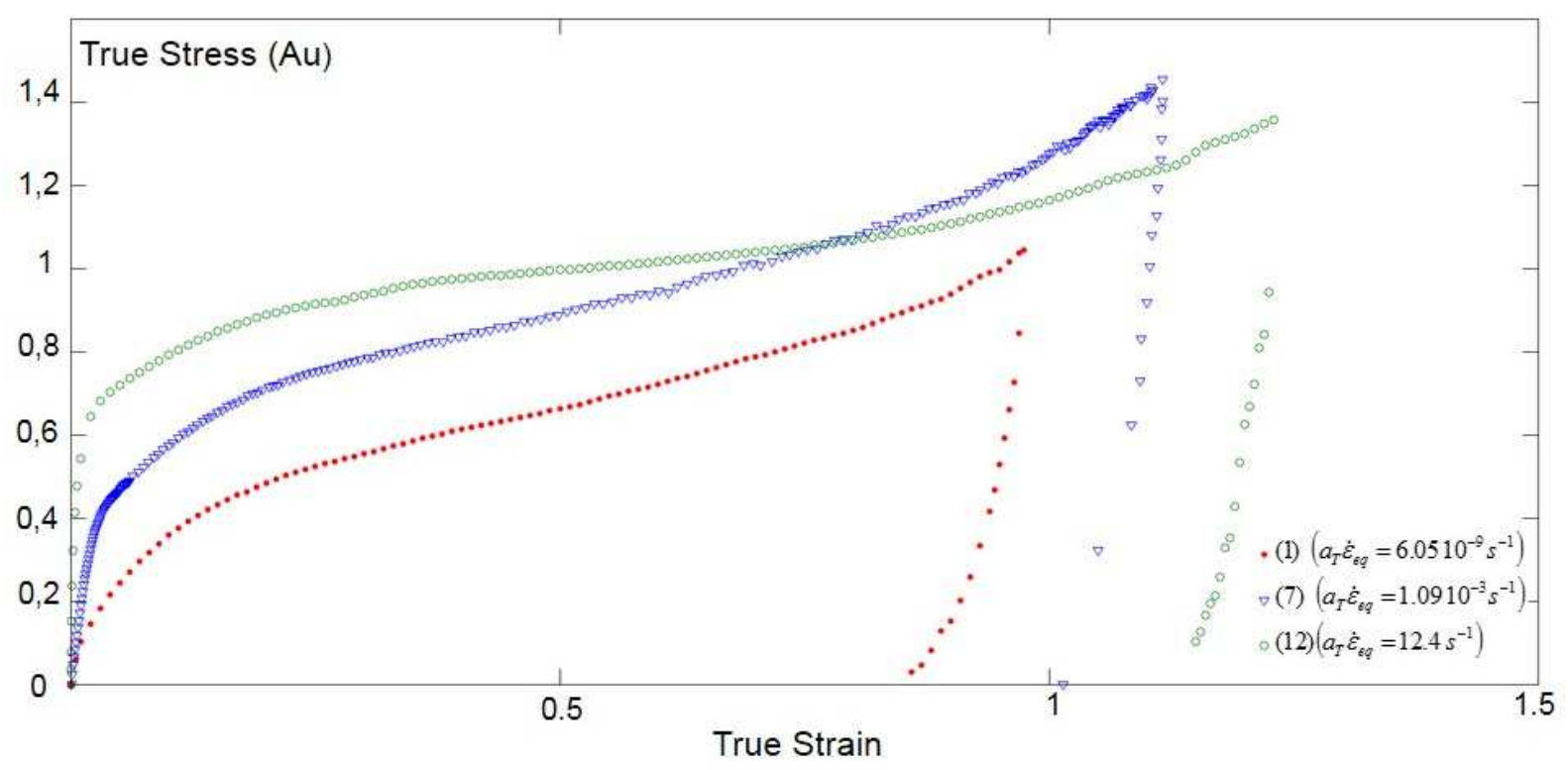

(b)

Fig.13. (a) $\left(\mathrm{a}_{\mathrm{T}} \dot{\varepsilon}_{\mathrm{eq}}, \mathrm{T}\right)$ curve and (b) stress-strain master curves defined for: (1) ( $\dot{\varepsilon}=310^{-3} \mathrm{~s}^{-1}, \mathrm{~T}=60^{\circ} \mathrm{C}, \mathrm{a}_{\mathrm{T}} \dot{\varepsilon}_{\mathrm{eq}}$ $\left.=6.0510^{-9} \mathrm{~s}^{-1}\right) ;(7)\left(\dot{\varepsilon}=4.710^{-1} \mathrm{~s}^{-1}, \mathrm{~T}=40^{\circ} \mathrm{C}, \mathrm{a}_{\mathrm{T}} \dot{\varepsilon}_{\mathrm{eq}}=1.0910^{-3} \mathrm{~s}^{-1}\right),(12)\left(\dot{\varepsilon}=1.310^{-2} \mathrm{~s}^{-1}, \mathrm{~T}=10^{\circ} \mathrm{C}, \quad \mathrm{a}_{\mathrm{l}} \dot{\varepsilon}_{\mathrm{eq}}=12.4\right.$ $\left.10^{-3} \mathrm{~s}^{-1}\right)$. 
Thus, main stress-strain curves were used to describe the overall experimental database. As shown in Fig. 13b, one master curve was used for each value of equivalent strain-rate (Fig 13a).

Regarding the tensile tests, twelve master stress-strain curves (obtained for twelve different equivalent strains) were considered in this study. Regarding the shear tests, four stress-strain curves were added to the experimental database. Thus, the thermo-mechanical behavior of the material was studied through sixteen stress-strain and temperature-strain curves corresponding to a wide range of experimental conditions (as shown in Fig. 10).

\section{Thermo-mechanical constitutive equations}

A thermodynamic framework is used in this work to formulate the three-dimensional (3D) constitutive equations of the polymer. The purpose of the model is to capture: i) the viscoelastic/visco-plastic behavior of the material; ii) the different stress states (tension and shear); iii) the thermo-mechanical coupling observed under deformation; iv) the material timetemperature superposition through the introduction of an equivalent strain rate. In a first section, the kinematics of the problem are described. Then, the First and Second Laws of the thermodynamics are used to express the states laws (deriving from the Helmholtz free energy) and the complementary laws (deriving from a convex dissipative potential). The last section will describe the 3D constitutive equations of the model, motivated by Billon [1]. The constitutive equations of the model will be written in the intermediate configuration following methodology similar to Bouvard et al. [2010, 2012]. This work also uses Gibb's (direct) notation [Gurtin, 1981] to express tensor quantities and their mathematical operations. Considering two second order tensors $\mathbf{A}$ and $\mathbf{B}$, tensor operations between the tensors $\mathbf{A}$ and $\mathbf{B}$ are indicated as $\mathbf{A B}$ for the inner product, as $\mathbf{A} \otimes \mathbf{B}$ for the dyadic product, and $\mathbf{A}: \mathbf{B}$ for the scalar product. 


\subsection{Kinematics}

In standard continuum mechanics form, we let $\mathbf{X}$ represent an arbitrary material point in $\mathrm{B}_{0}$ (body in a reference configuration). The motion of B was described through the mapping $\mathbf{x}=\mathbf{y}(\mathbf{X}, \mathrm{t})$ via a deformation gradient $(\mathbf{F})$, velocity $(\mathbf{v})$, and velocity gradient (l) defined by:

$$
\mathbf{F}=\nabla \mathbf{y}, \mathbf{v}=\dot{\mathbf{y}}, \mathbf{l}=\operatorname{grad} \mathbf{v}=\dot{\mathbf{F}} \mathbf{F}^{-1}
$$

Using the classical Kröner [1960] and Lee [1969] multiplicative decomposition of the deformation gradient $\mathbf{F}$ into elastic and inelastic components, we have,

$$
\mathbf{F}=\mathbf{F}^{\mathrm{e}} \mathbf{F}^{\mathrm{v}}, \mathrm{J}=\operatorname{det} \mathbf{F}=\mathrm{J}^{\mathrm{e}} \mathrm{J}^{\mathrm{v}}, \mathrm{J}^{\mathrm{e}}=\operatorname{det} \mathbf{F}^{\mathrm{e}}, \mathrm{J}^{\mathrm{v}}=\operatorname{det} \mathbf{F}^{\mathrm{v}}
$$

where $\mathbf{F}^{\mathbf{e}}$ represents the elastic part due to "reversible elastic mechanisms" and $\mathbf{F}^{\mathbf{v}}$ represents the inelastic part due to "irreversible mechanisms". The decomposition (Eq. 3) suggests the existence of an intermediate configuration between the undeformed $\mathrm{B}_{0}$ and the current $\mathrm{B}$ configuration, denoted by $\overline{\mathrm{B}}$. The configuration $\overline{\mathrm{B}}$ was obtained from $\mathrm{B}$ by unloading through $\mathbf{F}^{\mathbf{e}-1}$ to a zero stress state or relaxed state.

Using Eq. (4), the velocity gradient $\mathbf{l}$ is written in B as

$$
\mathbf{l}=\dot{\mathbf{F}} \mathbf{F}^{-1}=\mathbf{l}^{\mathrm{e}}+\mathbf{F}^{\mathrm{e}} \overline{\mathbf{L}}^{\mathrm{v}} \mathbf{F}^{\mathrm{e}-1}, \overline{\mathbf{L}}^{\mathrm{v}}=\dot{\mathbf{F}}^{\mathrm{v}} \mathbf{F}^{\mathrm{v}-\mathbf{1}}
$$

where $\mathbf{l}^{\mathbf{e}}=\dot{\mathbf{F}}^{\mathrm{e}} \mathbf{F}^{\mathbf{e}-\mathbf{1}} . \mathbf{l}^{\mathbf{e}}$ and $\overline{\mathbf{L}}^{\mathrm{v}}$ can be decomposed into their symmetric and skew parts, i.e., $\mathbf{l}^{\mathrm{e}}=\mathbf{d}^{\mathrm{e}}+\mathbf{w}^{\mathrm{e}}$ and $\overline{\mathbf{L}}^{\mathrm{v}}=\overline{\mathbf{D}}^{\mathrm{v}}+\overline{\mathbf{W}}^{\mathrm{v}}$.

Three main assumptions are made regarding the model: i) the material is incompressible ( $\operatorname{det} \mathbf{F}=1$ ); ii) the flow is incompressible, implying $\operatorname{det} \mathbf{F}^{\mathbf{v}}=1$ and $\operatorname{tr} \overline{\mathbf{L}}^{\mathbf{v}}=0$, and iii) the flow is irrotational, meaning $\overline{\mathbf{W}}^{\mathbf{v}}=\mathbf{0}$ [Boyce et al., 1989; Gurtin and Anand, 2005] and then $\overline{\mathbf{L}}^{\mathbf{v}}=\overline{\mathbf{D}}^{\mathrm{v}}$. This last assumption was used to simplify the equations and was not based on experimental evidence.

\subsection{Thermodynamics}

A reduced global form of balance energy (Holzapfel (2000)) can be expressed in spatial description as 


$$
\frac{\mathrm{D}}{\mathrm{Dt}} \int_{\mathrm{B}} \mathrm{e}_{\mathrm{v}} \mathrm{dv}=\int_{\mathrm{B}}\left(\boldsymbol{\sigma}: \mathbf{l}-\nabla \cdot \mathbf{q}+\mathrm{r}_{\mathrm{v}}\right) \mathrm{dv}
$$

where $e_{v}$ is the specific (per unit volume in the current volume) internal energy, $\boldsymbol{\sigma}$ is the Cauchy stress, $q$ is the heat flux per unit area, and $r_{v}$ is the heat source per unit volume in $B$.

The Clausius-Duhem inequality can be expressed in spatial description as (Holzapfel (2000))

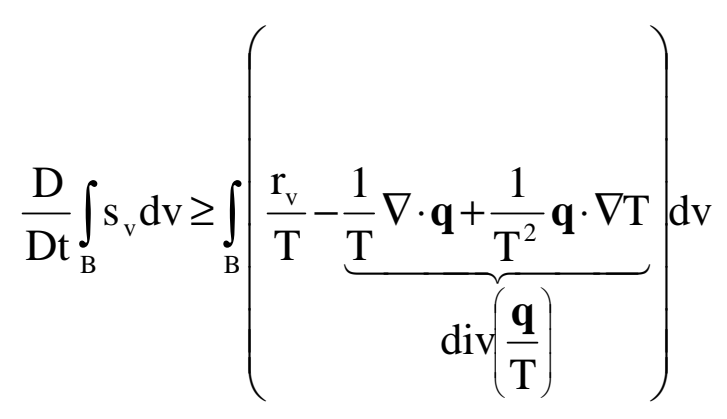

where $s_{v}$ is the specific entropy (per unit volume in the current volume).

A local form of the First Law and the Second Law of thermodynamics can be expressed in the configuration $\overline{\mathrm{B}}$ as (see Bouvard et al. (2010) for more details)

$$
\begin{gathered}
\dot{\overline{\mathrm{e}}}_{\mathrm{v}}-\left(\overline{\mathbf{S}}: \mathbf{F}^{\mathrm{eT}} \mathbf{d}^{\mathrm{e}} \mathbf{F}^{\mathrm{e}}+\overline{\mathbf{M}}: \overline{\mathbf{D}}{ }^{\mathrm{v}}\right)+\bar{\nabla} \cdot \overline{\mathbf{Q}}-\overline{\mathrm{R}}_{\mathrm{v}}=0 \\
\dot{\overline{\mathrm{S}}}_{\mathrm{v}} \geq \frac{\overline{\mathrm{R}}_{\mathrm{v}}}{\mathrm{T}}-\frac{1}{\mathrm{~T}} \bar{\nabla} \cdot \overline{\mathbf{Q}}+\frac{1}{\mathrm{~T}^{2}} \overline{\mathbf{Q}} \cdot \bar{\nabla} \mathrm{T}
\end{gathered}
$$

where $\overline{\mathrm{e}}_{\mathrm{v}}$ and $\overline{\mathrm{s}}_{\mathrm{v}}$ are the specific (per unit volume) internal energy and entropy, respectively; $\overline{\mathbf{Q}}$ is the heat flux per unit area; $\bar{R}_{v}$ is the heat source per unit volume; $\overline{\mathbf{M}}=\overline{\mathbf{C}}^{\mathrm{e}} \overline{\mathbf{S}}$ is the Mandel stress, with $\overline{\mathbf{C}}^{\mathbf{e}}=\mathbf{F}^{\mathbf{e T}} \mathbf{F}^{\mathbf{e}}$ being the elastic Cauchy-Green tensor; $\overline{\mathbf{S}}$ is the corresponding second Piola-Kirchhoff stress expressed in configuration $\overline{\mathrm{B}}$ as $\overline{\mathbf{S}}=\mathrm{J}^{\mathrm{e}} \mathbf{F}^{\mathrm{e}-1} \boldsymbol{\sigma} \mathbf{F}^{\mathrm{eT}-1}=\mathbf{F}^{\mathrm{e}-1} \boldsymbol{\tau} \mathbf{F}^{\mathrm{eT}-1}$ ( $\boldsymbol{\tau}$ is the Kirchhoff stress). 
The Helmholtz free energy per unit volume, $\bar{\psi}_{\mathrm{v}}$, in the current relaxed $\overline{\mathrm{B}}$ is related to the internal energy and entropy by

$$
\bar{\Psi}_{\mathrm{v}}=\overline{\mathrm{e}}_{\mathrm{v}}-\mathrm{T} \overline{\mathrm{s}}_{\mathrm{v}}, \dot{\bar{\psi}}_{\mathrm{v}}=\dot{\overline{\mathrm{e}}}_{\mathrm{v}}-\dot{\mathrm{TS}}_{\mathrm{v}}-\dot{\mathrm{TS}}_{\mathrm{v}}
$$

The Clausius-Duhem inequality can then be obtained by using Eq. (10) and substituting the expression for $\bar{R}_{\mathrm{v}}$ from Eq. (8) into Eq. (9), we get the following,

$$
-\dot{\bar{\psi}}_{\mathrm{v}}-\dot{\mathrm{T}}_{\mathrm{v}}+\left(\overline{\mathbf{S}}: \mathbf{F}^{\mathrm{eT}} \mathbf{d}^{\mathrm{e}} \mathbf{F}^{\mathbf{e}}+\overline{\mathbf{M}}: \overline{\mathbf{D}}^{\mathrm{v}}\right)-\frac{1}{\mathrm{~T}} \overline{\mathbf{Q}} \cdot \bar{\nabla} \mathrm{T} \geq 0
$$

The Helmholtz free energy function was assumed to depend on a number of independent state variables: the elastic Cauchy-Green tensor $\overline{\mathbf{C}}^{\mathbf{e}}$, a set of internal state variables (ISVs) $\bar{\Pi}$, and temperature $\mathrm{T}$ as

$$
\bar{\psi}_{\mathrm{v}}=\hat{\bar{\psi}}_{\mathrm{v}}\left(\overline{\mathbf{C}}^{\mathrm{e}}, \bar{\Pi}, \mathrm{T}\right)
$$

As described in [Billon, 2012], an ISV, $\bar{\eta}$, was used to quantify the degree of mobility of the slip links (entanglement points).

Thus, the time derivative of $\bar{\psi}$ can be calculated as

$$
\dot{\bar{\psi}}_{\mathrm{v}}=\frac{\partial \hat{\bar{\psi}}_{\mathrm{v}}}{\partial \overline{\mathbf{C}}^{\mathrm{e}}}: \dot{\overline{\mathbf{C}}}^{\mathrm{e}}+\frac{\partial \hat{\bar{\psi}}_{\mathrm{v}}}{\partial \bar{\eta}} \dot{\bar{\eta}}+\frac{\partial \hat{\bar{\psi}}_{\mathrm{v}}}{\partial \mathrm{T}} \dot{\mathrm{T}}
$$

The first term of Eq. (13) can be expressed as

$$
\frac{\partial \hat{\bar{\psi}}}{\partial \overline{\mathbf{C}}^{\mathbf{e}}}: \dot{\overline{\mathbf{C}}}{ }^{\mathbf{e}}=\frac{\partial \hat{\bar{\psi}}}{\partial \overline{\mathbf{C}}^{\mathbf{e}}}:\left(\dot{\mathbf{F}}^{\mathrm{e} \mathbf{T}} \mathbf{F}^{\mathbf{e}}+\mathbf{F}^{\mathbf{e} \mathbf{T}} \dot{\mathbf{F}}^{\mathbf{e}}\right)=2 \mathbf{F}^{\mathbf{e}} \frac{\partial \hat{\bar{\psi}}}{\partial \overline{\mathbf{C}}} \mathbf{F}^{\mathbf{e} \mathbf{T}}: \dot{\mathbf{F}}^{\mathrm{e}} \mathbf{F}^{\mathbf{e}-1}=2 \frac{\partial \hat{\bar{\psi}}}{\partial \overline{\mathbf{C}}^{\mathbf{e}}}: \mathbf{F}^{\mathbf{e} \mathbf{T}} \mathbf{d}^{\mathbf{e}} \mathbf{F}^{\mathbf{e}}
$$

Substituting Eq. (14) into Eq. (11), we obtain

$$
\left[\overline{\mathbf{S}}-\left(2 \frac{\partial \hat{\bar{\Psi}}_{\mathrm{v}}}{\partial \overline{\mathbf{C}}^{\mathbf{e}}}\right)\right]: \mathbf{F}^{\mathrm{e} \mathrm{T}} \mathbf{d}^{\mathrm{e}} \mathbf{F}^{\mathbf{e}}+\overline{\mathbf{M}}: \overline{\mathbf{D}}^{\mathbf{v}}+\left[-\frac{\partial \hat{\bar{\Psi}}_{\mathrm{v}}}{\partial \mathrm{T}}-\overline{\mathrm{s}}_{\mathrm{v}}\right] \dot{\mathrm{T}}-\frac{\partial \hat{\bar{\psi}}_{\mathrm{v}}}{\partial \overline{\bar{\eta}}}-\frac{1}{\mathrm{~T}} \overline{\mathbf{Q}} \cdot \bar{\nabla} \mathrm{T} \geq 0
$$

Using standard arguments (Coleman and Gurtin, 1967), we obtain from Eq. (15) the constitutive equations of $\overline{\mathbf{S}}$ and $\overline{\mathrm{s}}_{\mathrm{v}}$ : 


$$
\overline{\mathbf{S}}=2 \frac{\partial \hat{\bar{\psi}}_{\mathrm{v}}}{\partial \overline{\mathbf{C}}^{\mathbf{e}}}, \overline{\mathrm{s}}_{\mathrm{v}}=-\frac{\partial \hat{\bar{\psi}}_{\mathrm{v}}}{\partial \mathrm{T}}
$$

The dissipation inequality can now be reduced to

$$
\underbrace{\overline{\mathbf{M}}: \overline{\mathbf{D}}^{\mathrm{v}}-\frac{\partial \hat{\bar{\psi}}_{\mathrm{v}}}{\partial \bar{\eta}} \dot{\bar{\eta}}}_{\phi_{\mathrm{int}}}-\underbrace{\frac{1}{\theta} \overline{\mathbf{Q}} \cdot \bar{\nabla} \mathrm{T}}_{\phi_{\mathrm{th}}} \geq 0
$$

where the first term $\phi_{\text {int }}$ regroups the inelastic work dissipated from irreversible mechanisms and the internal work associated with the polymer network reorganization (chains relaxation inducing chains disentanglement). The second term represents the thermal dissipation.

The heat equation can be expressed by a combination of some of the above equations. Thus, substituting Eqs. (16) into Eq. (13), we obtain the following for the derivative expression of the free energy:

$$
\dot{\bar{\Psi}}_{\mathrm{v}}=\frac{1}{2} \overline{\mathbf{S}}: \dot{\overline{\mathbf{C}}}^{\mathrm{e}}+\frac{\partial \hat{\bar{\psi}}_{\mathrm{v}}}{\partial \bar{\eta}} \dot{\bar{\eta}}-\overline{\mathrm{S}}_{\mathrm{v}} \dot{\mathrm{T}}
$$

Using this equation in Eq. (10) with Eq. (8), we obtain

$$
-\overline{\mathbf{M}}: \overline{\mathbf{D}}^{\mathbf{v}}+\frac{\partial \hat{\bar{\psi}}_{\mathrm{v}}}{\partial \bar{\eta}} \dot{\bar{\eta}}+\mathrm{T}_{\overline{\mathrm{s}}}+\bar{\nabla} \cdot \overline{\mathbf{Q}}-\overline{\mathbf{R}}_{\mathrm{v}}=0
$$

Using Eq. (16) 2 , the material time derivative of the entropy $\overline{\mathrm{s}}_{\mathrm{v}}$ can be obtained as

$$
\dot{\overline{\mathrm{s}}}_{\mathrm{v}}=-\frac{\partial^{2} \bar{\Psi}_{\mathrm{v}}}{\partial \mathrm{T} \partial \overline{\mathbf{C}}^{\mathbf{e}}}: \dot{\mathbf{C}}^{\mathbf{e}}-\frac{\partial^{2} \hat{\bar{\psi}}_{\mathrm{v}}}{\partial \mathrm{T} \partial \overline{\bar{\eta}}}+\frac{\partial \overline{\mathrm{s}}_{\mathrm{v}}}{\partial \mathrm{T}} \dot{\mathrm{T}}
$$

The last term of Eq. (20) can be obtained using the definition of the heat capacity per unit volume $\overline{\mathrm{C}}_{\mathrm{v}}$ with Eq. $(16)_{2}$ as the following,

$$
\overline{\mathrm{C}}_{\mathrm{v}}=\frac{\partial \overline{\mathrm{e}}_{\mathrm{v}}}{\partial \mathrm{T}}=\frac{\partial}{\partial \mathrm{T}}\left(\bar{\psi}_{\mathrm{v}}+\mathrm{T} \overline{\mathrm{s}}_{\mathrm{v}}\right), \overline{\mathrm{C}}_{\mathrm{v}}=\mathrm{T} \frac{\partial \overline{\mathrm{s}}_{\mathrm{v}}}{\partial \mathrm{T}}
$$


Then, the heat equation can be found combining Eqs. (19) and (20) and using Eqs. (16) and (21):

$$
-\bar{\nabla} \cdot \overline{\mathbf{Q}}=-\overline{\mathbf{M}}: \overline{\mathbf{D}}^{\mathrm{v}}+\frac{\partial \hat{\bar{\psi}}_{\mathrm{v}}}{\partial \bar{\eta}} \dot{\bar{\eta}}-\overline{\mathbf{R}}_{\mathrm{v}}-\frac{1}{2} \mathrm{~T} \frac{\partial \overline{\mathbf{S}}}{\partial \mathrm{T}}: \dot{\mathbf{C}}^{\mathbf{e}}-\mathrm{T} \frac{\partial^{2} \hat{\bar{\psi}}_{\mathrm{v}}}{\partial \mathrm{T} \partial \overline{\bar{\eta}}}+\overline{\mathrm{C}}_{\mathrm{v}} \dot{\mathrm{T}}
$$

After arranging some terms, one obtains

$$
\overline{\mathrm{C}}_{\mathrm{v}} \dot{\mathrm{T}}=\overbrace{\overbrace{\mathbf{M}}: \overline{\mathbf{D}}^{\mathrm{v}}}^{\text {inelastic dissipation }}+\overbrace{\frac{1}{2} \mathrm{~T} \frac{\partial \overline{\mathbf{S}}}{\partial \mathrm{T}}: \dot{\overline{\mathbf{C}}}^{\mathbf{e}}}^{\text {thermoelastic coupling }}-\overbrace{\left(\frac{\partial \hat{\bar{\psi}}_{\mathrm{v}}}{\partial \bar{\eta}}-\mathrm{T} \frac{\partial^{2} \hat{\bar{\psi}}_{\mathrm{v}}}{\partial \mathrm{T} \partial \bar{\eta}}\right)}^{\text {int ernal work }}+\overline{\mathrm{R}}_{\mathrm{v}}-\bar{\nabla} \cdot \overline{\mathbf{Q}}
$$

\subsection{Constitutive equations (based on Billon (2012))}

\section{- Helmholtz free energy}

The model developed by Billon (2012) is based on the non-gaussian statistic approach of entangled polymer network developed by Edwards and Vilgis (1986). The Edwards-Vilgis free energy can be decomposed into two components: i) the energy due to the polymer network deformation constrained by permanent nodes (crosslinks); and ii) the energy due to the polymer network deformation constrained by slip links such as entanglement points. The Edwards and Vilgis hyper-elastic model can therefore be described by:

$$
\hat{\bar{\Psi}}_{\mathrm{v}}\left(\overline{\mathbf{C}}^{\mathrm{e}}, \eta, \mathrm{T}\right)=(1 / 2) \mathrm{kT}\left(\mathrm{N}_{\mathrm{c}} \hat{\bar{\Psi}}_{\mathrm{c}}\left(\overline{\mathbf{C}}^{\mathrm{e}}, \alpha\right)+\mathrm{N}_{\mathrm{s}} \hat{\bar{\Psi}}_{\mathrm{s}}\left(\overline{\mathbf{C}}^{\mathrm{e}}, \bar{\eta}\right)\right)
$$

where $\mathrm{k}$ is the Boltzmann's constant; $\mathrm{N}_{\mathrm{c}}$ is the density per unit volume of crosslinking; $\mathrm{N}_{\mathrm{s}}$ is the density per unit volume of entanglement points; the variable $\bar{\eta}$ accounts for the degree of mobility of the entanglement points ( $\bar{\eta}$ being 0 for permanent nodes); $\alpha$ is the limit of chain extensibility. 
The energy of Edward and Vilgis can also be written as:

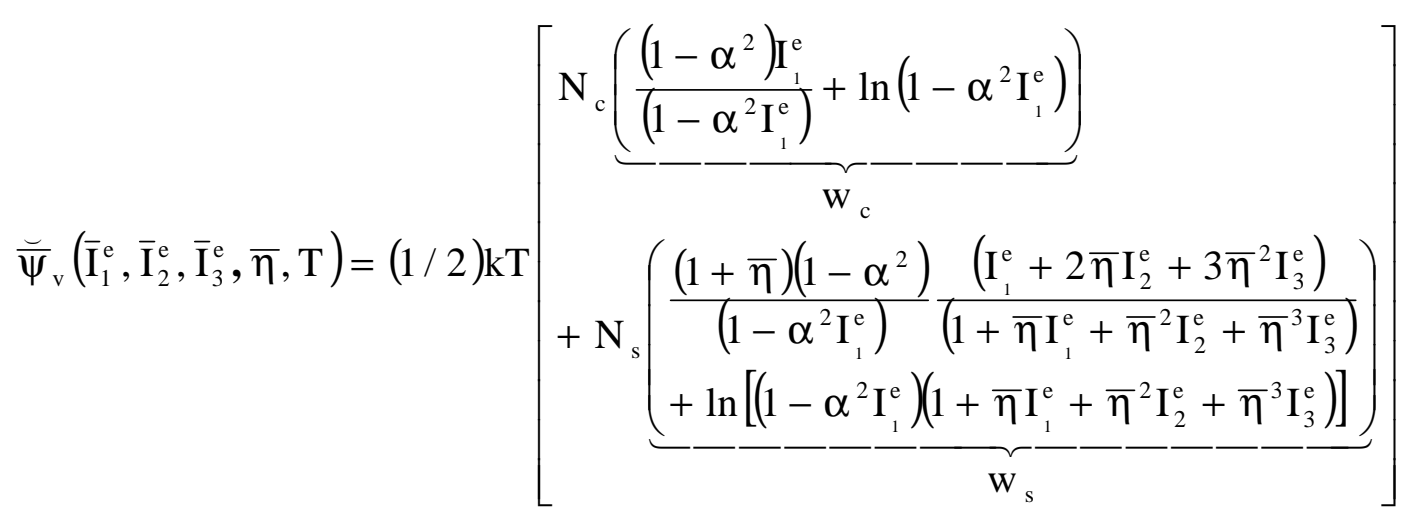

with $\left\{\begin{array}{l}\mathrm{I}_{1}^{\mathrm{e}}=\operatorname{tr}\left(\overline{\mathbf{C}}_{\mathrm{e}}\right) \\ \mathrm{I}_{2}{ }^{\mathrm{e}}=\frac{1}{2}\left[\mathrm{I}_{1}{ }^{\mathrm{e}^{2}}-\operatorname{trace}\left(\overline{\mathbf{C}}_{\mathrm{e}}{ }^{2}\right)\right] \\ \mathrm{I}_{3}{ }^{\mathrm{e}}=\operatorname{det}\left(\overline{\mathbf{C}}_{\mathbf{e}}\right)\end{array}\right.$

Some of the variables were assumed to be dependent of the time and temperature by the use of an equivalent strain rate $\mathrm{a}_{\mathrm{T}} \dot{\varepsilon}_{\mathrm{eq}}$ (defined at the reference temperature, $\mathrm{T}_{\text {ref). This equivalent }}$ strain rate follows classical time - temperature equivalence principle. Let's emphasize that this latter assumption did not rely on theoretical developments but on an experimental observation described in Section 2.5. The use of an equivalent strain rate needs to be related to the use of a corresponding equivalent temporal scale. The shift factor, $\mathrm{a}_{\mathrm{T}}$, is well known at each time for an instantaneous temperature. So, the development of a temporal equivalence at a reference temperature must be related to a time discretization. The equivalent time at reference temperature, $\mathrm{t}_{\mathrm{eq}}$, is defined in Eq. (26). This equivalent time is a function of the physical history seen by the material during the loading and is directly linked to the temperature history. 


$$
\left\{\begin{array}{l}
\mathrm{a}_{\mathrm{T}} \dot{\varepsilon}_{\mathrm{eq}}=\mathrm{a}_{\mathrm{T}} \frac{\mathrm{d} \varepsilon_{\mathrm{eq}}}{\mathrm{dt}}=\frac{\mathrm{d} \varepsilon_{\mathrm{eq}}}{\left(\mathrm{dt} / \mathrm{a}_{\mathrm{T}}\right)}=\frac{\mathrm{d} \varepsilon_{\mathrm{eq}}}{\mathrm{dt}_{\mathrm{eq}}} \\
\mathrm{dt}_{\mathrm{eq}}=\frac{\mathrm{dt}}{\mathrm{a}_{\mathrm{T}}} \\
\mathrm{t}_{\mathrm{eq}}=\int_{0}^{\mathrm{t}} \frac{\mathrm{dt}}{\mathrm{a}_{\mathrm{T}}(\mathrm{t})}
\end{array}\right.
$$

where $\dot{\varepsilon}_{\mathrm{eq}}=\sqrt{\frac{2}{3} \mathbf{d}: \mathbf{d}}$ is the equivalent rate of deformation.

Two new parameters, $\left\{\mathrm{N}_{\mathrm{c}}^{*}\left(\mathrm{a}_{\mathrm{T}} \dot{\varepsilon}_{\text {eq }}\right), \mathrm{N}_{\mathrm{s}}^{*}\left(\mathrm{a}_{\mathrm{T}} \dot{\varepsilon}_{\mathrm{eq}}\right)\right\}$, was introduced in the Edwards-Vilgis model in substitution of $\left\{\mathrm{N}_{\mathrm{c}} \mathrm{kT}, \mathrm{N}_{\mathrm{s}} \mathrm{kT}\right\}$. The expression of the parameters will be clarified in Section 3.6.

\section{- Cauchy stress}

The Cauchy stress can be computed using Eq. (16)1. Using the polar decomposition of $\mathbf{F}^{\mathbf{e}}$ along with the spectral representation of $\mathbf{U}^{\mathbf{e}}$ and $\overline{\mathbf{C}}^{\mathrm{e}}$ (see Bouvard et al. (2010) for more details) such as

$$
\mathbf{U}^{\mathrm{e}}=\sum_{\mathrm{I}=1}^{3} \lambda_{\overline{\mathrm{I}}}^{\mathrm{e}} \overline{\mathbf{n}}_{\overline{\mathrm{I}}} \otimes \overline{\mathbf{n}}_{\overline{\mathrm{I}}}, \overline{\mathbf{C}}^{\mathbf{e}}=\mathbf{U}^{\mathrm{e} 2}=\sum_{\overline{\mathrm{I}}=1}^{3} \lambda_{\overline{\mathrm{I}}}^{\mathrm{e} 2} \overline{\mathbf{n}}_{\overline{\mathrm{I}}} \otimes \overline{\mathbf{n}}_{\overline{\mathrm{I}}}
$$

with $\lambda_{\overline{\mathrm{I}}}^{\mathrm{e}}$ being the positive eigenvalues and $\overline{\mathbf{n}}_{\overline{\mathrm{I}}}$ being the orthonormal eigenvectors of $\mathbf{U}^{\mathrm{e}}$. One can express the stress $\overline{\mathbf{S}}$, Eq. (16) 1 , as

$$
\overline{\mathbf{S}}=2 \frac{\partial \hat{\bar{\Psi}}_{v}}{\partial \overline{\mathbf{C}}^{\mathrm{e}}}=2 \sum_{\mathrm{I}=1}^{3} \frac{\partial \overline{\bar{\Psi}}_{\mathrm{v}}\left(\overline{\mathrm{I}}_{\overline{\mathrm{I}}}^{\mathrm{e}}\right)}{\partial \mathrm{I}_{\overline{\mathrm{I}}}^{\mathrm{e}}} \frac{\partial \overline{\mathrm{I}}_{\overline{\mathrm{I}}}^{\mathrm{e}}}{\partial \overline{\mathbf{C}}^{\mathrm{e}}}
$$

The Cauchy stress is then given by 


$$
\begin{aligned}
& \boldsymbol{\sigma}=\mathrm{J}^{\mathrm{e}-1} \mathbf{F}^{\mathrm{e}} \overline{\mathbf{S}} \mathbf{F}^{\mathrm{eT}}-\mathrm{p}^{\mathbf{I}} \mathbf{I}=2 \mathbf{J}^{\mathrm{e}-1} \mathbf{F}^{\mathrm{e}} \frac{\partial \hat{\bar{\psi}}_{\mathrm{v}}}{\partial \overline{\mathbf{C}}^{\mathrm{e}}} \mathbf{F}^{\mathrm{eT}}-\mathrm{p}^{\prime} \mathbf{I} \\
& =2 \mathbf{J}^{\mathrm{e}-1} \mathbf{F}^{\mathbf{e}}\left(\sum_{\overline{\mathrm{I}}=1}^{2} \frac{\partial \overline{\bar{\Psi}}_{\mathrm{v}}}{\partial \overline{\mathrm{I}}_{\overline{\mathrm{I}}}^{\mathrm{e}}} \frac{\partial \overline{\mathrm{I}}_{\overline{\mathrm{I}}}^{\mathrm{e}}}{\partial \overline{\mathbf{C}}^{\mathbf{e}}}\right) \mathbf{F}^{\mathrm{e} \mathbf{T}}-\mathrm{p}^{\prime} \mathbf{I}
\end{aligned}
$$

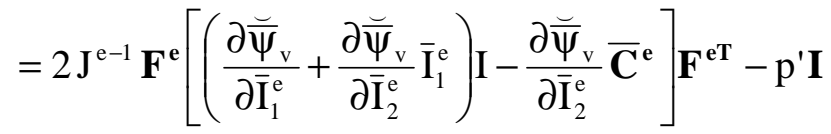

$$
\begin{aligned}
& =2 \mathbf{J}^{\mathrm{e}-1}\left[\left(\frac{\partial \breve{\Psi}_{\mathrm{v}}}{\partial \overline{\mathrm{I}}_{1}^{\mathrm{e}}}+\frac{\partial \breve{\Psi}_{\mathrm{v}}}{\partial \overline{\mathbf{I}}_{2}^{\mathrm{e}}} \overline{\mathbf{I}}_{1}^{\mathrm{e}}\right) \mathbf{b}^{\mathrm{e}}-\frac{\partial \breve{\Psi}_{\mathrm{v}}^{\mathrm{e}}}{\partial \overline{\mathrm{I}}_{2}^{\mathrm{e}}} \mathbf{b}^{\mathrm{e} 2}\right]-\mathrm{p}^{\prime} \mathbf{I}
\end{aligned}
$$

where $\mathrm{p}^{\prime}$ is a pressure term that must be determined from the equilibrium equations and the boundary conditions of the problem.

and $\left\{\begin{array}{l}\frac{\partial \overline{\mathrm{I}}_{1}^{\mathrm{e}}}{\partial \overline{\mathbf{C}}^{\mathbf{e}}}=\mathbf{I} \\ \frac{\partial \overline{\mathrm{I}}_{2}^{\mathrm{e}}}{\partial \overline{\mathbf{C}}^{\mathbf{e}}}=\overline{\mathrm{I}}_{1}^{\mathrm{e}} \mathbf{I}-\overline{\mathbf{C}}^{\mathbf{e}}\end{array}\right.$

The terms $\frac{\partial \bar{\Psi}_{\mathrm{v}}^{\mathrm{v}}}{\partial \overline{\mathrm{I}}_{1}^{\mathrm{e}}}$ and $\frac{\partial \breve{\Psi}_{\mathrm{v}}}{\partial \overline{\mathrm{I}}_{2}^{\mathrm{e}}}$ are defined in Appendix (A).

\section{- Evolution equation of the internal state variable $\{\bar{\eta}\}$}

The evolution equation of $\bar{\eta}$ is related to the rate of polymer chains network reorganization when submitted to an external loading. More especially, the variable $\bar{\eta}$ accounts for the disentanglement of the polymer chains. Following Billon [2012], the kinetic of $\bar{\eta}$ depends on the elastic energy stored in the entangled network (driven by $\omega_{S}$ ) (Eq. (25)). Thus, more the elastic energy stored in the entangled network is important, more this network is constraint and would have a tendency to disentangle and to relax. Therefore, the evolution equation of $\bar{\eta}$ was defined as

$$
\dot{\bar{\eta}}=z_{0 p}^{*}\left(\exp \left[z_{p 1}\left(\omega_{s}\left(\mathbf{b}^{\mathbf{e}}, \bar{\eta}\right)-\omega_{s}(\mathbf{I}, \bar{\eta})\right)\right]-1\right)
$$


where $\left\{z_{0 p}^{*}, z_{p 1}\right\}$ are material parameters. The specific form of $z_{0 p}^{*}$ will be clarified in Sections

\section{5 and 3.6.}

Notice that such concepts can easily be justified for amorphous phase of polymers. However, in the case of a semi-crystalline polymer, theEdward Vilgis theory needs to be seen as an equivalent chain network of the polymer. Crystalline phases may be considered as a crosslink network and the amorphous region as the entangled network. Disentanglement may represent the reorganization of the amorphous region under deformation as well as the possible change of topology of the crystalline phases under large deformation. The current effort focus on validating a first approach of the model on the available material database. Further effort may focus on the introduction of a new potential to describe more accurately the crystalline phase deformation.

\section{- Inelastic mechanisms}

To complement the constitutive description, the material viscous flow needs to be described in order to capture the kinetics of inelastic mechanisms observed during the deformation of the polymer along with the non-linear loading/unloading response of the material.

The velocity gradient of deformation, $\overline{\mathbf{D}}^{\mathbf{v}}$, can be expressed from $\phi_{\text {int }}$ in Eq. (17)

$$
\phi_{\text {int }}=\overline{\mathbf{M}}: \overline{\mathbf{D}}^{\mathbf{v}}-\frac{\partial \hat{\bar{\psi}}_{\mathrm{v}}}{\partial \overline{\bar{\eta}}} \dot{\bar{\eta}} \geq 0
$$

During testing, mechanical loading provides energy that is made available to the polymer chains networks to rearrange themselves. The idea for getting an expression of the material inelasticity was to assume that one part of the mechanical energy is stored elastically in the chain network and another part is released and used to reorganize/relax the polymer network. This reorganization will lead to dissipative mechanism such as heat. Therefore, we assumed 
that a part of the internal work is proportional to the inelastic energy by introducing the coefficient of Taylor-Quinney, $\beta$ :

$$
\frac{\partial \hat{\bar{\psi}}_{\mathrm{v}}}{\partial \bar{\eta}} \dot{\bar{\eta}}=(1-\beta) \overline{\mathbf{M}}: \overline{\mathbf{D}}^{\mathbf{v}}
$$

The coefficient of Taylor-Quinney, $\beta=\mathrm{f}\left(\mathrm{a}_{\mathrm{T}} \dot{\varepsilon}_{\mathrm{eq}}\right)$, was assumed to depend to the applied strain rate and temperature. Its expression will be formulated in Section 3.6.

Eq. (31) is given by

$$
\begin{aligned}
\phi_{\text {int }} & =\overline{\mathbf{M}}: \overline{\mathbf{D}}^{\mathbf{v}}-\frac{\partial \hat{\bar{\psi}}_{\mathrm{v}}}{\partial \bar{\eta}} \dot{\bar{\eta}} \\
& =\overline{\mathbf{M}}: \overline{\mathbf{D}}^{\mathbf{v}}-(1-\beta) \overline{\mathbf{M}}: \overline{\mathbf{D}}^{\mathbf{v}} \\
& =\beta \overline{\mathbf{M}}: \overline{\mathbf{D}}^{\mathbf{v}}
\end{aligned}
$$

The rate of inelastic deformation can be deduced from Eqs. (30) and (32) as

$$
\overline{\mathbf{D}}^{\mathbf{v}}=\frac{3}{2} \frac{1}{(1-\beta)} \frac{1}{\|\operatorname{dev}(\overline{\mathbf{M}})\|} \frac{\partial \hat{\bar{\psi}}_{\mathrm{v}}}{\partial \bar{\eta}} \dot{\bar{\eta}}\left(\frac{\operatorname{dev}(\overline{\mathbf{M}})}{\|\operatorname{dev}(\overline{\mathbf{M}})\|}\right)
$$

where the Mandel stress, $\overline{\mathbf{M}}$, and the norm $\|\bullet\|$ can be expressed, respectively, as

$$
\begin{aligned}
& \overline{\mathbf{M}}=\mathrm{J}^{\mathrm{e}} \mathbf{R}^{\mathrm{e}-1} \sigma \mathbf{R}^{\mathrm{e}-\mathbf{T}} \\
& \| \bullet=\sqrt{\frac{3}{2} \bullet: \bullet}
\end{aligned}
$$

The evolution equation for $\mathbf{F}^{\mathbf{v}}$ is then represented by

$$
\dot{\mathbf{F}}^{\mathbf{v}}=\overline{\mathbf{D}}^{\mathrm{v}} \mathbf{F}^{\mathrm{v}}, \overline{\mathbf{D}}^{\mathrm{v}}=\dot{\bar{\gamma}}^{\mathrm{v}} \overline{\mathbf{N}}^{\mathrm{v}}
$$

where $\overline{\mathbf{N}}^{\mathbf{v}}=\operatorname{dev}(\overline{\mathbf{M}}) /\|\operatorname{dev}(\overline{\mathbf{M}})\|$ is the direction of viscous flow, and $\dot{\bar{\gamma}}^{v}$ is a viscous shear strain rate. The term $\frac{\partial \hat{\bar{\psi}}_{\mathrm{v}}}{\partial \bar{\eta}}$ in Eq. (35) is defined in Appendix (B).

\section{- Heat equation}

The heat equation (written in the intermediate configuration) given by Eq. (23) can be simplified into: 


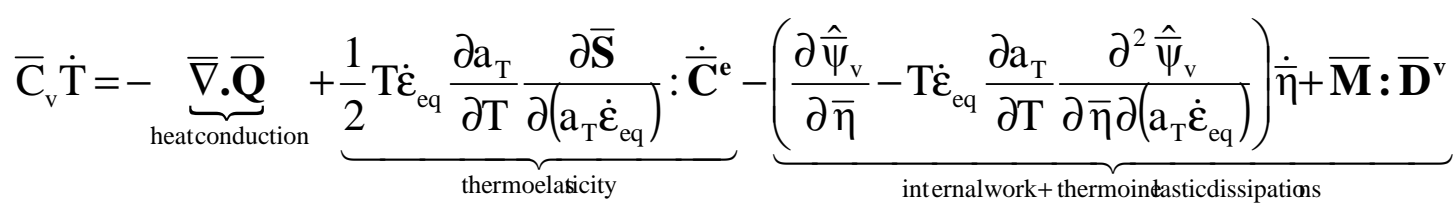

In this equation, different physical mechanisms were illustrated: the heat conduction, the thermo-elasticity, the internal work and the thermo-inelastic dissipations. The thermo-elastic processes are reversible and induce the cooling of the polymer, whereas dissipative processes are irreversible and cause the self-heating of the polymer.

Using Eq. (32) with Eq. (38), the previous equation can also be written as

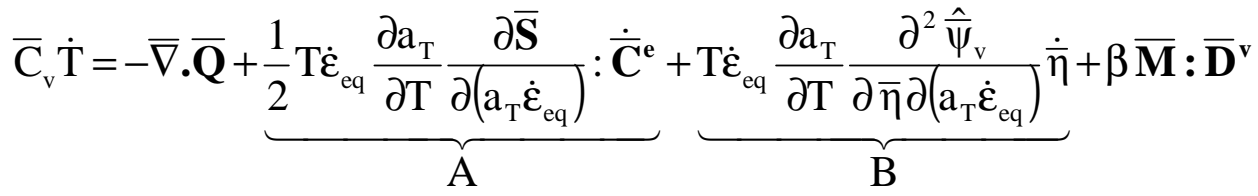

where

$$
\mathrm{A}=\frac{1}{2}\left(\mathrm{w}_{\mathrm{C}}^{*}+\mathrm{w}_{\mathrm{S}}^{*}\right) \overline{\mathbf{S}}: \dot{\mathbf{C}}^{\mathbf{e}}, \mathrm{B}=(1-\beta)\left(\mathrm{w}_{\mathrm{C}}^{*}+\mathrm{w}_{\mathrm{s}}^{*}\right) \overline{\mathbf{M}}: \overline{\mathbf{D}}^{\mathrm{v}}
$$

with

$$
\mathrm{w}_{\mathrm{C}}^{*}=\frac{\mathrm{T}}{\mathrm{N}_{\mathrm{C}}^{*}} \dot{\varepsilon}_{\mathrm{eq}} \frac{\partial \mathrm{a}_{\mathrm{T}}}{\partial \mathrm{T}} \frac{\partial \mathrm{N}_{\mathrm{C}}^{*}}{\partial\left(\mathrm{a}_{\mathrm{T}} \dot{\varepsilon}_{\mathrm{eq}}\right)}, \mathrm{w}_{\mathrm{s}}^{*}=\frac{\mathrm{T}}{\mathrm{N}_{\mathrm{s}}^{*}} \dot{\varepsilon}_{\mathrm{eq}} \frac{\partial \mathrm{a}_{\mathrm{T}}}{\partial \mathrm{T}} \frac{\partial \mathrm{N}_{\mathrm{S}}^{*}}{\partial\left(\mathrm{a}_{\mathrm{T}} \dot{\varepsilon}_{\mathrm{eq}}\right)}
$$

The terms $\frac{\partial \mathrm{a}_{\mathrm{T}}}{\partial \theta}, \frac{\partial \mathrm{N}_{\mathrm{C}}^{*}}{\partial\left(\mathrm{a}_{\mathrm{T}} \dot{\varepsilon}_{\mathrm{eq}}\right)}, \frac{\partial \mathrm{N}_{\mathrm{s}}^{*}}{\partial\left(\mathrm{a}_{\mathrm{T}} \dot{\varepsilon}_{\mathrm{eq}}\right)}, \frac{\partial \overline{\mathbf{S}}}{\partial\left(\mathrm{a}_{\mathrm{T}} \dot{\varepsilon}_{\mathrm{eq}}\right)}, \frac{\partial^{2} \hat{\bar{\psi}}_{\mathrm{v}}}{\partial \bar{\eta} \partial\left(\mathrm{a}_{\mathrm{T}} \dot{\varepsilon}_{\mathrm{eq}}\right)}, \frac{\partial \hat{\bar{\psi}}_{\mathrm{v}}}{\partial \bar{\eta}}, \mathrm{T} \dot{\varepsilon}_{\mathrm{eq}} \frac{\partial \mathrm{a}_{\mathrm{T}}}{\partial \mathrm{T}} \frac{\partial \overline{\mathbf{S}}}{\partial\left(\mathrm{a}_{\mathrm{T}} \dot{\varepsilon}_{\mathrm{eq}}\right)}: \dot{\overline{\mathbf{C}}}^{\mathrm{e}}$, and $\mathrm{T} \dot{\varepsilon}_{\mathrm{eq}} \frac{\partial \mathrm{a}_{\mathrm{T}}}{\partial \mathrm{T}} \frac{\partial^{2} \hat{\bar{\psi}}_{\mathrm{v}}}{\partial \bar{\eta} \partial\left(\mathrm{a}_{\mathrm{T}} \dot{\varepsilon}_{\mathrm{eq}}\right)} \dot{\bar{\eta}}$ are expressed in details in Appendix (B).

Finally, the heat equation can be expressed as

$$
\overline{\mathrm{C}}_{\mathrm{v}} \dot{\mathrm{T}}=-\underbrace{\bar{\nabla} \cdot \overline{\mathbf{Q}}}_{\text {heat conduction }}+\underbrace{\frac{1}{2}\left(\mathrm{w}_{\mathrm{C}}^{*}+\mathrm{w}_{\mathrm{S}}^{*}\right) \overline{\mathbf{S}}: \dot{\overline{\mathbf{C}}}^{\mathbf{e}}}_{\text {thermoelas ticity }}+\underbrace{\left(\beta+(1-\beta)\left(\mathrm{w}_{\mathrm{C}}^{*}+\mathrm{w}_{\mathrm{S}}^{*}\right)\right) \overline{\mathbf{M}}: \overline{\mathbf{D}}^{\mathbf{v}}}_{\text {int ernal work + thermoine lastic dissipation }}
$$

\subsection{Thermomechanical coupling}

The heat equation is applied to calculate the temperature from a computed stress. As a first step, the model was implemented in MATLAB and calculations were made for the specimen 
thickness (1D) as shown in Fig.14. Only heat conduction expression and surface heat convection equation were considered. The heat equation can be rewritten using Eq. (14) as

$$
\rho C_{\text {th }} \dot{T}=\lambda \frac{\partial^{2} T}{\partial x^{2}}+\left(w_{C}^{*}+w_{S}^{*}\right) \tau: d^{e}+\left(\beta+(1-\beta)\left(w_{C}^{*}+w_{S}^{*}\right)\right) \bar{M}: \bar{D}^{v}
$$

where $\lambda$ is the heat conductivity (equal to 0.3 in the case of PA66). The surface heat convection equation is considered as a boundary condition for the thermal resolution:

$$
-\mathrm{k} \frac{\mathrm{dT}}{\mathrm{dx}}=\mathrm{h}\left(\mathrm{T}-\mathrm{T}_{\infty}\right) \quad \text { Neumann condition }
$$

where $\mathrm{h}$ is the thermal convection coefficient (classically equal to 10 for a vertical surface with natural air flow at temperatures close to room temperature), and $\mathrm{T}_{\infty}$ is the applied temperature.
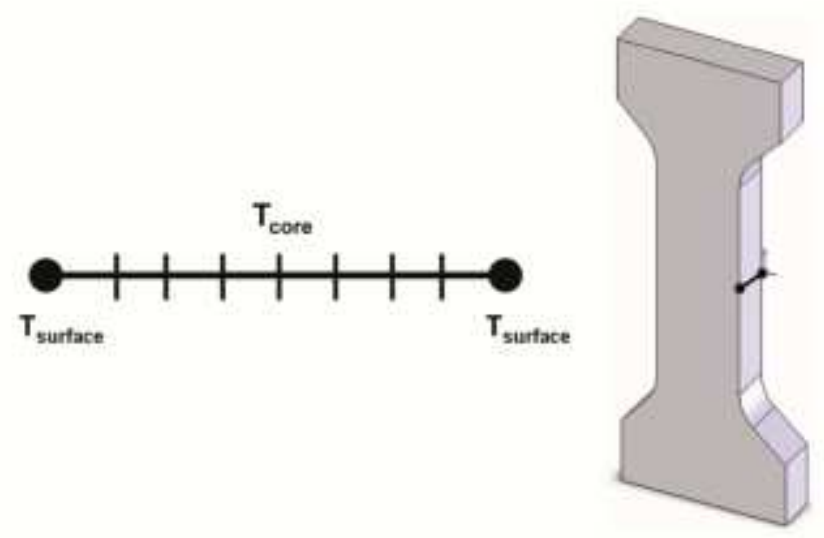

Fig.14. 1D calculation of the temperature field in the sample thickness

\subsection{Tensile and shear correction coefficient}

Polymeric materials exhibit a strong dependence to the stress state. A study was initially performed to characterize which model parameter will be the most influent in capturing the material stress state dependence. We observed that the model was able to fit the tensile and shear tests by mainly modifying the parameter $z_{0 p}^{*}$. Note that $z_{0 p}^{*}$ controls the kinetic of 
disentanglement. Such kinetic should be different under tension and shear loading. Therefore to account for the stress state dependence, we assumed the following form for $z_{0 p}^{*}$ :

$$
z_{0 p}^{*}=a_{T} * \sqrt{\frac{2}{3} \mathbf{d}: \mathbf{z}_{\mathbf{p}}: \mathbf{d}}
$$

with

$$
\stackrel{\mathbf{z}_{\mathbf{p}}}{=}=\left[\begin{array}{cccccc}
\frac{2}{3} z_{p 0} & -\frac{1}{3} z_{p 0} & -\frac{1}{3} z_{p 0} & 0 & 0 & 0 \\
-\frac{1}{3} z_{p 0} & \frac{2}{3} z_{p 0} & -\frac{1}{3} z_{p 0} & 0 & 0 & 0 \\
-\frac{1}{3} z_{p 0} & -\frac{1}{3} z_{p 0} & \frac{2}{3} z_{p 0} & 0 & 0 & 0 \\
0 & 0 & 0 & \frac{1}{2} z_{p 0} \times \chi & 0 & 0 \\
0 & 0 & 0 & 0 & \frac{1}{2} z_{p 0} \times \chi & 0 \\
0 & 0 & 0 & 0 & 0 & \frac{1}{2} z_{p 0} \times \chi
\end{array}\right]
$$

where $\mathbf{d}$ is the velocity gradient, $\underline{\underline{z_{p}}}$ is a tensorial expression dependent of the parameter $z_{p 0}$ (fitted from tensile tests) and of $\chi$, a correction coefficient (fitted from shear tests),

\subsection{Model parameters}

The main parameters $\left\{\mathrm{N}_{\mathrm{c}}^{*}, \mathrm{~N}_{\mathrm{s}}^{*}, \beta, \mathrm{z}_{\mathrm{p} 0}^{*}, \mathrm{z}_{\mathrm{p} 1}, \alpha\right\}$ were summarized below:

- $\quad \mathrm{N}_{\mathrm{c}}^{*}$ : The density per unit volume of crosslinking or fixed nodes

- $\quad \mathrm{N}^{*}$ : The density per unit volume of entanglement points or sliding nodes

- $\alpha$ : The limit of chain extensibility

- $z_{p 0}, \mathrm{Z}_{\mathrm{pl}}$ : Evolution parameters of the sliding potential between the entanglement points

- $\beta$ : Taylor-Quinney coefficient

Moreover, six material parameters characteristic of the polyamide 6.6 were used: 
- The WLF law parameters $\mathrm{C}_{1}$ and $\mathrm{C}_{2}$

- $\eta_{0}=0.2343$ the theoretical value minimizing free energy of molecular system [16]

- $\rho_{0}$ : the material density

- $\mathrm{C}_{\mathrm{th}}$ : the heat capacity

- $\mathrm{h}$ : the thermal convection coefficient

To account for the equivalent strain rate notion, $\mathrm{a}_{\mathrm{T}} \dot{\varepsilon}_{\text {eq }}$ defined in Section 2.5 , some of these parameters needed to be refined. Thus, we have assumed that the parameters $\left(N_{c}^{*}, N_{s}^{*}, \beta\right)$ follows a sigmoid function. This choice was motivated by the range of investigated experimental strain rates and temperatures that crosses the alpha transition temperature of the material and leads to a wide variety of mechanical behavior. Thus, following the storage modulus evolution with the temperature observed in DMA (Fig. 8), a sigmoid function was used to capture the important variation of mechanical behavior that characterizes the polymer from its glassy to its rubbery state. Then we assumed the following expressions for $\left(\mathrm{N}_{c}^{*}, \mathrm{~N}_{\mathrm{s}}^{*}, \beta\right.$ ) :

$$
\begin{aligned}
& N_{c}^{*}=N_{c 0}^{*}+N_{c 1}^{*}\left(\frac{2}{1+\left(\tau a_{T} \dot{\varepsilon}_{e q}\right)^{-2 m}}\right) \\
& N_{s}^{*}=N_{s 0}^{*}+N_{s 1}^{*}\left(\frac{2}{1+\left(\tau a_{T} \dot{\varepsilon}_{e q}\right)^{-2 m}}\right)
\end{aligned}
$$

where $\left\{N_{c 0}^{*}, N_{c 1}^{*}, N_{s 0}^{*}, N_{s 1}^{*}, \tau, m\right\}$ are material parameters.

$$
\beta=\beta_{0}+\beta_{1}\left(\frac{2}{1+\left(\tau a_{T} \dot{\varepsilon}_{e q}\right)^{-2 m}}\right)
$$

where $\left\{\beta_{0}, \beta_{1}\right\}$ are material parameters. $z_{0 p}^{*}$ is defined in case of tension loading as 


$$
z_{0 p}^{*}\left(a_{T} \dot{\varepsilon}_{e q}\right)=z_{p 0} \cdot a_{T} \dot{\varepsilon}_{e q}
$$

where $z_{p 0}$ is a material parameter.

$$
\alpha\left(a_{T} \dot{\varepsilon}_{e q}\right)=\alpha
$$

where $\alpha$ is a material parameter. Finally a total of eleven parameters is needed for the model. The identification of the parameters with the equivalent strain rate can be found in Appendix C.

\section{Comparison model-experiments}

The model was implemented in MATLAB®. The implementation details can be found in Appendix D.

\subsection{Parameters identification on tensile and shear tests}

An identification procedure based on an inverse method was set up to calibrate the model parameters $\left\{N_{c 0}^{*}, N_{c 1}^{*}, N_{s 0}^{*}, N_{s 1}^{*}, \alpha, \tau, m, \beta_{0}, \beta_{1}, z_{p 0}, z_{p 1}, \chi\right\}$. Fig.15a displays the experimental testing conditions $\left(a_{T} \dot{\varepsilon}_{e q}, \mathrm{~T}\right)$ available in the PA66 experimental database (Section 2) in term of stress-strain master curves for tensile and shear loading conditions. Fig. 15b displays the three tensile and three shear conditions (corresponding to six equivalent strain rate $\mathrm{a}_{\mathrm{T}} \dot{\varepsilon}_{\mathrm{eq}}$ ) used to fit the parameters. 

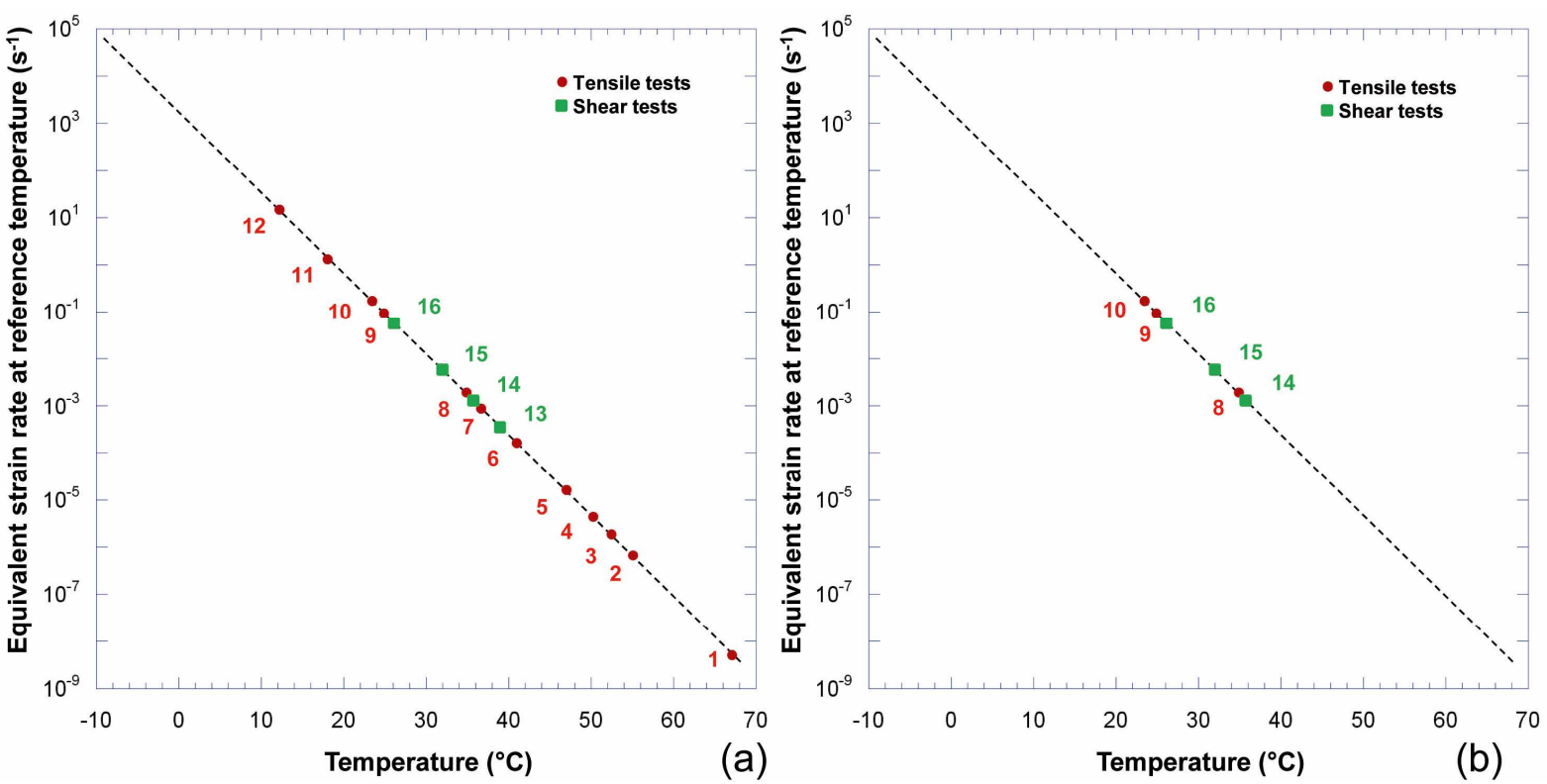

Fig.15. (a) The different testing conditions $\left(\mathrm{a}_{\mathrm{T}} \dot{\varepsilon}_{\mathrm{eq}}, \mathrm{T}\right)$ available in this study for the tensile and shear conditions.

(b) Presentation of the six conditions used to fit the model parameters.

A cost function (Eq. 51) was defined using a classical "mean squared" expression between the computed and the measured stress and temperature. The fitting algorithm was decomposed into two steps: i) first a kriging method (Roux and Bouchard (2013)) was used to build a response surface in order to select the best set of initial parameters; ii) then a simplex method was used to obtain the optimal parameters values. This last method consists to identify for a number of selected tests a set of parameters $\bar{x}$ minimizing the cost function $\mathrm{S}$ described below:

$$
S(\bar{x})=\frac{1}{n_{\text {mech }}}\left(\sum_{i=1}^{n_{\text {mech }}} \omega_{i}^{\text {mech }}\left[\sqrt{\frac{\sum_{j=1}^{p}\left(\sigma_{i, j}^{\text {num }}(\bar{x})-\sigma_{i, j}^{\exp }\right)^{2}}{\sum_{j=1}^{p}\left(\sigma_{i, j}^{\exp }\right)^{2}}}\right]+\frac{1}{n_{\text {therm }}}\left(\sum_{i=1}^{n_{\text {therm }}} \omega_{i}^{\text {therm }}\left[\sqrt{\frac{\sum_{j=1}^{p}\left(T_{i, j}^{n u m}(\bar{x})-T_{i, j}^{\exp }\right)^{2}}{\sum_{j=1}^{p}\left(T_{i, j}^{\exp }\right)^{2}}}\right]\right)\right.
$$

In Eq. 51, the same weight is chosen between thermal and mechanical information (i.e. $\left.\omega_{i}^{\text {mech }}=\omega_{i}^{\text {therm }}=1\right)$. After approximately 500 increments with the simplex method, the identification converged to an optimal set of parameters with an error of $1,26 \%$ with the experimental response. The identified parameters values are reported in Table 1. 
Table.1

Parameters identification for PA66 based on the testing conditions described in Fig. 18

\begin{tabular}{|c|c|c|}
\hline Parameters & Identified Values & Units \\
\hline $\mathrm{N}_{\mathrm{co}}$ & $3.579410^{7}$ & $\mathrm{~m}^{-3}$ \\
\hline $\mathrm{N}_{\mathrm{C} 1}$ & $5.097410^{8}$ & $\mathrm{~m}^{-3}$ \\
\hline$N_{S 0}$ & $1.827510^{7}$ & $\mathrm{~m}^{-3}$ \\
\hline$N_{S 1}$ & $2.797110^{7}$ & $\mathrm{~m}^{-3}$ \\
\hline$\beta_{0}$ & $7.53210^{-1}$ & - \\
\hline$\beta_{1}$ & $1.36810^{-1}$ & - \\
\hline $\mathrm{m}$ & $3.0410^{-2}$ & - \\
\hline$\tau$ & 1.4503 & s \\
\hline$z_{p 0}$ & $4.0889810^{1}$ & - \\
\hline $\mathrm{Z}_{\mathrm{p} 1}$ & 1.0 & - \\
\hline$\alpha$ & $5.310^{-3}$ & - \\
\hline $\mathrm{h}$ & $1.5768910^{1}$ & $\mathrm{~W} \cdot \mathrm{m}^{-2} \cdot \mathrm{K}^{-1}$ \\
\hline$\chi$ & $7.52210^{-1}$ & - \\
\hline
\end{tabular}



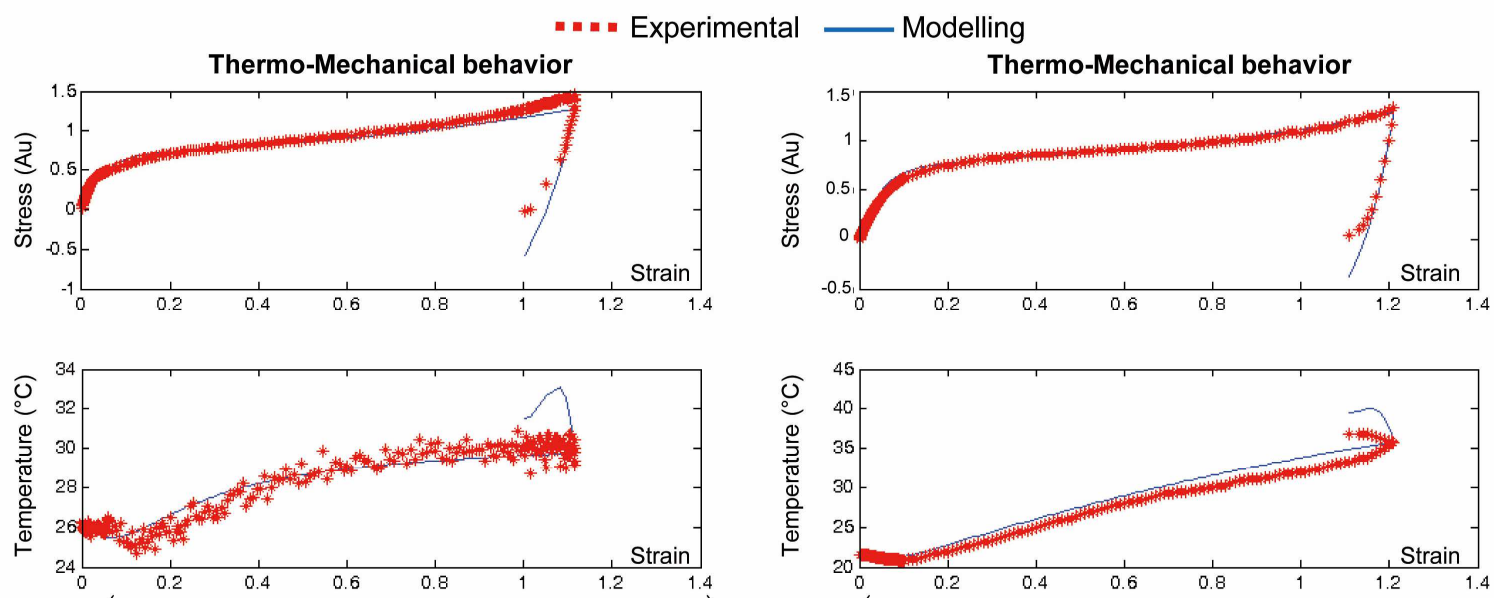

(8) $\left(\dot{\varepsilon}=2.410^{-3} s^{-1}, \mathrm{~T}=26^{\circ} \mathrm{C}, a_{T} \dot{\varepsilon}_{e q}=1.5710^{-3}\right)$
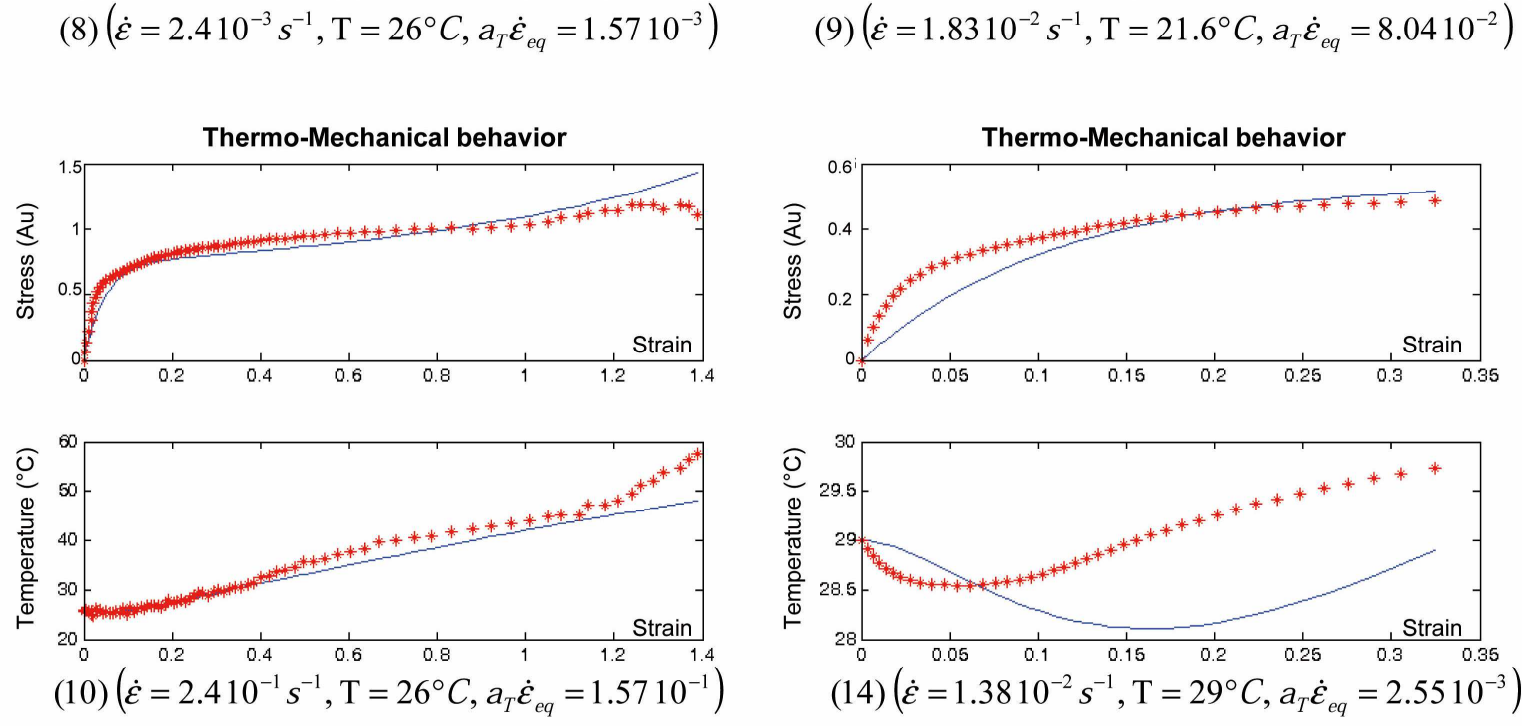

(10) $\left(\dot{\varepsilon}=2.410^{-1} s^{-1}, T=26^{\circ} C, a_{T} \dot{\varepsilon}_{e q}=1.5710^{-1}\right)$
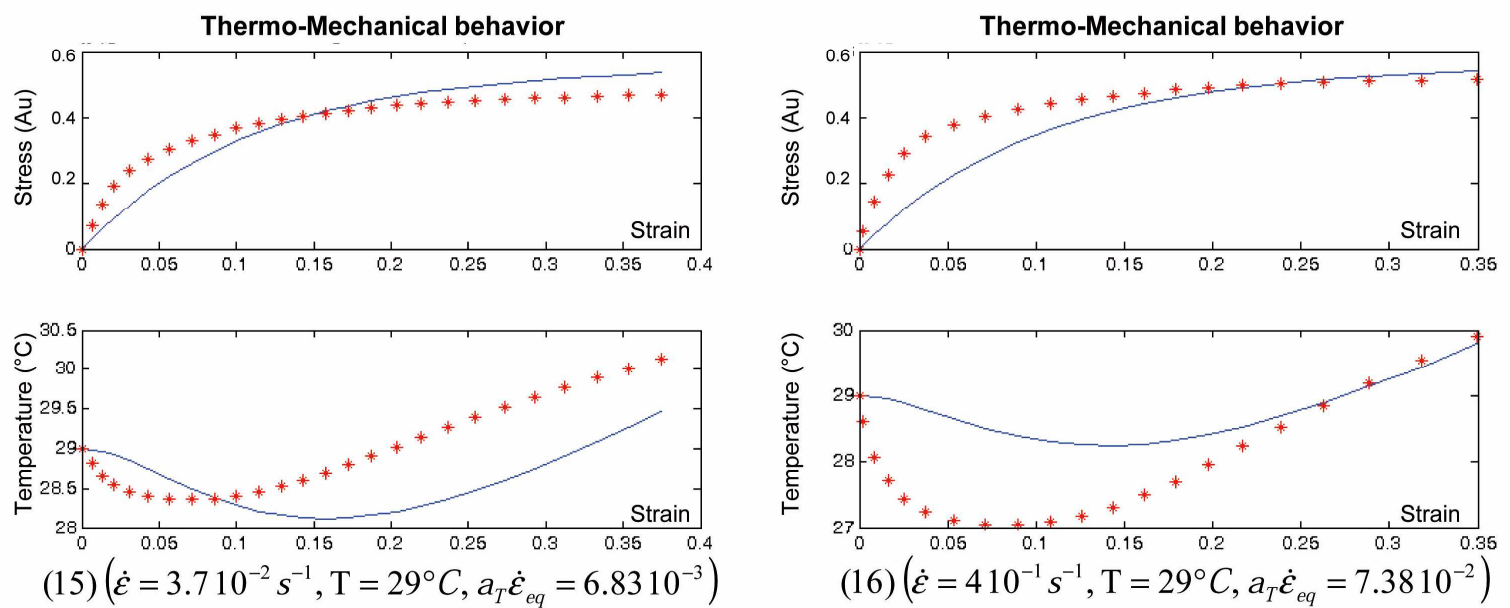

(15) $\left(\dot{\varepsilon}=3.710^{-2} \mathrm{~s}^{-1}, \mathrm{~T}=29^{\circ} \mathrm{C}, \mathrm{a}_{T} \dot{\varepsilon}_{\text {eq }}=6.8310^{-3}\right)$

Fig.16. Comparison model experiments for the six sets of conditions used to fit the model parameters for tensile conditions (8) (9) (10) and for shear conditions (14) (15) (16) as related in Fig. 18. 
Fig. 16 displays the comparison between the numerical and experimental results for the model parameters. Fig. 16 (8) to (10) depicts results for tensile loading while Fig. 16 (14) to (16) displays results for shear loading. The computations were performed using parameters reported in Table 1. In tension, the model response shows good agreement with the experimental testing. The model captures the viscoelastic/viscoplastic behavior of the material for different strain path (load-unload) as well as the material cooling/self-heating. Regarding shear loading, we can notice more discrepancy. The model seems to have more difficulties capturing the initial slope of the true stress-strain curve as well as capturing accurately the temperature evolution in the material. However the main trend in term of thermomechanical coupling is captured. Further investigation would need to be performed to improve the material stress state dependence of the model.

\subsection{Model validation}

Fig. 17 and Fig. 18 display the model prediction (with the set of parameters reported in Table 1) on the overall material database. We can notice that the model response is in good agreement with the different tensile tests performed at different strain rates and temperatures. The mechanical response of the material for loading/unloading path was accurately captured by the model as well as the self-cooling and self-heating of the material during loading. As noticed in the previous section, more discrepancy was observed for shear loading but again the trend was well reproduced. Such discrepancies could come for differences of boundary conditions assumed for the model and those observed experimentally.

However, we can notice that this model characterized by only twelve parameters $\left\{N_{c 0}^{*}, N_{c 1}^{*}, N_{s 0}^{*}, N_{s 1}^{*}, \alpha, \tau, m, \beta_{0}, \beta_{1}, z_{p 0}, z_{p 1}, \chi\right\}$ and written in term of equivalent strain rate was able to capture the mechanical behavior of PA6.6 over a wide range of strain rates (ranging 
from $10^{-4} \mathrm{~s}^{-1}$ to $2.4 \mathrm{~s}^{-1}$ ) and temperatures (ranging from $-5^{\circ} \mathrm{C}$ to $60^{\circ} \mathrm{C}$ ). An error of $4,12 \%$ was observed between experimental and numerical curves on the overall loading conditions.
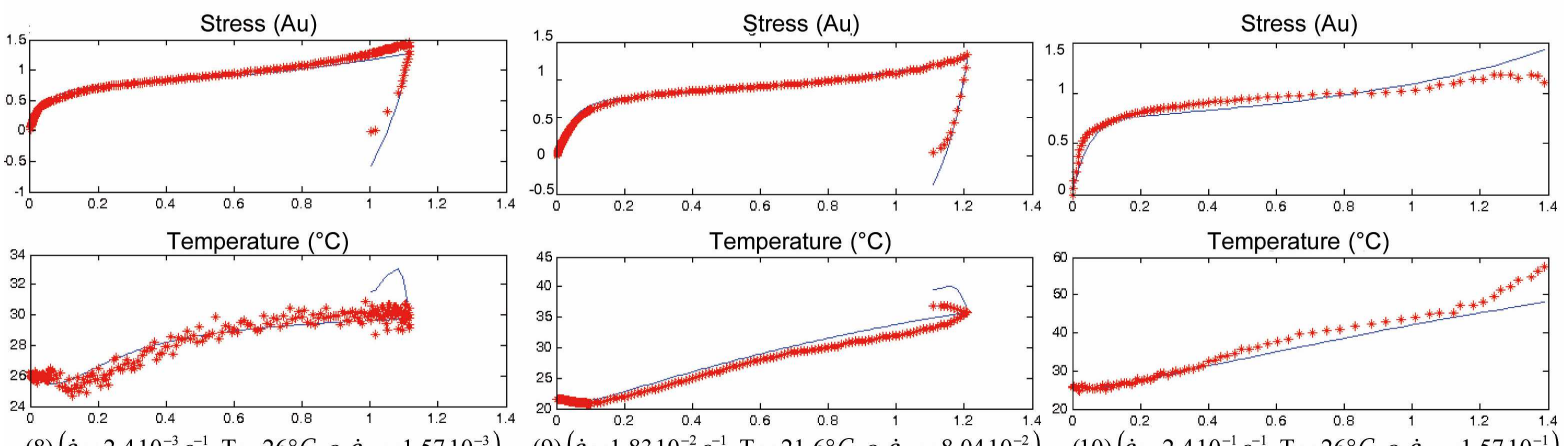

(8) $\left(\dot{\varepsilon}=2.410^{-3} \mathrm{~s}^{-1}, \mathrm{~T}=26^{\circ} \mathrm{C}, \mathrm{a}_{T} \dot{\varepsilon}_{\text {eq }}=1.5710^{-3}\right)$

(9) $\left(\dot{\varepsilon}=1.8310^{-2} \mathrm{~s}^{-1}, \mathrm{~T}=21.6^{\circ} \mathrm{C}, \mathrm{a}_{\mathrm{T}} \dot{\varepsilon}_{\text {eq }}=8.0410^{-2}\right)$
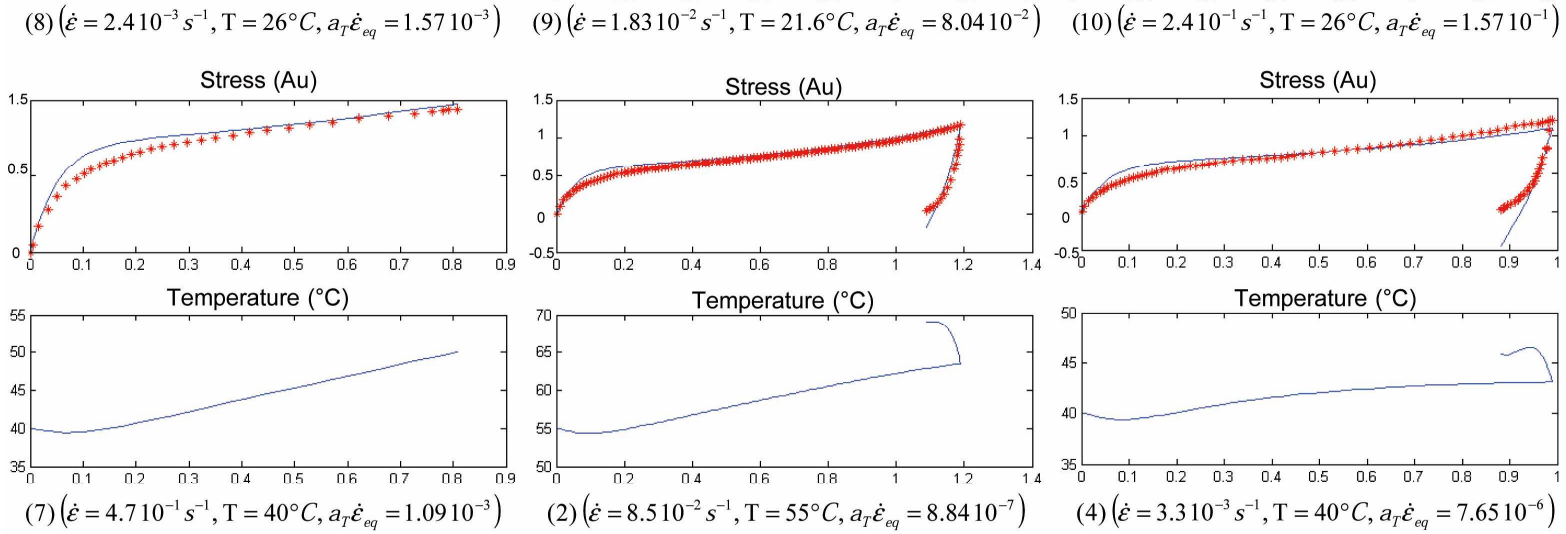

(4) $\left(\dot{\varepsilon}=3.310^{-3} \mathrm{~s}^{-1}, \mathrm{~T}=40^{\circ} \mathrm{C}, \mathrm{a}_{T} \dot{\varepsilon}_{\text {eq }}=7.6510^{-6}\right)$
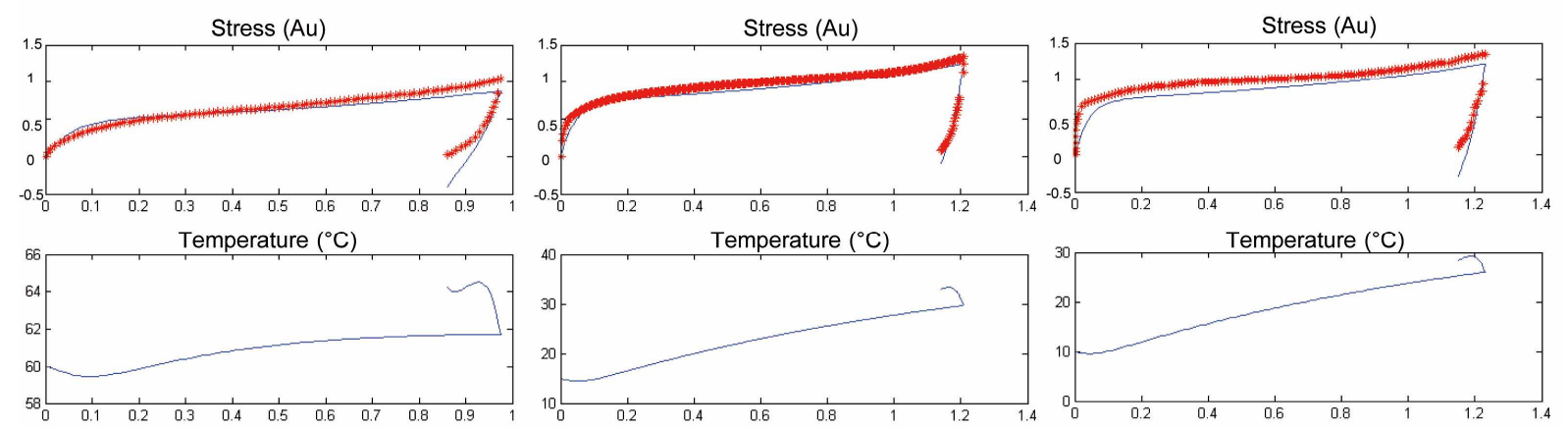

(1) $\left(\dot{\varepsilon}=3.110^{-3} s^{-1}, \mathrm{~T}=60^{\circ} \mathrm{C}, \mathrm{a}_{T} \dot{\varepsilon}_{\text {eq }}=6.0510^{-9}\right)$

(11) $\left(\dot{\varepsilon}=1.3610^{-2} s^{-1}, \mathrm{~T}=15^{\circ} \mathrm{C}, a_{T} \dot{\varepsilon}_{\text {eq }}=1.19\right)$

(12) $\left(\dot{\varepsilon}=1.310^{-2} s^{-1}, \mathrm{~T}=10^{\circ} \mathrm{C}, a_{T} \dot{\varepsilon}_{\text {eq }}=12.4\right)$
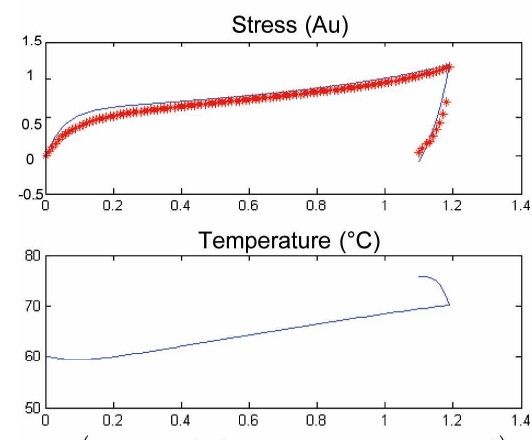

(3) $\left(\dot{\varepsilon}=7.710^{-1} s^{-1}, \mathrm{~T}=60^{\circ} \mathrm{C}, \mathrm{a}_{T} \dot{\varepsilon}_{\text {eq }}=1.510^{-6}\right)$
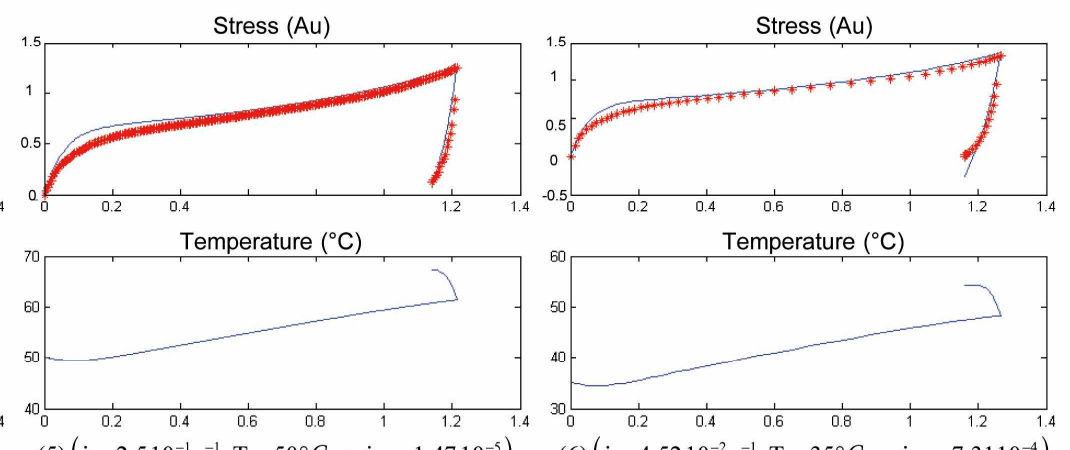

(5) $\left(\dot{\varepsilon}=2.510^{-1} s^{-1}, \mathrm{~T}=50^{\circ} \mathrm{C}, \mathrm{a}_{T} \dot{\varepsilon}_{\text {eq }}=1.4710^{-5}\right)$

(6) $\left(\dot{\varepsilon}=4.5210^{-2} s^{-1}, \mathrm{~T}=35^{\circ} \mathrm{C}, \mathrm{a}_{T} \dot{\varepsilon}_{\text {eq }}=7.3110^{-4}\right)$

Fig.17. Model validation for all experimental tensile conditions. 
Stress $(\mathrm{Au})$
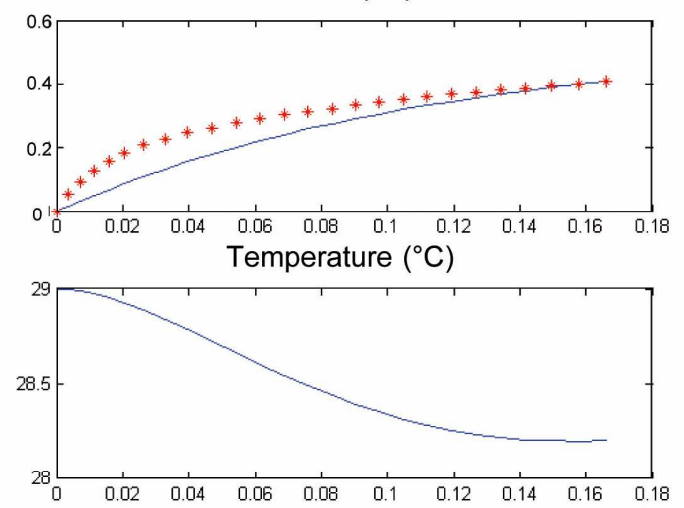

(13) $\left(\dot{\varepsilon}=3.6410^{-3} \mathrm{~s}^{-1}, \mathrm{~T}=29^{\circ} \mathrm{C}, \mathrm{a}_{T} \dot{\varepsilon}_{\text {eq }}=6.7210^{-4}\right)$
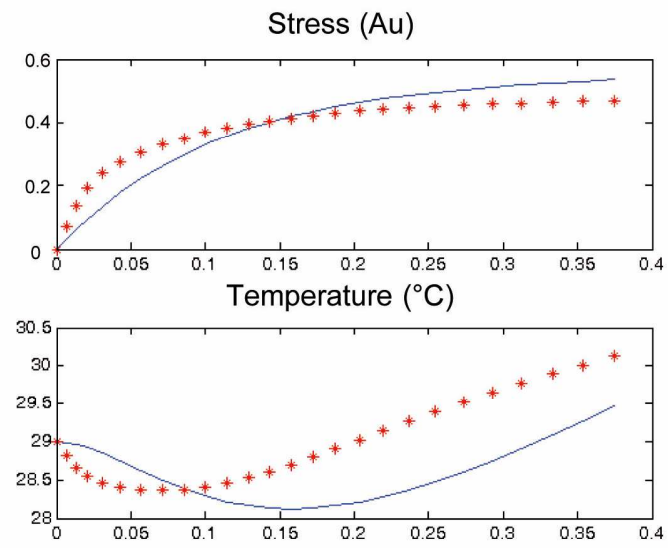

(15) $\left(\dot{\varepsilon}=3.710^{-2} s^{-1}, \mathrm{~T}=29^{\circ} \mathrm{C}, a_{T} \dot{\varepsilon}_{e q}=6.8310^{-3}\right)$
Stress $(\mathrm{Au})$
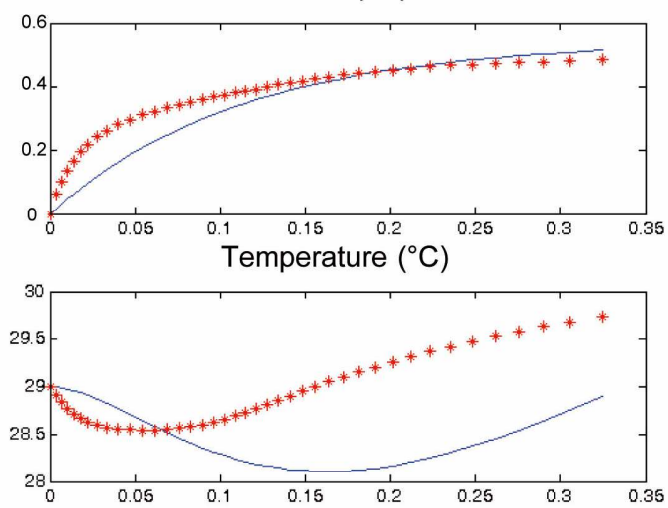

(14) $\left(\dot{\varepsilon}=1.3810^{-2} s^{-1}, \mathrm{~T}=29^{\circ} \mathrm{C}, \mathrm{a}_{T} \dot{\varepsilon}_{\text {eq }}=2.5510^{-3}\right)$

Stress $(\mathrm{Au})$
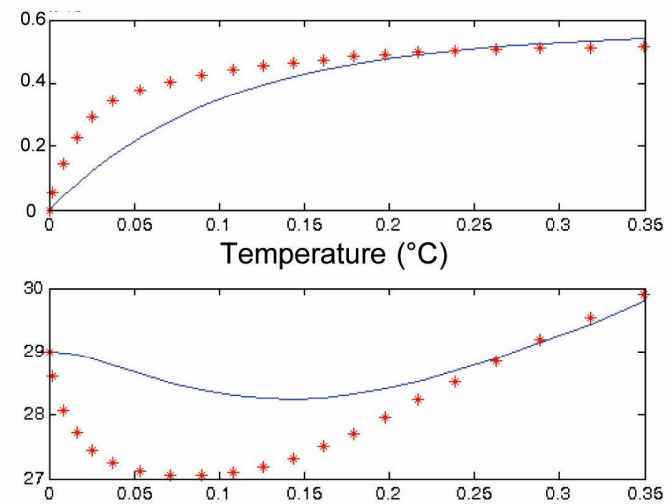

(16) $\left(\dot{\varepsilon}=410^{-1} s^{-1}, \mathrm{~T}=29^{\circ} \mathrm{C}, a_{T} \dot{\varepsilon}_{e q}=7.3810^{-2}\right)$

Fig.18. Model validation for all experimental shear conditions.

\section{Conclusions}

A thermomechanical constitutive model, based on the approach proposed by (Billon, 2012) for amorphous rubbery polymers was extended to three-dimensional constitutive equations and framed in a thermodynamic framework. The model was applied to a semicrystalline polyamide polymer, PA66. The mechanical behavior of the PA66 was investigated through tensile and shear loading testing performed at different strain rates and temperatures. The mechanical tests were coupled with synchronized digital image correlation and infrared measurements device with the purpose of capturing the time, temperature, and stress state dependence, as well as the complex thermomechanical coupling exhibited by the polymer under large deformation. A notion of equivalent strain rate based on the time-temperature 
superposition was also used to decrease the number of experimental testing needed for the material characterization and the model calibration. The model based on the Edward Vilgis theory (1986) and accounting for chains network reorganization under external loading through the introduction of an evolution equation for the internal state variable, $\bar{\eta}$, was validated on the experimental mechanical and temperature measurements under tension and shear conditions. Good agreement was observed between model response and experimental results. Further investigations are needed to improve the stress state dependence of the model as well as its implementation in FE code to fully predict the thermomechanical behavior of the material.

\section{Acknowledgements}

This material was based upon work supported by the European project EUREKA 3785, DAMOFIP in partnership with Rhodia, X-Stream and Université de Louvain (UCL).

\section{Appendix A}

The terms $\frac{\partial \breve{\bar{\psi}}_{\mathrm{e}}}{\partial \overline{\mathrm{I}}_{1}^{\mathrm{e}}}$ and $\frac{\partial \overline{\bar{\psi}}_{\mathrm{e}}}{\partial \overline{\mathrm{I}}_{2}^{\mathrm{e}}}$ are defined below:

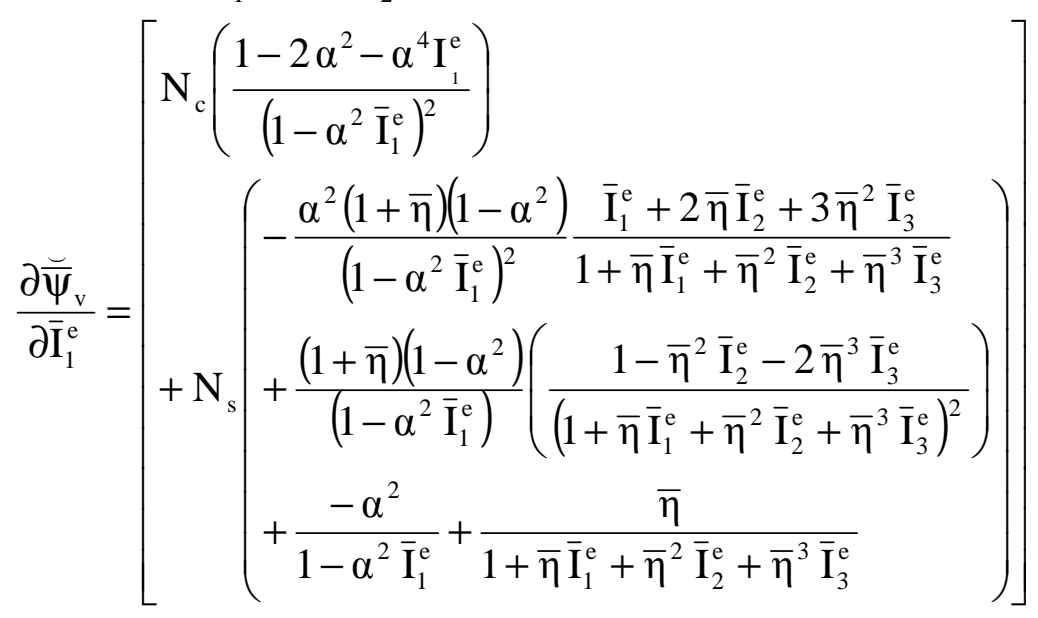




$$
\frac{\partial \overline{\bar{\Psi}}_{v}}{\partial \overline{\mathbf{I}}_{2}^{\mathrm{e}}}=\mathrm{N}_{\mathrm{s}}\left(\begin{array}{l}
\frac{(1+\bar{\eta})\left(1-\alpha^{2}\right)}{\left(1-\alpha^{2} \overline{\mathrm{I}}_{1}^{\mathrm{e}}\right)}\left(\frac{2 \bar{\eta}\left(1+\bar{\eta} \overline{\mathrm{I}}_{1}^{\mathrm{e}}+\bar{\eta}^{2} \overline{\mathrm{I}}_{2}^{\mathrm{e}}+\bar{\eta}^{3} \overline{\mathrm{I}}_{3}^{\mathrm{e}}\right)-\bar{\eta}^{2}}{\left(1+\bar{\eta} \overline{\mathrm{I}}_{1}^{\mathrm{e}}+\bar{\eta}^{2} \overline{\mathrm{I}}_{2}^{\mathrm{e}}+\bar{\eta}^{3} \overline{\mathrm{I}}_{3}^{\mathrm{e}}\right)^{2}}\right) \\
+\frac{\bar{\eta}^{2}}{\left(1+\bar{\eta} \overline{\mathbf{I}}_{1}^{\mathrm{e}}+\bar{\eta}^{2} \overline{\mathrm{I}}_{2}^{\mathrm{e}}+\bar{\eta}^{3} \overline{\mathrm{I}}_{3}^{\mathrm{e}}\right)}
\end{array}\right)
$$




\section{Appendix B}

The terms $\frac{\partial \mathrm{a}_{\mathrm{T}}}{\partial \theta}, \frac{\partial \overline{\mathbf{S}}}{\partial\left(\mathrm{a}_{\mathrm{T}} \dot{\varepsilon}_{\text {eq }}\right)}, \frac{\partial \mathrm{N}_{\mathrm{C}}^{*}}{\partial\left(\mathrm{a}_{\mathrm{T}} \dot{\varepsilon}_{\text {eq }}\right)}, \frac{\partial \mathrm{N}_{\mathrm{s}}^{*}}{\partial\left(\mathrm{a}_{\mathrm{T}} \dot{\varepsilon}_{\text {eq }}\right)}, \frac{\partial^{2} \hat{\bar{\psi}}_{\mathrm{v}}}{\partial \bar{\eta} \partial\left(\mathrm{a}_{\mathrm{T}} \dot{\varepsilon}_{\text {eq }}\right)}, \frac{\partial \hat{\bar{\psi}}_{\mathrm{v}}}{\partial \bar{\eta}}, \mathrm{T} \dot{\varepsilon}_{\text {eq }} \frac{\partial \mathrm{a}_{\mathrm{T}}}{\partial \mathrm{T}} \frac{\partial \overline{\mathbf{S}}^{2}\left(\mathrm{a}_{\mathrm{T}} \dot{\varepsilon}_{\text {eq }}\right)}{\partial^{2}} \dot{\overline{\mathbf{C}}}^{\mathrm{e}}$, and $\mathrm{T} \dot{\varepsilon}_{\text {eq }} \frac{\partial \mathrm{a}_{\mathrm{T}}}{\partial \mathrm{T}} \frac{\partial^{2} \hat{\bar{\psi}}_{\mathrm{v}}}{\partial \bar{\eta} \partial\left(\mathrm{a}_{\mathrm{T}} \dot{\varepsilon}_{\text {eq }}\right)} \dot{\bar{\eta}}$ are expressed below:

$$
\begin{gathered}
\frac{\partial \mathrm{a}_{\mathrm{T}}}{\partial \mathrm{T}}=-\frac{\mathrm{C}_{1} \mathrm{C}_{2}}{\left(\mathrm{C}_{2}+\mathrm{T}-\mathrm{T}_{\mathrm{ref}}\right)^{2}} \mathrm{a}_{\mathrm{T}} \\
\frac{\partial \overline{\mathbf{S}}}{\partial\left(\mathrm{a}_{\mathrm{T}} \dot{\varepsilon}_{\text {eq }}\right)}=\frac{\partial \mathrm{N}_{\mathrm{c}}^{*}}{\partial\left(\mathrm{a}_{\mathrm{T}} \dot{\varepsilon}_{\text {eq }}\right)} \frac{\partial \overline{\mathbf{S}}}{\partial \mathrm{N}_{\mathrm{c}}^{*}}+\frac{\partial \mathrm{N}_{\mathrm{s}}^{*}}{\partial\left(\mathrm{a}_{\mathrm{T}} \dot{\varepsilon}_{\text {eq }}\right)} \frac{\partial \overline{\mathbf{S}}}{\partial \mathrm{N}_{\mathrm{s}}^{*}}
\end{gathered}
$$

with

$$
\begin{aligned}
& \frac{\partial \mathrm{N}_{\mathrm{c}}^{*}}{\partial\left(\mathrm{a}_{\mathrm{T}} \dot{\varepsilon}_{\mathrm{eq}}\right)}=\frac{4 \mathrm{~N}_{\mathrm{c}}^{*} \mathrm{~m} \tau\left(\tau_{\mathrm{T}} \dot{\varepsilon}_{\mathrm{eq}}\right)^{-(2 \mathrm{~m}+1)}}{\left(1+\left(\tau \mathrm{a}_{\mathrm{T}} \dot{\varepsilon}_{\mathrm{eq}}\right)^{-2 \mathrm{~m}}\right)^{2}} ; \frac{\partial \mathrm{N}_{\mathrm{s}}^{*}}{\partial\left(\mathrm{a}_{\mathrm{T}} \dot{\varepsilon}_{\mathrm{eq}}\right)}=\frac{4 \mathrm{~N}_{\mathrm{s}}^{*} \mathrm{~m} \tau\left(\tau \mathrm{a}_{\mathrm{T}} \dot{\varepsilon}_{\mathrm{eq}}\right)^{-(2 \mathrm{~m}+1)}}{\left(1+\left(\tau \mathrm{a}_{\mathrm{T}} \dot{\varepsilon}_{\mathrm{eq}}\right)^{-2 \mathrm{~m}}\right)^{2}} \\
& \frac{\partial \overline{\mathbf{S}}}{\partial \mathbf{N}_{\mathrm{c}}^{*}}=\frac{\overline{\mathbf{S}}}{\mathbf{N}_{\mathrm{c}}^{*}} ; \frac{\partial \overline{\mathbf{S}}}{\partial \mathbf{N}_{\mathrm{s}}^{*}}=\frac{\overline{\mathbf{S}}}{\mathbf{N}_{\mathrm{s}}^{*}} \\
& \frac{\partial^{2} \hat{\bar{\psi}}_{\mathrm{v}}}{\partial \bar{\eta} \partial\left(\mathrm{a}_{\mathrm{T}} \dot{\varepsilon}_{\text {eq }}\right)}=\frac{\partial^{2} \hat{\bar{\Psi}}_{\mathrm{v}}}{\partial \bar{\eta} \partial \mathrm{N}_{\mathrm{c}}^{*}} \frac{\partial \mathrm{N}_{\mathrm{c}}^{*}}{\partial\left(\mathrm{a}_{\mathrm{T}} \dot{\varepsilon}_{\text {eq }}\right)}+\frac{\partial^{2} \hat{\bar{\Psi}}_{\mathrm{v}}}{\partial \bar{\eta} \partial \mathrm{N}_{\mathrm{s}}^{*}} \frac{\partial \mathrm{N}_{\mathrm{s}}^{*}}{\partial\left(\mathrm{a}_{\mathrm{T}} \dot{\varepsilon}_{\text {eq }}\right)} \\
& =\frac{1}{\mathrm{~N}_{\mathrm{c}}^{*}} \frac{\partial \hat{\bar{\psi}}_{\mathrm{v}}}{\partial \bar{\eta}} \frac{\partial \mathrm{N}_{\mathrm{c}}^{*}}{\partial\left(\mathrm{a}_{\mathrm{T}} \dot{\varepsilon}_{\mathrm{eq}}\right)}+\frac{1}{\mathrm{~N}_{\mathrm{s}}^{*}} \frac{\partial \hat{\bar{\psi}}_{\mathrm{v}}}{\partial \bar{\eta}} \frac{\partial \mathrm{N}_{\mathrm{s}}^{*}}{\partial\left(\mathrm{a}_{\mathrm{T}} \dot{\varepsilon}_{\mathrm{eq}}\right)} \\
& \frac{\partial \hat{\bar{\psi}}_{\mathrm{v}}}{\partial \bar{\eta}}=\mathrm{N}_{\mathrm{s}}^{*}\left[\begin{array}{l}
\frac{\left(1-\alpha^{2}\right)\left(\left(\overline{\mathrm{I}}_{1}^{\mathrm{e}}+2 \bar{\eta} \overline{\mathrm{I}}_{2}^{\mathrm{e}}+3 \bar{\eta}^{2} \overline{\mathrm{I}}_{3}^{\mathrm{e}}\right)+2(1+\bar{\eta})\left(\overline{\mathrm{I}}_{2}^{\mathrm{e}}+3 \bar{\eta} \overline{\mathrm{I}}_{3}^{\mathrm{e}}\right)\right)}{\left(1-\alpha^{2} \overline{\mathrm{I}}_{1}^{\mathrm{e}}\right)\left(1+\bar{\eta} \overline{\mathrm{I}}_{1}^{\mathrm{e}}+\bar{\eta}^{2} \overline{\mathrm{I}}_{2}^{\mathrm{e}}+\bar{\eta}^{3} \overline{\mathrm{I}}_{3}^{\mathrm{e}}\right)} \\
-\frac{\left(1-\alpha^{2}\right)(1+\bar{\eta})\left(\overline{\mathrm{I}}_{1}^{\mathrm{e}}+2 \bar{\eta} \overline{\mathrm{I}}_{2}^{\mathrm{e}}+3 \bar{\eta}^{2} \overline{\mathrm{I}}_{3}^{\mathrm{e}}\right)^{2}}{\left(1-\alpha^{2}\right)\left(1+\bar{\eta} \overline{\mathrm{I}}_{1}^{\mathrm{e}}+\bar{\eta}^{2} \overline{\mathrm{I}}_{2}^{\mathrm{e}}+\bar{\eta}^{3} \overline{\mathrm{I}}_{3}^{\mathrm{e}}\right)} \\
+\frac{\left(\overline{\mathrm{I}}_{1}^{\mathrm{e}}+2 \bar{\eta} \overline{\mathrm{I}}_{2}^{\mathrm{e}}+3 \bar{\eta}^{2} \overline{\mathrm{I}}_{3}^{\mathrm{e}}\right)}{\left(1+\bar{\eta} \overline{\mathrm{I}}_{1}^{\mathrm{e}}+\bar{\eta}^{2} \overline{\mathrm{I}}_{2}^{\mathrm{e}}+\bar{\eta}^{3} \overline{\mathrm{I}}_{3}^{\mathrm{e}}\right)}
\end{array}\right]
\end{aligned}
$$




$$
\begin{aligned}
\mathrm{T} \dot{\varepsilon}_{\mathrm{eq}} \frac{\partial \mathrm{a}_{\mathrm{T}}}{\partial \mathrm{T}} \frac{\partial \overline{\mathbf{S}}}{\partial\left(\mathrm{a}_{\mathrm{T}} \dot{\varepsilon}_{\mathrm{eq}}\right)}: \dot{\overline{\mathbf{C}}}^{\mathrm{e}}= & \mathrm{T} \dot{\varepsilon}_{\mathrm{eq}} \frac{\partial \mathrm{a}_{\mathrm{T}}}{\partial \mathrm{T}}\left(\frac{\partial \mathrm{N}_{\mathrm{C}}^{*}}{\partial\left(\mathrm{a}_{\mathrm{T}} \dot{\varepsilon}_{\mathrm{eq}}\right)} \frac{\partial \overline{\mathbf{S}}}{\partial \mathrm{N}_{\mathrm{C}}^{*}}+\frac{\partial \mathrm{N}_{\mathrm{S}}^{*}}{\partial\left(\mathrm{a}_{\mathrm{T}} \dot{\varepsilon}_{\mathrm{eq}}\right)} \frac{\partial \overline{\mathbf{S}}}{\partial \mathrm{N}_{\mathrm{S}}^{*}}\right): \dot{\mathbf{C}}^{\mathrm{e}} \\
& =\left(\frac{\mathrm{T}}{\mathrm{N}_{\mathrm{C}}^{*}} \dot{\varepsilon}_{\mathrm{eq}} \frac{\partial \mathrm{a}_{\mathrm{T}}}{\partial \mathrm{T}} \frac{\partial \mathrm{N}_{\mathrm{C}}^{*}}{\partial\left(\mathrm{a}_{\mathrm{T}} \dot{\varepsilon}_{\mathrm{eq}}\right)}+\frac{\mathrm{T}}{\mathrm{N}_{\mathrm{S}}^{*}} \dot{\varepsilon}_{\mathrm{eq}} \frac{\partial \mathrm{a}_{\mathrm{T}}}{\partial \mathrm{T}} \frac{\partial \mathrm{N}_{\mathrm{S}}^{*}}{\partial\left(\mathrm{a}_{\mathrm{T}} \dot{\varepsilon}_{\mathrm{eq}}\right)}\right) \overline{\mathbf{S}}: \dot{\overline{\mathbf{C}}}^{\mathrm{e}} \\
& =\left(\mathrm{w}_{\mathrm{C}}^{*}+\mathrm{w}_{\mathrm{S}}^{*}\right) \overline{\mathbf{S}}: \dot{\mathbf{C}}^{\mathrm{e}}
\end{aligned}
$$

$$
\begin{aligned}
& \mathrm{T} \dot{\varepsilon}_{\mathrm{eq}} \frac{\partial \mathrm{a}_{\mathrm{T}}}{\partial \mathrm{T}} \frac{\partial^{2} \hat{\bar{\psi}}_{\mathrm{v}}}{\partial \bar{\eta} \partial\left(\mathrm{a}_{\mathrm{T}} \dot{\varepsilon}_{\mathrm{eq}}\right)} \dot{\bar{\eta}}=\mathrm{T} \dot{\varepsilon}_{\mathrm{eq}} \frac{\partial \mathrm{a}_{\mathrm{T}}}{\partial \mathrm{T}}\left(\frac{1}{\mathrm{~N}_{\mathrm{C}}^{*}} \frac{\partial \mathrm{N}_{\mathrm{C}}^{*}}{\partial\left(\mathrm{a}_{\mathrm{T}} \dot{\varepsilon}_{\mathrm{eq}}\right)} \frac{\partial \hat{\bar{\psi}}_{\mathrm{v}}}{\partial \bar{\eta}}+\frac{1}{\mathrm{~N}_{\mathrm{S}}^{*}} \frac{\partial \mathrm{N}_{\mathrm{S}}^{*}}{\partial\left(\mathrm{a}_{\mathrm{T}} \dot{\varepsilon}_{\mathrm{eq}}\right)} \frac{\partial \hat{\bar{\psi}}_{\mathrm{v}}}{\partial \bar{\eta}}\right) \dot{\bar{\eta}} \\
& =\left(\frac{\mathrm{T}}{\mathrm{N}_{\mathrm{C}}^{*}} \dot{\varepsilon}_{\mathrm{eq}} \frac{\partial \mathrm{a}_{\mathrm{T}}}{\partial \mathrm{T}} \frac{\partial \mathrm{N}_{\mathrm{C}}^{*}}{\partial\left(\mathrm{a}_{\mathrm{T}} \dot{\varepsilon}_{\mathrm{eq}}\right)}+\frac{\mathrm{T}}{\mathrm{N}_{\mathrm{S}}^{*}} \dot{\varepsilon}_{\mathrm{eq}} \frac{\partial \mathrm{a}_{\mathrm{T}}}{\partial \mathrm{T}} \frac{\partial \mathrm{N}_{\mathrm{S}}^{*}}{\partial\left(\mathrm{a}_{\mathrm{T}} \dot{\varepsilon}_{\mathrm{eq}}\right)}\right) \frac{\partial \hat{\bar{\psi}}_{\mathrm{v}}}{\partial \bar{\eta}} \dot{\bar{\eta}} \\
& =\left(w_{C}^{*}+w_{S}^{*}\right) \frac{\partial \hat{\bar{\psi}}_{v}}{\partial \bar{\eta}} \dot{\bar{\eta}} \\
& =\left(w_{C}^{*}+w_{S}^{*}\right) \times(1-\beta) \overline{\mathbf{M}}: \overline{\mathbf{D}}^{\mathrm{v}}
\end{aligned}
$$




\section{Appendix C}

Figure $\mathrm{C} 1$ displays: i) the value of the parameters $\left\{N_{c}^{*}, N_{s}^{*}, \beta, z_{p 0}, \alpha\right\}$ identified for each experimental condition in tensile tests (i.e. for each equivalent strain-rate $\mathrm{a}_{\mathrm{T}} \dot{\varepsilon}_{\mathrm{eq}}$ selected on the master curves described in Fig.13(a)) and; ii) the evolution of $\left\{N_{c}^{*}, N_{s}^{*}, \beta, z_{p 0}, \alpha\right\}$ with the equivalent strain rate given by Eqs. 47 to 50 .

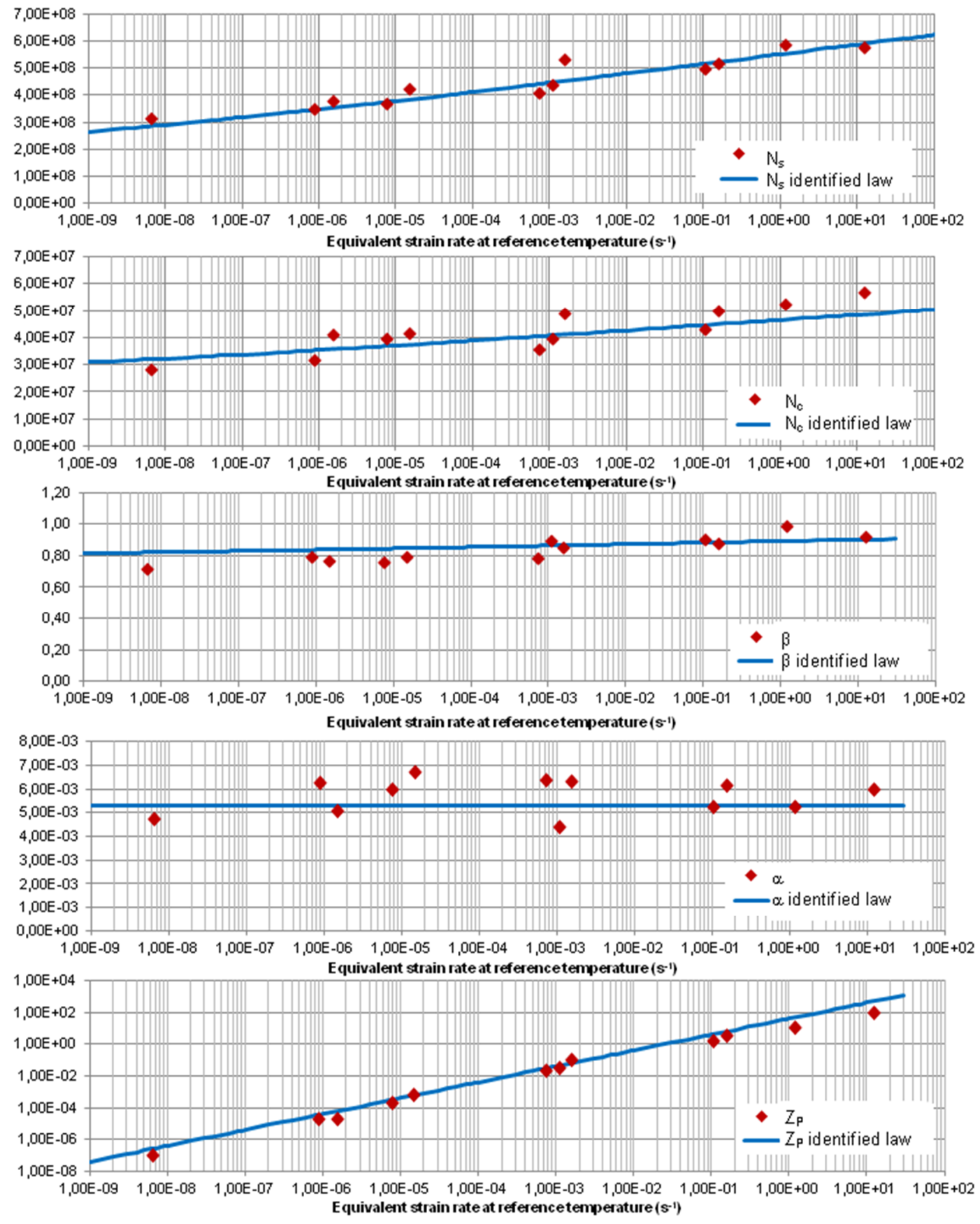

Fig.C1. Comparison between the parameter values identified for each tensile stress-strain master curves (red dots) and evolution of these parameters as defined by Eqs. 46 to 49 (blue line). 


\section{Appendix D}

The model was implemented in MATLAB ${ }^{\circledR}$ following the schema described in Fig. D1. The $\eta$ variable was defined as the driver of the mechanical model. In a first step, the computation and experimental conditions were initialized, then a Newton-Raphson algorithm was used to determine $\eta$ with a criterion based on the inelastic strain-rate tensor value.

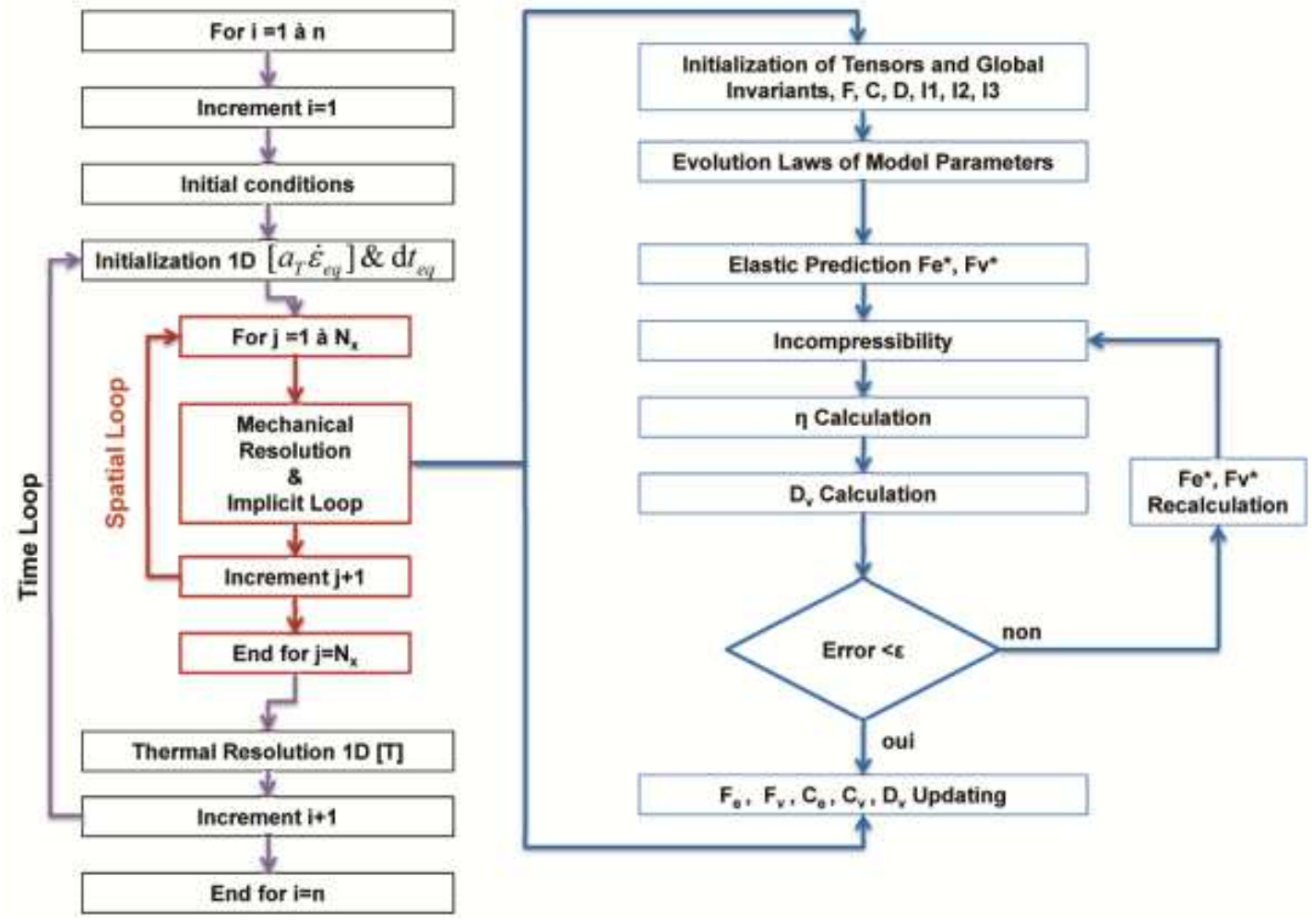

Fig.D1. Schematic representation of the thermo-mechanical model implementation.

The heat equation was solved using a finite difference $\theta$-method, where we have defined a number of elements, $\mathrm{N}_{\mathrm{x}}$, in the sample thickness. The model is well conditioned and converges quickly to the optimal value of $\eta$. Results are presented in Fig. D2.

Fig. D2 displays the model response in term of stress-strain curve and temperature evolution during a tensile loading for the experimental condition (9) $\left(\dot{\varepsilon}=1.8310^{-2} \mathrm{~s}^{-1}, \mathrm{~T}=21.6^{\circ} \mathrm{C}\right)$ as displayed in Fig. 13 (a). Fig.D2a gives a comparison between the experimental and numerical stress-strain curves. The model correctly predicts the polymer mechanical behavior under 
large deformation and captures the viscoelastic/viscoplastic behavior for a load-unload strain path. We can notice that the model slightly overestimates the elastic modulus as well as the transition between elastic and inelastic behavior. Fig. D2b gives a comparison between the temperature-strain curve measured experimentally on the sample surface and the model prediction. The model response is in good agreement with the material self-heating induced by the thermo-mechanical coupling evolving during the deformation. However, we observe that the model overestimates the material self-heating during unloading. Fig. D2c shows two numerical results: the temperature-strain response at the sample surface and in the bulk of the material. Due to the small thickness of the specimen, the thermal gradient in the thickness stays limited. Such temperature evolution in the thickness is described in Fig. D2d.
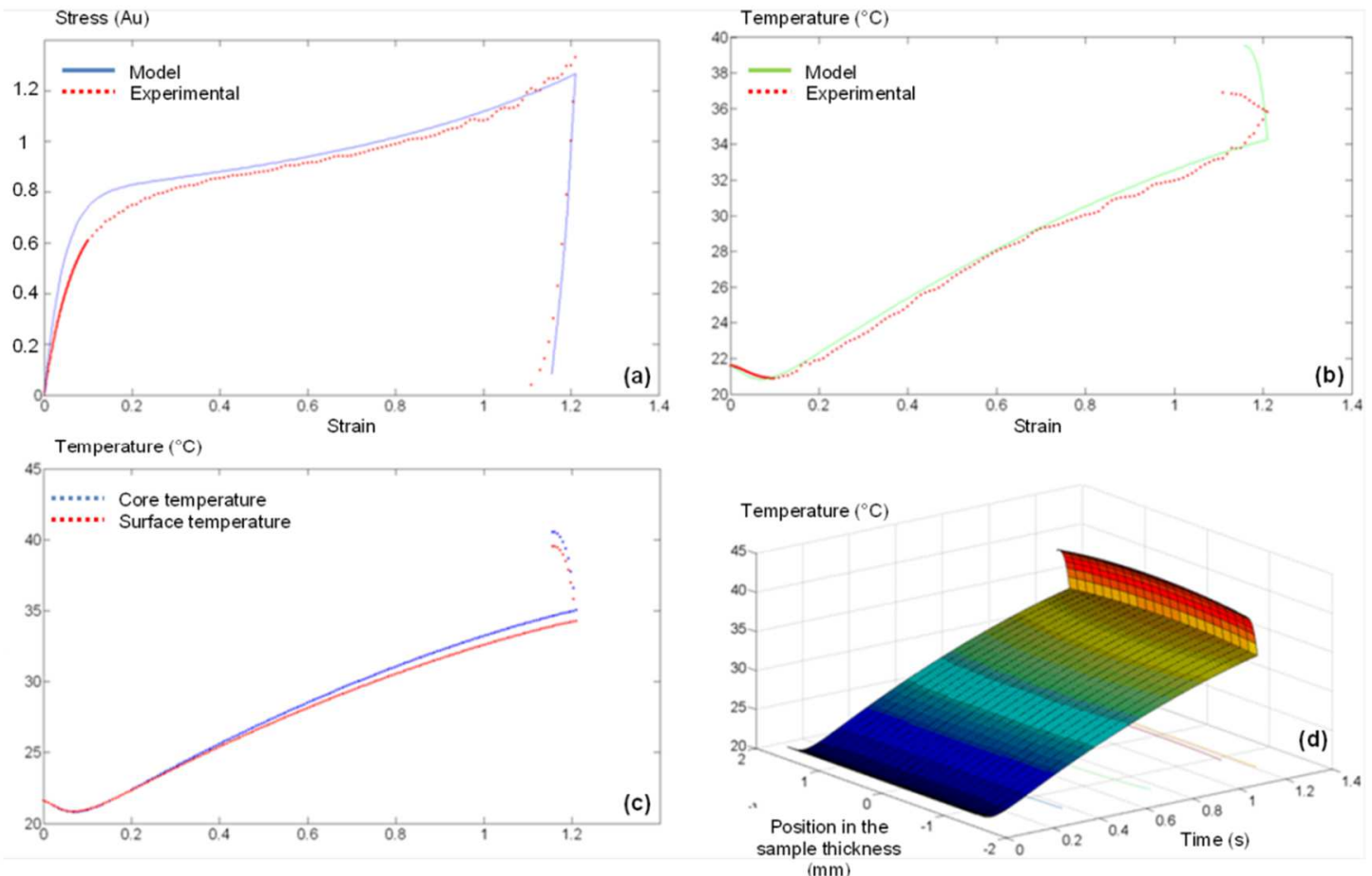

Fig.D2. Model predictions: (a) tensile stress-strain curve for $\dot{\varepsilon}=1.8310^{-2} \mathrm{~s}^{-1}, \mathrm{~T}=21.6^{\circ} \mathrm{C}, \mathrm{a}_{\mathrm{T}} \dot{\varepsilon}_{\mathrm{eq}}=8.0410^{-2} \mathrm{~s}^{-1}$; (b) temperature-strain curve at the sample surface; (c) numerical prediction of the temperature at the surface and core sample; (d) evolution of the predicted temperature field in the sample thickness. 


\section{References}

Ahzi, S., Makradi, A., Gregory, R.V., Edie, D.D., 2003. Modeling of deformation behavior and strain-induced crystallization in poly(ethylene terephthalate) above the glass transition temperature. Mech. of Mat. 35, 1139-1148.

Ames, N.M., Srivastava, V., Chester, S.A., Anand, L., 2009. A thermo-mechanically coupled theory for large deformations of amorphous polymers. Part II: Applications. Int. J. Plast. 25, $1495-1539$.

Anand, L., Gurtin, M.E., 2003. A theory of amorphous solids undergoing large deformations, with application to polymeric glasses. Int. J. Solids Struct. 40, 1465-1487.

Anand, L., Ames, N.M., 2006. On modeling the micro-indentation response of an amorphous polymer. Int. J. Plast. 22, 1123-1170.

Anand, L., Ames, N.M., Srivastava, V., Chester, S.A., 2009. A thermo-mechanically coupled theory for large deformations of amorphous polymers. Part I: Formulation. Int. J. Plast. 25, $1474-1494$.

Andrews R. D. and Tobolsky A. V., 1952. Elastoviscous properties of polyisobutylene. IV. Relaxation time spectrum and calculation of bulk viscosity. J. Polym. Sci. 7, 221-242.

Argon, A.S., 1973. A theory for the low temperature plastic deformation of glassy polymers. Phil. Mag. 28, 839-865. 
Arruda, E.M., Boyce, M.C., 1993. A three-dimensional constitutive model for the large stretch behavior of rubber elastic materials. J. Mech. Phys. Solids 41, 389-412.

Arruda, E.M., Boyce, M.C., Jayachandran, R., 1995. Effects of strain rate, temperature and thermomechanical coupling on the finite strain deformation of glassy polymers. Mech. Mat. 19, 193-212.

Ayoub, G., Zaïri, F., Naït-Abdelaziz, M., Gloaguen, J.M., 2010. Modelling large deformation behaviour under loading-unloading of semicrystalline polymers: application to a high density polyethylene. Int. J. Plast. 26 (30), 329-347.

Ayoub, G., Zaïri, F., Fréderix, C., Gloaguen, J.M., Naït-Abdelaziz, M., Seguela, R., Lefebvre, J.M., 2011. Effects of crystal content on the mechanical behaviour of polyethylene under finite strains: experiments and constitutive modelling. Int. J. Plast. 27 (4), 492-511.

Ball R., Doi M., Edwards S., Warner M., 1981. Elasticity of entangled networks. Polymer. 22, $1010-1018$

Bardenhagen, S.G., Stout, M.G., Gray, G.T., 1997. Three-dimensional, finite deformation, viscoplastic constitutive models for polymeric materials. Mech. Mat. 25, 235-253.

Bauwens, J.C., Bauwens-Crowet, C., Homes, G., 1969. Tensile yield-stress behavior of poly(vinyl chloride) and polycarbonate in the glass transition region. J. Polym. Sci. 7 (Pt. A2), 1745-1754. 
Bauwens-Crowet, C., 1973. The compression yield behaviour of polymethyl methacrylate over a wide range of temperatures and strain-rates. J. Mater. Sci. 8, 968-979.

Bédoui, F., Diani, J., Régnier, G., Seiler, W., 2006. Micromechanical modeling of isotropic elastic behavior of semicrystalline polymers. Acta Mater. 54, 1513-1523.

Belbachir, S., Zaïri, F., Ayoub, G., Maschke, U., Naït-Abdelaziz, M., Gloaguen, J.M., Benguediab, M., Lefebvre, J.M., 2010. Modelling of photodegradation effect on elasticviscoplastic behaviour of amorphous polylactic acid films. J. Mech. Phys. Solids 58, 241-255.

Billon N., 2012. New constitutive modelling for time-dependent mechanical behaviour of polymers close to glass transition: fundamental and experimental validation. J. App. Polym. Sci. 125 (6), 4390-4401.

Bouvard, J.L., Ward, D.K., Hossain, D., Nouranian, S., Marin, E.B., Horstemeyer, M.F., 2009. Review of hierarchical multiscale modeling to describe the mechanical behavior of amorphous polymers. J. Eng. Mater. Technol.131 (4), 041206

Bouvard, J.L., Ward, D.K., Hossain, D., Marin, E.B., Bammann, D.J., Horstemeyer, M.F., 2010. A general inelastic internal state variables model for amorphous glassy polymers. Acta Mech. 213 (1), 71-96.

Bouvard, J.L., Francis, D.K., Tschopp, M.A., Marin, E.B., Bammann, D.J., Horstemeyer, M.F., 2013. An internal state variable material model for predicting the time, 
thermomechanical, and stress state dependence of amorphous glassy polymers under large deformation. Int. J. Plast. 42, 168-193.

Boyce, M.C., Parks, D.M., Argon, A.S., 1988. Large inelastic deformation of glassy polymers. Part I: Rate dependent constitutive model. Mech. Mat. 7, 15-33.

Boyce, M.C., Socrate, S., Llana, P.G., 2000. Constitutive model for the finite deformation stress-strain behavior of poly(ethylene terephthalate) above the glass transition. Polymer 41, $2183-2201$.

Buckley, C.P., Jones, D.C., 1995. Glass-rubber constitutive model for amorphous polymers near the glass transition. Polymer 36, 3301-3312.

Cayzac, H.-A., Saï, K., Laiarinandrasana, L., 2013. Damage based constitutive relationships in semi-crystalline polymer by using multi-mechanisms model. Int. J. Plast. 51, 47-64.

Chaboche J., 1997. Thermodynamic formulation of constitutive equations and application to the viscoplasticity and viscoelasticity of metals and polymers. Int. J. Sol. Struct. 34, 22392254.

Colak, O., 2005. Modeling deformation behavior of polymers with viscoplasticity theory based on overstress. Int. J. Plast. 21, 145-160. 
Colak, O., Krempl, E., 2005. Modeling of the monotonic and cyclic swift effects using an isotropic, finite viscoplasticity theory based on overstresses (FVBO). Int. J. Plast. 21, 573588.

Drozdov, A.D., 2009. Mullins' effect in semicrystalline polymers. Int. J. Sol. Struct. 46, $3336-3345$.

Dupaix, R.B., Krishnan, D., 2006. A constitutive model for strain-induced crystallization in poly(ethylene terephthalate) (PET) during finite strain load-hold simulations. J. Eng. Mater. Technol. 128, 28-33.

Dusunceli, N., Colak, O.U., 2008. Modelling effects of degree of crystallinity on mechanical behavior of semicrystalline polymers. Int. J. Plast. 24 (7), 1224-1242.

Edwards S. F. and Vilgis T., 1986. The effect of entaglements in rubber elasticity. Polymer. $27,483-492$.

Eyring, H., 1936. Viscosity, plasticity, and diffusion as examples of absolute reaction rates. J. Chem. Phys. 4, 283-291.

Germain P., Nguyen Q., Suquet P., 1983. Continuum thermodynamics. J. App. Mech. 50, $1010-1020$.

Ghorbel, E., 2008. A viscoplastic constitutive model for polymeric materials. Int. J. Plast. 24, 2032-2058. 
Gorlier E., Haudin J. M., Billon N., 2001. Strain induced crystallization in bulk amorphous PET under uni-axial loading. Polymer. 42, 9541-9549.

Govaert, L.E., Timmermans, P.H.M., Brekelmans, W.A.M., 2000. The influence of intrinsic strain softening on strain localization in polycarbonate: modeling and experimental validation. J. Eng. Mater. Technol. 122, 177-185.

G'Sell C. and Jonas J. J., 1979. Determination of the plastic behaviour of solid polymers at constant true strain-rate. Mat. Sci. 14, 583-591.

G'sell, C., Hiver, J.M., Dahoun, A., 2002. Experimental characterization of deformation damage in solid polymers under tension, and its interrelation with necking. Int. J. Sol. Struct. $39,3857-3872$.

Gueguen, O., Richeton, J., Ahzi, S., Makradi, A., 2008. Micromechanically based formulation of the cooperative model for the yield behavior of semi-crystalline polymers. Acta Mater. 56, $1650-1655$.

Horstemeyer, M.F., Bammann, D.J., 2010. Historical review of internal state variable theory for inelasticity. Int. J. Plast. 26, 1310-1334.

Kennedy, M.A., Peacock, A.J., Mandelkern, L., 1994. Tensile properties of crystalline polymers: linear polyethylene. Macromolecules 27 (19), 5297-5310. 
Khan, A., Zhang, H., 2001. Finite deformation of a polymer: experiments and modeling. Int. J. Plast. 17, 1167-1188.

Khan A., Lopez-Pamies O., Kazmi R., 2006. Thermo-mechanical large deformation response and constitutive modeling of viscoelastic polymers over a wide range of strain-rates and temperatures. Int. J. Plast. 22, 581-601.

Khan, F., Yeakle, C., 2011. Experimental investigation and modeling of non-monotonic creep behavior in polymers. Int. J. Plast. 27 (4), 512-521.

Krempl, E., Ho, K., 2002. Extension of the viscoplasticity theory based on overstress (VBO) to capture non-standard rate dependence in solids. Int. J. Plast. 18, 851-872.

Krempl, E., Khan, F., 2003. Rate (time)-dependent deformation behavior: an overview of some properties of metals and solid polymers. Int. J. Plast. 19, 1069-1095.

Lai D., Yakimets I., Guignon M., 2005. A non linear viscoelastic model developed for semicrystalline polymer deformed at small strains with loading and unloading paths. Mat. Sci. Eng. A. 405, 266-271.

Lee, B.J., Parks, D.M., Ahzi, S., 1993a. Micromechanical modeling of large plastic deformation and texture evolution in semi-crystalline polymers. J. Mech. Phys. Sol. 41, 16511687. 
Lee, B.J., Argon, A.S., Parks, D.M., Ahzi, S., Bartczak, Z., 1993b. Simulation of large strain plastic deformation and texture evolution in high density polyethylene. Polymer 34, 35553575 .

Lee, S.Y., Bassett, D.C., Olley, R.H., 2003. Lamellar deformation and its variation in drawn isolated polyethylene spherulites. Polymer 44 (19), 5961-5967.

Lemaitre J., and Chaboche J.L., 1994. Mechanics of Solid Materials, Cambridge University Press.

Li, G., Shojaei, A., 2012. A viscoplastic theory of shape memory polymer fibres with application to self-healing materials. Proc. R. Soc. A: Math. Phys. Eng. Sci. 468, 2319-2346.

Makradi, A., Ahzi, S., Gregory, R.V., Edie, D.D., 2005. A two-phase self-consistent model for the deformation and phase transformation behavior of polymers above the glass transition temperature: application to PET. Int. J. Plast. 21, 741-758.

Marco, Y., Chevalier, L., Chaouche, M., WAXD study of induced crystallization and orientation in poly(ethylene terephtalate) during biaxial elongation. Polymer. 43, 6569-6574.

Maurel-Pantel, A., Baquet, E., Bikard, J., Billon, N., 2011. Coupled thermo mechanical characterisation of polymers based on inverse analyses and IR measurements. App. Mech. Mat. 70, 393-398. 
Meissner B. and Matejka L., 2002. Comparison of recent rubber elasticity theories with biaxial stress strain data : the slip-link theories of Edwards and Vilgis. Polymer. 43, 38033809.

Miehe, C., Goktepe, S., Mendez Diez, J., 2009. Finite viscoplasticity of amorphous glassy polymers in the logarithmic strain space. Int. J. Solids Struct. 46, 181- 202.

Moreau S., Chrysochoos A., Muracciole J., Wattrisse B., 2005. Analysis of thermoelastic effects accompanying the deformation of PMMA and PC polymers. Comptes Rendus Mécanique. 333, 648-653.

Nikolov, S., Doghri, I., 2000. A micro/macro constitutive model for the small deformation behavior of polyethylene. Polymer 41, 1883-1891.

Nikolov, S., Doghri, I., Pierard, O., Zealouk, L., Goldberg, A., 2002. Multi-scale constitutive modelling for the small deformations of semi-crystalline polymers. J. Mech. Phys. Solids. 50, $2275-2302$.

Pierron F. and Vautrin A., 1997. Measurement of in-plane shear strengths of unidirectional composites with the Iosipescu test. Comp. Sci. Techno. 57, 1653-1660.

Ponçot, M., Addiego, F., Dahoun, A., 2013. True intrinsic mechanical behaviour of semicrystalline and amorphous polymers : influences of volume deformation and cavities shape. Int. J. Plast. 40, 126-139. 
Pyrz, M., Zaïri, F., 2007. Identification of viscoplastic parameters of phenomenological constitutive equations for polymers by deterministic and evolutionary approach. Mod. Simul. Mat. Sci. Eng. 15, 85-103.

Regrain, C., Laiarinandrasana, L., Toillon, S., Saï, K., 2009. Multi-mechanism models for semi-crystalline polymer: constitutive relations and finite element implementation. Int. J. Plast. 25, 1253-1279.

Richeton, J., Ahzi, S., Vecchio, K.S., Jiang, F.C., Makradi, A., 2007. Modeling and validation of the large deformation inelastic response of amorphous polymers over a wide range of temperatures and strain rates. International Journal of Solids and Structures 44, 7938-7954.

Robertson, R.E., 1966. Theory for the plasticity of glassy polymers. J. Chem. Phys. 44, 39503956.

Roguet E., Castagnet S., Grandidier J., 2007. Mechanical features of the rubbery amorphous phase in tension and torsion in a semi-crystalline polymer. Mech. Mat. 39, 380-391.

Roux E., Bouchard P.-O., 2013. Kriging metamodel global optimization of clinching joining processes accounting for ductile damage. J. Mat. Proc. Tech. 213 (7), 1038-1047.

Rozanski, A., Galeski, A., 2013. Plastic yielding of semicrystalline polymers affected by amorphous phase. Int. J. Plast. 41, 14-29. 
Shojaei, A., Li, G., Voyiadjis, G.Z., 2013. Cyclic viscoplastic-viscodamage analysis of shape memory polymers fibers with application to self-healing smart materials. J. Appl. Mech. 80, $11-14$.

Srivastava, V. and Chester, S.A. and Ames, N.M. and Anand, L., 2010a, A thermomechanically-coupled large-deformation theory for amorphous polymers in a temperature range which spans their glass transition, Int. J. Plast. 26, 1138-1182.

Srivastava, V., Chester, S.A., and Anand, L., 2010b, Thermally-actuated shape-memory polymers: experiments, theory, and numerical simulations, J. Mech. Phys. Sol. 58, 11001124.

Sweeney J. and Ward I. M., 1995. Rate dependent and network phenomena in the multiaxial drawing of PVC. Polymer. 36, 299-308.

Sweeney J., Ward I. M., 1996. A Constitutive Law For Large Deformation Of Polymers At High Temperatures. J. Mech. Phys. Sol. 44-7, 1033-1049.

Sweeney J., Collins T., Coates P., Ward I., 1997. Application of an elastic model to the large deformation, high temperature stretching of polypropylene. Polymer. 38, 5991-5999.

Sweeney J., Collins T., Coates P., Unwin A., Duckett R., Ward I., 2002. Application of a large deformation model to unstable tensile streching of polyethylene. Int. J. Plast. 18, 399414. 
Tomita, Y., 2000. Constitutive modeling of deformation behavior of glassy polymers and applications. Int. J. Mech. Sci. 42, 1455-1469.

Uchida, M., Tada, N., 2013. Micro-, meso- to macroscopic modeling of deformation behavior of semi-crystalline polymer. Int. J. Plast. 49, 164-184.

Urayama K., Yokoyama K., Kohjiya S., 2001. Viscoelastic relaxation of guest linear poly(dymethylsiloxane) in end-linked poly(dimethylsiloxane) networks. Macromolecules. 34, $4513-4518$.

Valentin, D., Paray, F., Guetta, B., 1987. The hygrothermal behaviour of glass fibre reinforced PA66 composites: a study of the effect of water absorption on their mechanical properties. J. Mat. Sci. 22, 46-56.

van Dommelen, J.A.W., Parks, D.M., Boyce, M.C., Brekelmans, W.A.M., Baaijens, F.P.T., 2003. Micromechanical modeling of the elasto-viscoplastic behavior of semi-crystalline polymers. J. Mech. Phys. Solids 51, 519-541.

Verdu, J., 2000. Action de l'eau sur les plastiques. Techniques de l'ingénieur. Plastiques et composites $1,1-8$.

Voyiadjis, G.Z., Shojaei, A., Li, G., 2012. A generalized coupled viscoplastic-viscodamageviscohealing theory for glassy polymers. Int. J. Plast. 28 (1), 21-45. 
Wu, P.D., Van der Giessen, E., 1993. On improved network models for rubber elasticity and their applications to orientation hardening in glassy polymers. J. Mech. Phys. Solids 41, 427456.

Wu, P.D., van der Giessen, E., 1995. On neck propagation in amorphous glassy polymers under plane strain tension. Int. J. Plast. 11, 211-235.

Zaïri, F., Woznica, K., Naït-Abdelaziz, M., 2005a. Phenomenological nonlinear modelling of glassy polymers. Comptes Rendus Mecanique 333, 359-364.

Zaïri, F., Naït-Abdelaziz, M., Woznica, K., Gloaguen, J.M., 2005b. Constitutive equations for the viscoplastic-damage behaviour of a rubber-modified polymer. Eur. J. Mech. A: Solids 24, $169-182$.

Zaïri, F., Naït-Abdelaziz, M., Woznica, K., Gloaguen, J.M., 2007. Elasto-viscoplastic constitutive equations for the description of glassy polymers behavior at constant strain rate. J. Eng. Mat. Techno. 129, 29-35.

Zaïri, F., Naït-Abdelaziz, M., Gloaguen, J.M., Lefebvre, J.M., 2008. Modelling of the elastoviscoplastic damage behaviour of glassy polymers. Int. J. Plast. 24, 945-965.

Zaïri, F., Naït-Abdelaziz, M., Gloaguen, J.M., Lefebvre, J.M., 2010. Constitutive modelling of the large inelastic deformation behaviour of rubber-toughened poly(methyl methacrylate): effects of strain rate, temperature and rubber-phase volume fraction. Mod. Sim. Mat. Sci. Eng. 18, 1-22. 
Zaïri, F., Naït-Abdelaziz, M., Gloaguen, J.M., Lefebvre, J.M., 2011. A physically-based constitutive model for anisotropic damage in rubber-toughened glassy polymers during finite deformation. Int. J. Plast. 27, 25-51. 